The 1 -n Gen is Peltigera (Lichenit a Asomycetes) int lighta

Bemard Goffinet Ress 1. Hastings

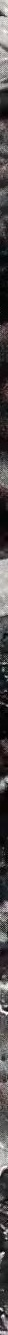

\footnotetext{
$\mathrm{T} \cdot \mathrm{H} \cdot \mathrm{E}$

PROVINCIAL

MUSEUM

OF ALBERTA
}

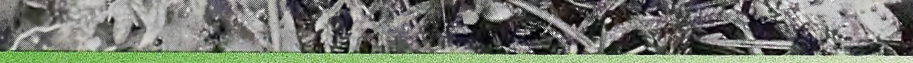

Alborta COMMUNITY DEVELOPMENT 
Digitized by the Internet Archive in 2015 
Provincial Museum of Alberta

Natural History

Occasional Paper No. 21

1994

\title{
The Lichen Genus Peltigera (Lichenized Ascomycetes) in Alberta
}

\author{
Bernard Goffinet \\ Department of Botany, University of Alberta, \\ Edmonton, Alberta, T6G 2E9 Canada. \\ Ross I. Hastings \\ Provincial Museum of Alberta, Curatorial Section, \\ 12845-102 Ave., Edmonton, Alberta, T5N OM6 Canada.
}

Prepared and Published by:

Curatorial Section

Provincial Museum of Alberta

12845-102 Avenue

Edmonton, Alberta

T5N OM6 


\section{NATURAL HISTORY OCCASIONAL PAPER SERIES}

Occasional paper titles are published by the Provincial Museum of Alberta on subjects pertaining to the natural history of Alberta. Potential contributors are requested to submit manuscript proposals to the Assistant Director, Curatorial and Collections Administration, Provincial Museum of Alberta, 12845-102 Avenue, Edmonton, Alberta T5N OM6

\section{Editorial Board}

W. Bruce McGillivray

Ronald Mussieux

Ross I. Hastings

Julie Hrapko

James Burns

Mark Steinhilber

Harold Bryant

Albert Finnamore

Jocelyn Hudon

\section{Publication Committee}

W. Bruce McGillivray

Ross I. Hastings

Mark Steinhilber

Colleen Steinhilber

\section{CATALOGUING IN PUBLICATION DATA}

Goffinet, Bernard

The Lichen Genus Peltigera (Lichenized Ascomycetes) in Alberta

(Provincial Museum of Alberta natural history occasional paper no. 21) Includes bibliographic references

ISSN 0838-5971; no. 21

ISBN 0-7732-1317-1

1. Lichens - Alberta. 2. Plants - Alberta. I. Hastings, Ross I. II. Title. III.

Series: Natural history occasional paper no. 21

QK587.7.82 $\quad 589.1$

Cover photo: Peltigera aphthosa. Photo courtesy Robin Bovey. 


\section{Acknowledgments}

The authors are grateful to Dale Vitt (ALTA) for providing support from his NSERC Research Grant (86390) and to the Provincial Museum of Alberta for providing operating funds for the Non-Vascular Plant program. The senior author would like to express his special thanks to Emmanuël Sérusiaux (LG) who through his passion for lichenology arose his interest in Peltigera, to Dale Vitt for his continuous encouragement and advice, and to Trevor Goward (UBC) for the stimulating interactions, for sharing his expertise on Peltigera and authorizing us to use the ined. name $P$. cinnamomea. Trevor Goward and Orvo Vitikainen $(\mathrm{H})$ provided many judicious comments on an earlier version of the manuscript and further brought some critical specimens to our attention (blue-green phototype of $P$. aphthosa and recent collection of $P$. polydactyla, respectively). Orvo Vitikainen further kindly commented on certain critical issues and clarified some species concepts. Many thanks also to Suzan Crites, Bob Ellis and Catherine LaFarge-England for testing the key and commenting on the manuscript. This work would not have been possible without the loan of herbarium material, for which we thank the curators of the CAFB and CANL herbaria. Stewart Harris (UAC) kindly put his personal collections of Peltigera at our disposal. Finally, we would like to acknowledge the effort Mark Steinhilber put into producing the final layout and in desktop publishing this document. 


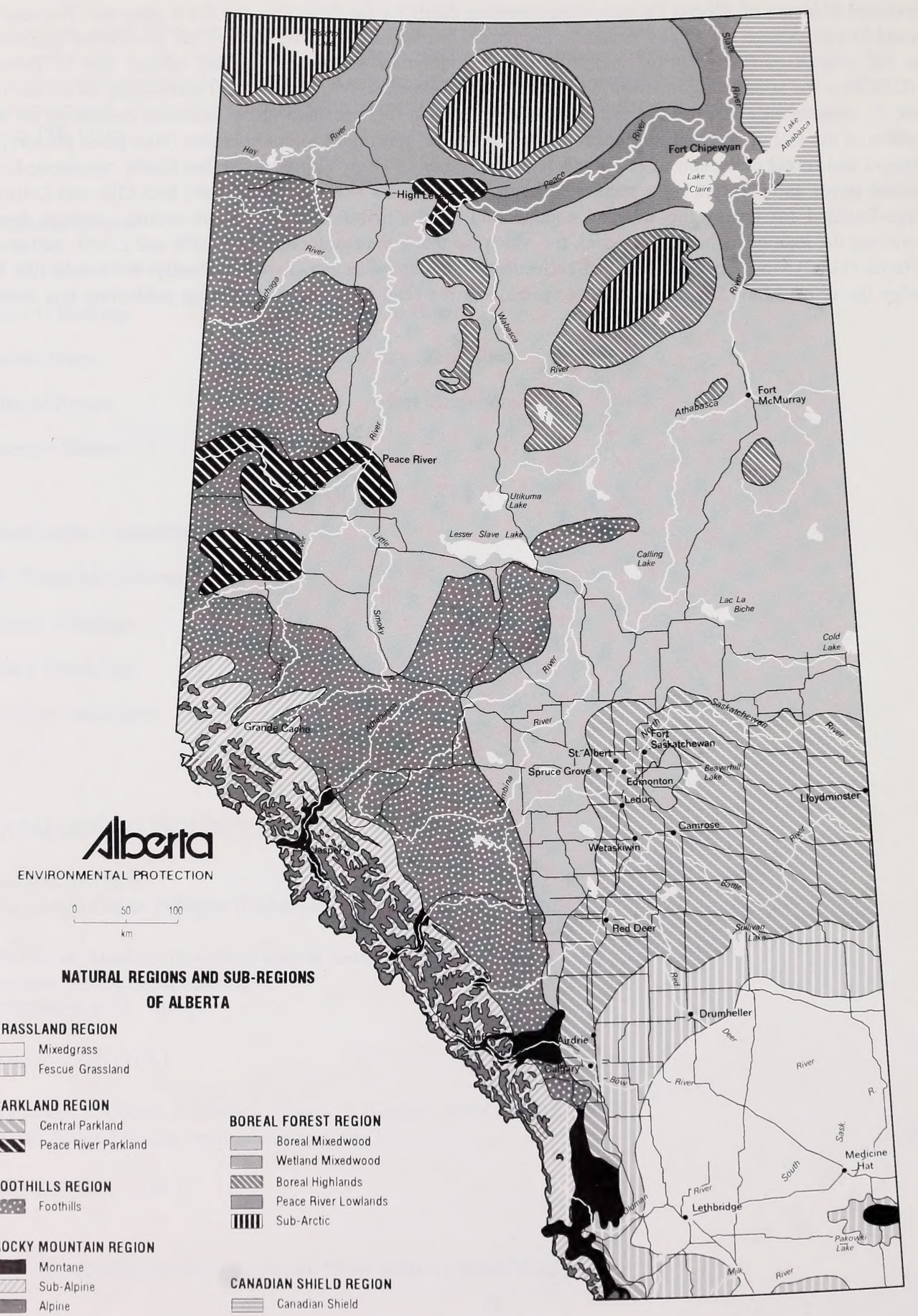

Produced by Alberta Parks Services, Management Support Branch - November 1993 


\section{Contents}

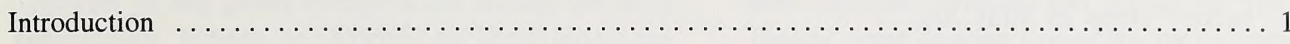

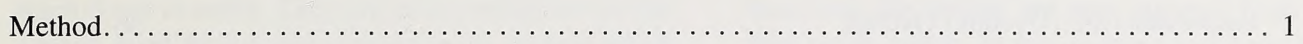

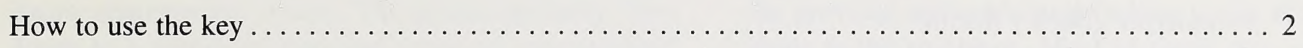

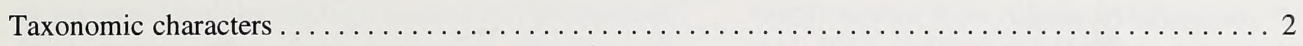

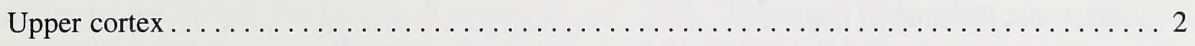

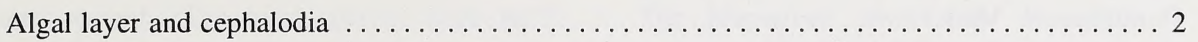

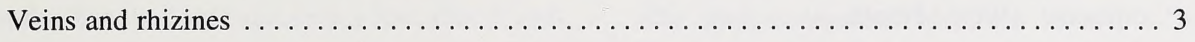

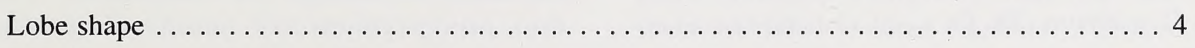

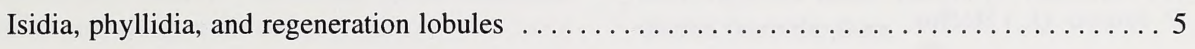

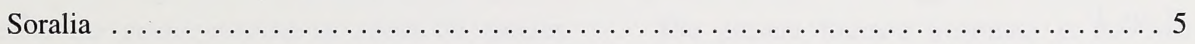

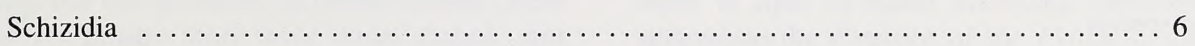

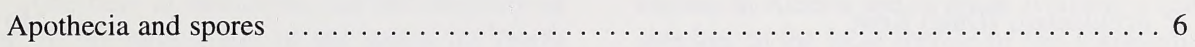

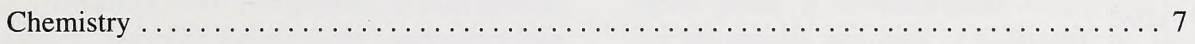

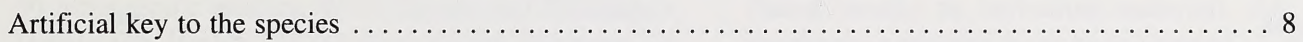

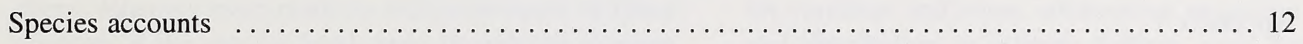

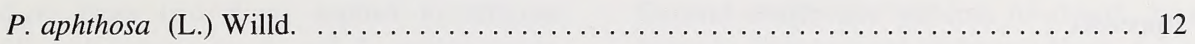

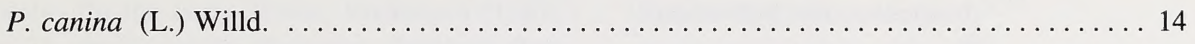

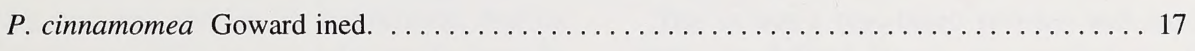

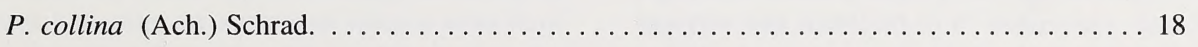

P. didactyla (With.) Laundon var. didactyla .......................... 19

P. didactyla (With.) Laundon var. extenuata (Nyl. ex. Vainio) Goffinet \& Hastings . . . . . 21

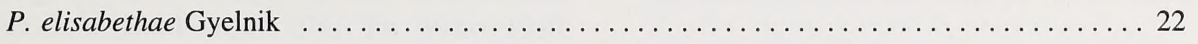

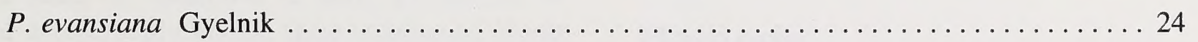

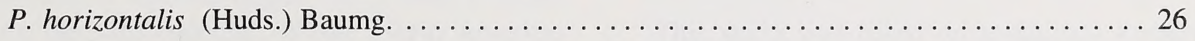

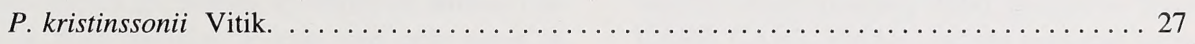

P. lepidophora (Nyl. ex Vainio) Bitter ............................... 28

P. leucophlebia (Nyl.) Gyelnik . ............................. 29 
P. membranacea (Ach.) Nyl.

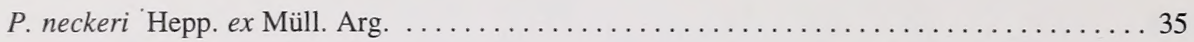

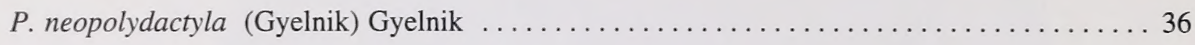

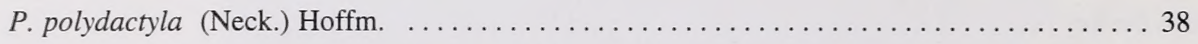

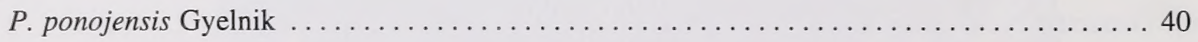

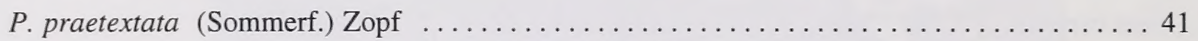

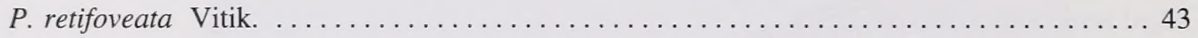

P. rufescens (Weis.) Humb. .......................................... 44

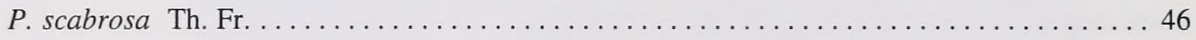

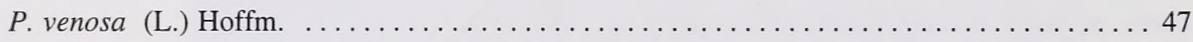

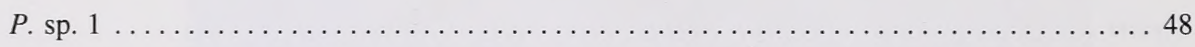

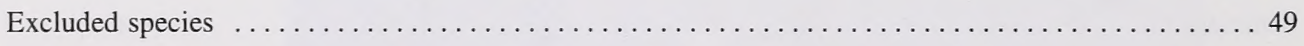

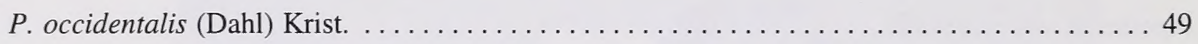

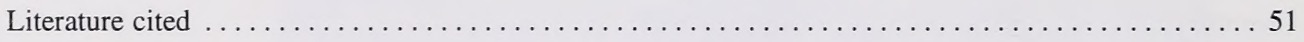

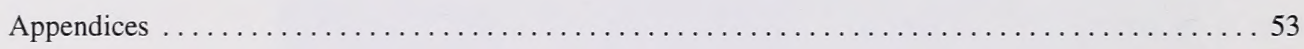

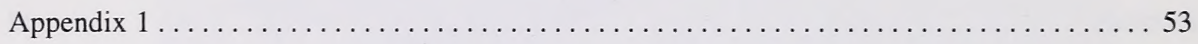

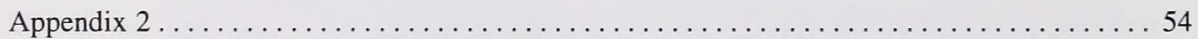




\section{Introduction}

Species of the genus Peltigera are among the most conspicuous lichens in Alberta, as their lobes can reach $6 \mathrm{~cm}$ in width. They are easily recognized at the generic level by the noncorticate lower surface which bears characteristic veins. The genus probably "belongs to a particularly ancient group of ascomycetes" as suggested both by the high number of lichenicolous fungi reported only from its species (Hawksworth 1980) and by its worldwide distribution. It occurs in montane habitats in the tropics to the antipodal arctic tundra environments. The large species, such as $P$. aphthosa or $P$. neopolydactyla, find their optimum on moist shaded forests floors and only a few, like $P$. collina and $P$. horizontalis, are reported as occasional epiphytes (outside Alberta). The smaller species, such as $P$. lepidophora and $P$. didactyla, grow often on bare mineral soil along trails or road sides.

At present the genus consists of about 60 species worldwide, but the taxonomy is poorly known. More extensive revisionary work over wider ranges, will certainly contribute to elucidating the full diversity of Peltigera. In his monograph of the genus for North America, Thomson (1950) recognized 35 taxa including 12 species, seven of which were subdivided into 30 infraspecific entities. With Ozenda and Clauzade's (1970) and Poelt's (1974) keys to the European lichens, attempts were made to recognize some of these varieties at the species level, even though the changes proposed in these two floras applied to different groups ( $P$. polydactyla group and $P$. canina group, respectively). In the early 1980 s, Vitikainen (1981) accepted 21 species in the European Peltigera flora (suggesting one new species, $P$. kristinssonii, that he would describe in 1985), and no infraspecific taxa. In the following decade, six additional species were reinstated or described from Europe and North America (Holtan-Hartwig 1988, Tønsberg and Holtan-Hartwig 1983, Vitikainen 1985) and others await formal recognition (Goward et al. in prep., Holtan-Hartwig 1993). Considering the recent additions to the North American lichen flora (Brodo et al. 1987; for Weber 1990 see note under $P$. didactyla in text) 25 species of Peltigera are presently known from continental North America north of Mexico (Egan 1987), with P. pacifica being the sole endemic. Within North America, the genus reaches its highest diversity in British Columbia; its flora includes at least one new taxon in addition to all other taxa reported from the continent north of Mexico (Goward et al. in prep.).

Ostafichuk (1966), following Thomson's (1950) taxonomic concepts, reported 17 taxa including nine species, three atypical varieties, and six forms from Alberta. Twenty three species (including two potentially new taxa) and one variety are here reported from Alberta; they occur mainly in the montane and boreal parts of the province and are almost lacking in the drier grasslands to the southeast. Most of these taxa were previously known from Alberta (Anonymous 1993, Brodo et al. 1987, Goffinet and Hastings in press, Ostafichuk 1966, Thomson 1950, Vitikainen 1985), except $P$. neckeri which is here reported as new to the province. The blue-green phototypes, $P$. aphthosa and $P$. venosa, are reported for the first time for the province (the most continental localities known at present in North America). Peltigera polydactyla has its occurrence restricted to three localities. Peltigera occidentalis, reported from Alberta by Ohlsson (1973), is excluded from the flora.

The present floristic treatment is the first attempt made in light of recent taxonomic developments to summarize the diversity of the Peltigera species occurring in Alberta and to make available a comprehensive key to the local species of this taxonomically difficult genus. A morphological description is provided for all species and each is illustrated by photographs (based mostly on herbarium material). All Albertan specimens examined have been mapped. A discussion on variation and some information regarding ecology and distribution in Alberta follows each description. General distribution patterns for North America are based on literature and additional North American collections that were examined.

This is not a type-based revision and species concepts are defined largely on morphology. Chemical analysis was restricted to $P$. didactyla s. lat. (Goffinet and Hastings in press) and the $P$. polydactyla group $s$. lat. The chemical diversity of Peltigera, as revealed by Holtan-Hartwig's (1993) study of the Norwegian taxa, suggests that extensive research will be required to define chemotypes for the North American flora.

\section{Methods}

This study was based on traditional herbarium taxonomy. Approximately 1500 specimens from ALTA, CAFB, CANL, PMAE, and the personal herbaria of B. Goffinet and S. Harris, were examined. The range of the spore size indicates the mean length $+/-1$ standard deviation based on measurements of 60 spores (except where otherwise stated) from three independent apothecia from Albertan material only; extreme observations are 
in parentheses. Only mature spores, those ejected from the ascus through squashing in water, were measured. Species distribution in Alberta follows a format slightly modified from the "Natural Regions and Subregions of Alberta" developed by Achuff (1992).

\section{How to use the key}

Much of the terminology in the key will be unfamiliar if you are not used to working with lichens and even if you are, our interpretation of the characters may vary somewhat from what you are used to. Therefore, to familiarize yourself with the terminology used to describe Peltigera you should review the section "Taxonomic characters of the genus" before you attempt to use the key. When using the key, it is important to refer back to this section. Critical characters which appear in the key are printed in bold and described. Similar characters are described together so you can easily choose the correct character from a suite of alternatives. Many of the structures are illustrated with photographs.

Habit shots of all Peltigera which we recognize in Alberta are included with the species descriptions. These photos should be examined when using the key, not only to get a general idea of the form of a species but also because the photos often clearly illustrate critical taxonomic features.

Many Peltigera cannot be separated easily based on a single or small set of contrasting characters as presented in the key. We suggest that after using the key to make an initial determination, you should read the appropriate "Species Account." Here we give a more detailed analysis of the critical characters which define the species and we discuss other species with which it may be confused. A final determination can best be made after reviewing this discussion.

We have provided two appendices, one for the canina group, the other for the polydactyla group. These appendices should be consulted when a specimen has been determined to be a species from one of these two groups. The appendices provide a ready reference comparing and contrasting the character complexes which separate the species.

Although, for most part, the key is strictly dichotomous, we have occasionally provided a third alternative when a complex of characters makes separation of three species difficult. The third choice always leads directly to a species name. In such a situation, you should read the descriptions of all three species carefully, before making a final determination.
The tomentum and scabrosity of $P$. kristinssonii are often scarce and difficult to see. Therefore, we have included that species on each of the glabrous and tomentose as well as the smooth and scabrous paths.

\section{Taxonomic characters of the genus}

\section{Upper cortex}

In Peltigera the upper cortex is of the paraplectenchymatous type; the hyphae form a tissue-like layer. In most species of the $P$. polydactyla group, these superficial cells form an even layer, giving the cortex a smooth appearance. In P. scabrosa, clusters of hyphae continue to grow, forming little "warts" (Jahns 1973) and give the cortex a rough appearance; the upper surface is said to be scabrous. Individual cortical hyphae may further extend through the upper surface and form a tomentum of either erect (e.g., P. malacea) or branched (e.g., P. rufescens) glassy "hairs." In the absence of such tomentum, the upper surface is said to be glabrous ( $P$. polydactyla group). The presence of tomentum is a critical taxonomic character. It should always be carefully checked as it is sometimes restricted to the extreme tip of the lobe.

\section{Algal layer and cephalodia}

The algae form a distinct layer below the upper cortex in most species of Peltigera (the thallus is heteromerous - layered); only in the blue-green phototype of $P$. venosa is the photobiont scattered (the thallus is then homoiomerous - not layered). In the latter case, the thallus, when wet, becomes somewhat gelatinous and resembles a small species of Leptogium. The photobiont can either be a green algae, producing an apple green color to the thallus when wet (e.g., $P$. aphthosa) or a cyanobacteria, in which case the thallus is a bluish-grey color when wet (e.g., species of the $P$. polydactyla group). In the $P$. aphthosa group the association can involve three symbionts: the fungus and green algae make up the main thallus whereas cyanobacteria are concentrated in external structures called cephalodia. These corticate "warts" arise as cortical hairs growing around the "algal" cells they contact (Jahns 1973). Cephalodia can occur on the upper cortex (e.g., P. aphthosa, Fig. 15) or on the lower surface, in which case they are found on the veins $(P$. venosa, Fig. 88). Mature cephalodia can be flat, concave, or convex. In the latter case they are either wart-shaped with only their margins incised (e.g., $P$. aphthosa) or cerebriform (brain-like, P. leucophlebia) with incisions across the whole surface (HoltanHartwig 1993). The advantage for these species to develop cephalodia, mainly for nitrogen fixation, must be of crucial importance as all taxa with green algae 
develop them. The mycobiont involved in these triple symbioses can develop two distinct phototypes. In the typical green phototype the thallus is made up mainly by the fungus and green algae, the cyanobacteria being restricted to the cephalodia. By contrast, in the rare blue-green phototype, the fungus and cyanobacteria form small lobules or lobes attached to the green thallus, or even an independent thallus which may or may not bear lobules, or lobes, of the green phototype. These blue-green counterparts are thought to be an alternative life history strategy for the lichen (Brodo and Richardson 1978, Ott 1988). Blue-green phototypes of $P$. aphthosa, $P$. britannica, and $P$. venosa are known from North America and Europe (Goward et al. in prep., Tønsberg and Holtan-Hartwig 1983). Armaleo and Clerc (1991) studied similar phototypes in southern temperate species of Pseudocyphellaria and Sticta. Their molecular analysis strongly suggests that the same mycobiont is involved in each of these symbioses. In British Columbia (Goward et al. unpubl. data), the blue-green phototypes of $P$. aphthosa and $P$. britannica appear to be restricted to extremely humid localities. So far, only two collections of blue-green phototypes are known from Alberta (see discussion under $P$. aphthosa and $P$. venosa).

The algal layer can be discontinuous in some taxa. The zones lacking the algal component are called maculae. The extent of the maculae is variable; they often form a rather inconspicuous network of whitish lines which are best seen through the cortex when the thallus is wet. In Western Canada, this situation is known to occur only in the blue-green phototypes of $P$. britannica, $P$. aphthosa, and in a few specimens from Vancouver Island belonging to the $P$. polydactyla group. Among Albertan taxa, some specimens included here under $P$. neckeri are somewhat maculate, whereas the blue-green phototype of $P$. aphthosa always has a distinctly maculate upper surface.

\section{Veins and rhizines}

Lobes of Peltigera lack a lower cortex; the medullary hyphae remain exposed. These hyphae can resume growth either extensively or locally and form veins. In the former case, the veins often anastomose, giving the appearance of a veinless lower surface with only a few scattered pits or interstices, (e.g., P. malacea or typical $P$. aphthosa). More often, however, a network (reticulation) of distinct veins forms. The veins can be narrow and raised (e.g., P. membranacea) or be broad and flat (e.g., P. scabrosa). Raised veins can either be rounded in section and have a ropy appearance (Peltigera sp. 1) or be rather angled and look like ridges (typical $P$. aphthosa or $P$. retifoveata). The hyphae making up the veins are either oriented along the axis of the veins (the veins are glabrous; e.g.,

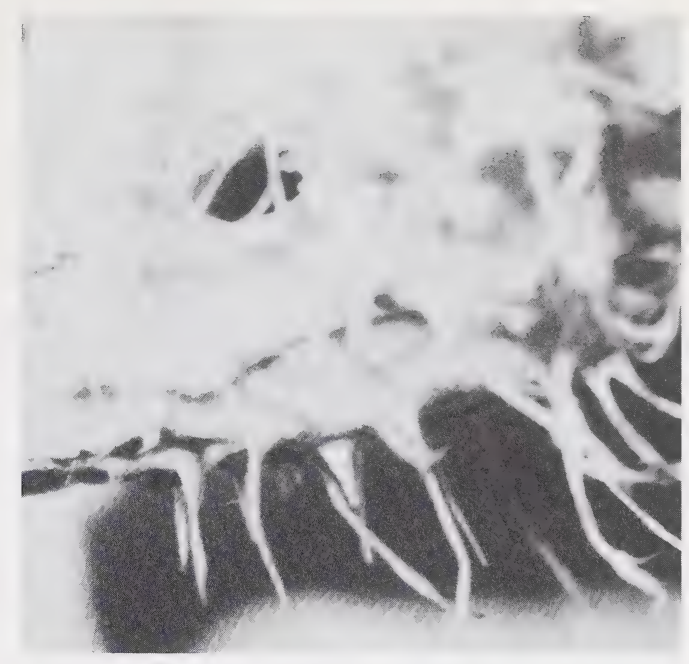

Figure 1. Thread-like rhizines (Peltigera praetextata, Martiny July 1992, herb. Goffinet).

$P$. canina) or they can appear as short erect hairs covering the veins (the veins are tomentose; e.g., P. membranacea). Some hyphae from these veins may continue to grow and become organized into rhizines which attach the thallus to the substrate. We distinguish several types of rhizines. Thread-like rhizines (Fig. 1) represent the simplest form; they are unbranched and distinctive. Fasciculate rhizines are simple rhizines of various length organized into tight bundles (Fig. 2). Penicillate rhizines are arranged as short, spreading bundles that resemble a shaving brush (Fig. 3). More often the rhizines are branched. The degree and kind of branching varies among, but also within, species. In typical $P$. canina, a conspicuous central strand abundantly branches in all directions. Sometimes the branches are longest near the base and

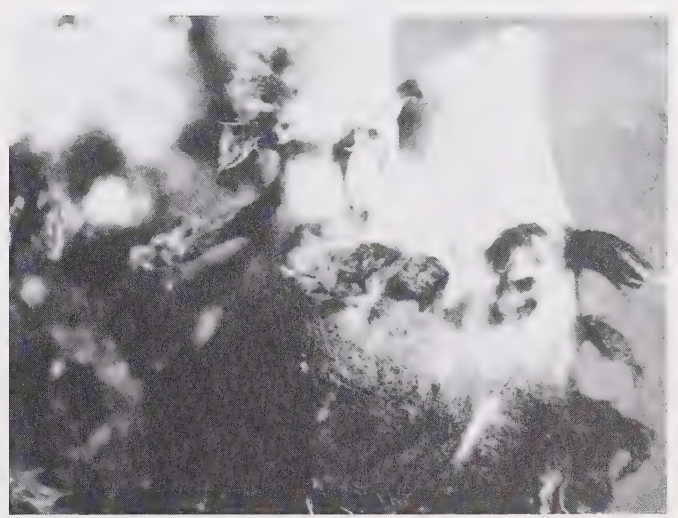

Figure 2. Fasciculate rhizines (Peltigera elisabethae, Goffinet 3083, herb. Goffinet). 


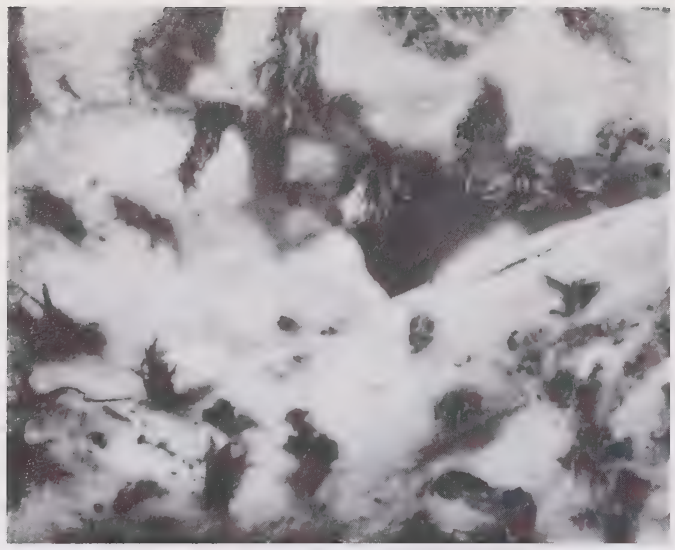

Figure 3. Penicillate rhizines (Peltigera scabrosa, Nyland 140, CAFB).

become gradually shorter towards the apex of the rhizine; at other times the rhizines only branch apically (Fig. 4). In $P$. retifoveata, the rhizines also branch abundantly, but the branches are shorter and more or less at right angles to the main axis (Fig. 5). These rhizines are squarrosely branched or tomentose. Finally, the rhizines may be poorly defined and appear only as loosely branching hyphae (e.g., $P$. didactyla var. extenuata, Fig. 6); these rhizines are fibrillose. The rhizines can be scattered (e.g., P. membranacea) or anastomose in which case they become confluent and either form rows or a more or less dense hyphal mat on the lower surface (e.g., P. rufescens, Fig. 83).

The hyphae which form veins and rhizines are often pigmented, their color varies from whitish (technically an absence of pigments) through grades of brown to black. Even within a species the color may change from the margin toward the centre and may vary with

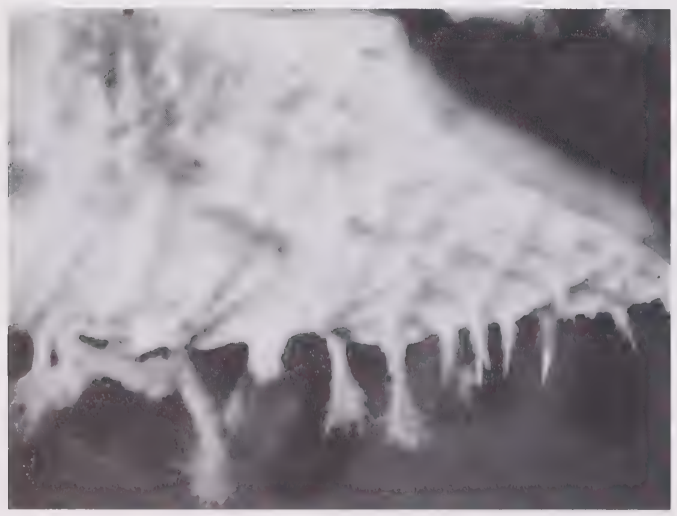

Figure 4. Apically branched rhizines (Peltigera canina, Goffinet 1557-2; herb. Goffinet).

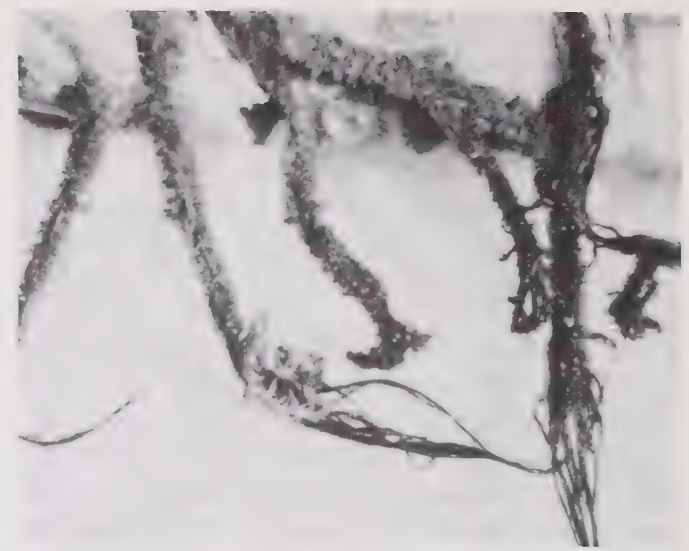

Figure 5. Squarrosely branched rhizines (Peltigera retifoveata, Goward 81-1533, ALTA).

locality. It is not yet clear if these variations can be accounted for by the nature of the substrate the lichen colonizes, as has been suggested by Olech and Alstrup (1988) for P. lactucifolia.

\section{Lobe shape}

The lobes of most species appear rather broad and rounded, only rarely do they seem elongate (as in some forms of $P$. praetextata). Most taxa have spreading lobes but some species, particularly the more xerophytic ones, have strongly concave ( $P$. lepidophora) or even erect lobes ( $P$. rufescens and some forms of $P$. malacea). In some species the fertile lobes are erect and supported by strong, ropy veins. These often differ from veins found on mature, sterile lobes. This phenomenon is particularly obvious in $P$. rufescens. The thickness of the thallus varies from extremely thick (in which case the lobes are often stiff and brittle; e.g., P. aphthosa) to membranous or papery (the

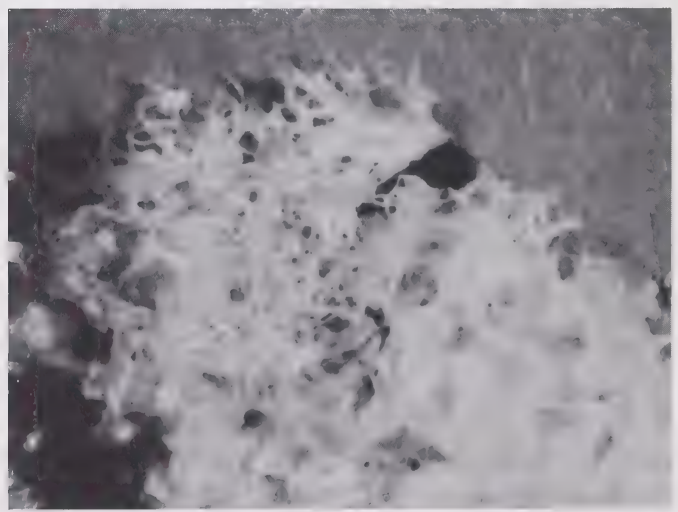

Figure 6. Fibrillose rhizines (Peltigera didactyla var. extenuata, Hastings C90.5.20b, PMAE). 


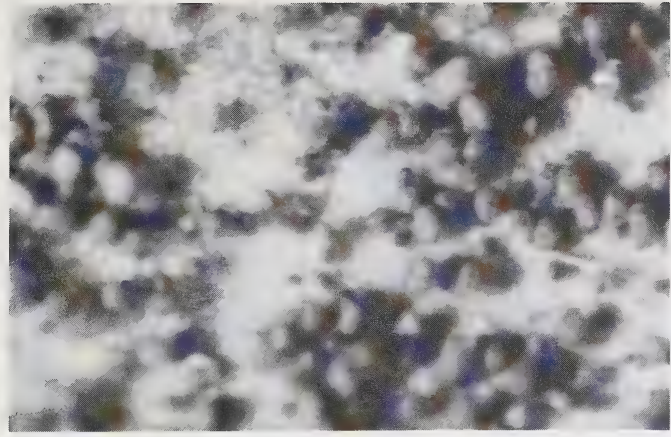

Figure 7. Granular isidia (Peltigera evansiana, Goffinet 3464 , herb. Goffinet).

lobes are then rather fragile; e.g., $P$. membranacea). Lobe width is a taxonomically useful character (e.g., to segregate taxa within the $P$. canina group). It is measured between two adjacent sinuses at the base of a lobe.

The margin is a critical character among species of the $P$. canina group. As distinguished here, a margin may either be plane (e.g., $P$. elisabethae), downturned (e.g., $P$. membranacea), or upturned (e.g., $P$. rufescens). In some cases, the lobe can be deeply concave giving the impression of an overall upright margin, but even in these specimens the extreme tip of the lobe can be pointing downwards (e.g., $P$. canina, Fig. 20). The margin is considered plane when the lobe is deeply concave and the margin does not form a distinct angle with the lobe, but appears to extend it.

\section{Isidia, phyllidia and regeneration lobules.}

Isidia occur in three species: $P$. evansiana, $P$. lepidophora, and $P$. praetextata. Their development in the latter two species has been investigated by Lindahl (1960) and Linkola $(1913,1923)$. In P. evansiana the isidia are mostly erect, club-shaped or granular, and corticate all around (Fig. 7). These isidia are radially symmetrical. In the two other taxa, the isidia are mainly dorsiventral, with the lower surface being ecor-
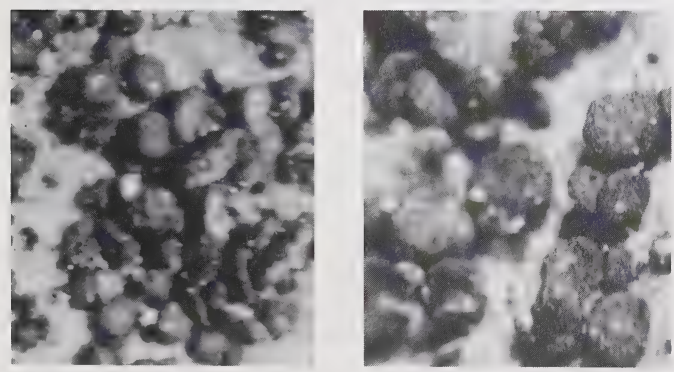

Figure 8. Peltate isidia (Peltigera lepidophora, Marsh, B86.141.123, PMAE). ticate. In P. lepidophora, the isidia are peltate. They are disc-shaped, attached at the centre and thus mostly horizontal (Fig. 8). In $P$. praetextata, the isidia are squamulose, constricted at their base, and mostly erect; they are often referred to as phyllidia (Fig. 9).

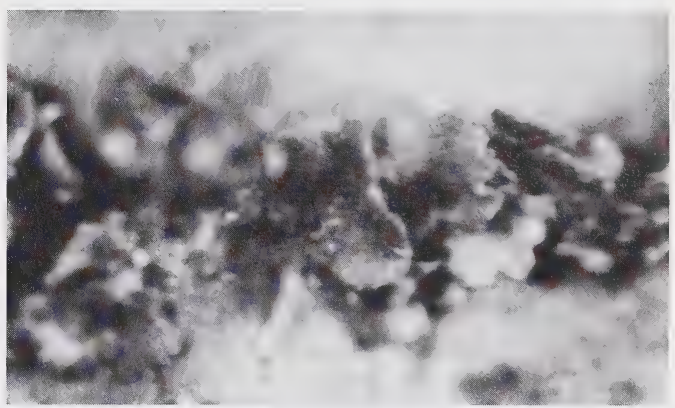

Figure 9. Phyllidia (Peltigera praetextata, Martiny July 1992, herb. Goffinet).

Regeneration lobules differ from phyllidia by their rather knobby appearance and seem to develop only in response to damage or stress. These structures appear similar to the isidia of $P$. evansiana, but differ by being more robust and restricted to cracks and wounds (Fig. 10). Recent observations (Goffinet 1992 and pers. obs.; Goward et al. in prep.; Holtan-Hartwig 1993) suggest that all species of Peltigera may develop these lobules.

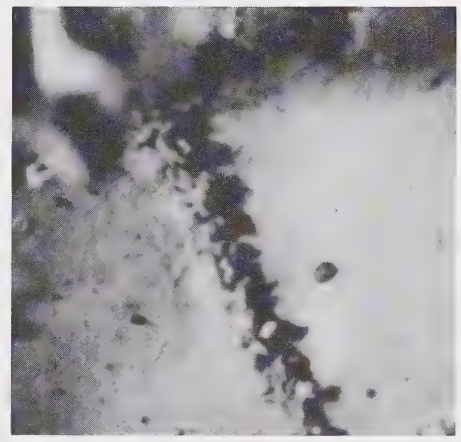

Figure 10. Regeneration lobules (Peltigera elisabethae, Goffinet 3083, herb. Goffinet).

\section{Soralia}

Soredia are granular, non-corticate outgrowths of the algal layer that are organized into soralia. In Alberta, these structures occur in two species: in $P$. collina, the soralia develop mainly along the lobe margin (Fig. 11 ), whereas in $P$. didactyla they are exclusively laminal (maculiform soralia; Fig. 12). Soredia can develop into isidia while still on the soralia; in this case the soralia are said to be isidiferous (e.g., $P$. didactyla). 


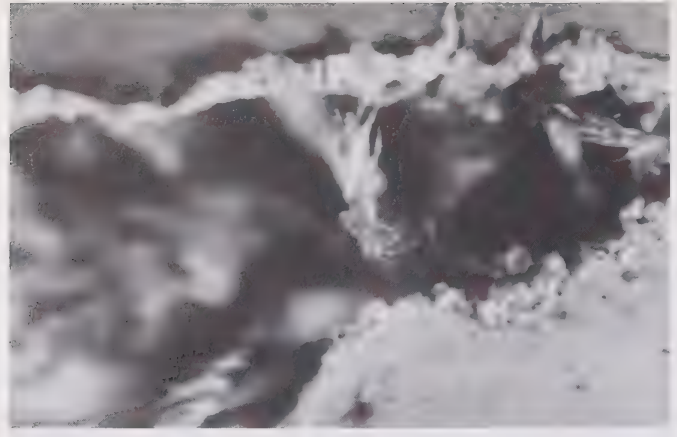

Figure 11. Marginal soredia (Peltigera collina, Pegg B88.2.55, PMAE).

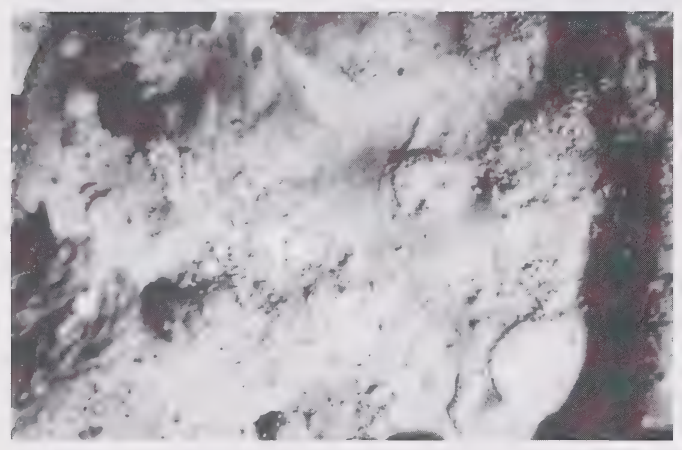

Figure 12. Laminal soredia (Peltigera didactyla var. extenuata, Hastings C90.5.20b, PMAE).

Soredia are not produced invariably by either of these taxa and cannot be used as a sole taxon-specific character.

\section{Schizidia}

Schizidia are found only in P. elisabethae (Fig. 13). The cortex, the underlying algal layer, and part of the medulla all peel off near the lobe tip or along cracks, leaving the remaining medullary hyphae exposed. In some specimens of $P$. praetextata with narrow and somewhat lacerate lobes, the medulla is often exposed along the margin. Such observations have been related to the development of schizidia (Purvis et al. 1992). However, it seems that these features are due to the "contortion" of the lobes, as large specimens (atypical for Alberta) with wide spreading lobes, are lacking such patches of exposed medulla. The cortex of $P$. neckeri is often cracked as well and the upper layers are slightly raised but do not split off to form schizidia.

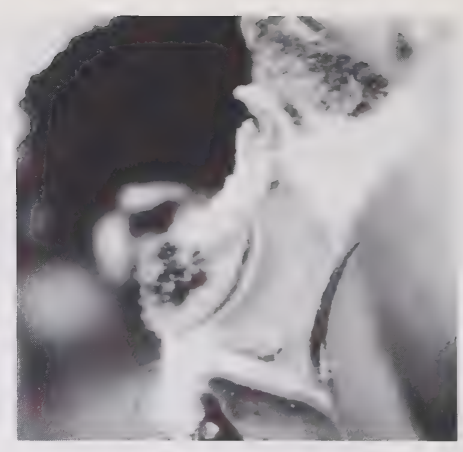

Figure 13. Schizidia (Peltigera elisabethae, Goffinet 3083, herb. Goffinet).

\section{Apothecia and spores}

Apothecia are commonly produced by most species of Peltigera. The roundish disk is either horizontal (e.g., $P$.' horizontalis), finger nail-shaped (e.g., $P$. neckeri) or even saddle-shaped (e.g., $P$. rufescens). Their color varies from brown to almost black. Jahns and Frey (1982) have shown that the thallus must reach a minimum size for the formation of the first apothecial primordia, "after which the development of the fruit bodies inhibits the growth of the supporting thallus lobes." Typically, the apothecia are developed on elongating lobes. The lobe length seems to be genetically determined, making it of taxonomic use (e.g., in the $P$. polydactylagroup). The lower surface of the apothecia typically lacks a cortex. However, all species of the $P$. aphthosa group are characterized by the development of at least a patchy cortex on the lower surface of the apothecia (Fig. 14).

Each ascus produces eight colorless spores. The ascus apex and spore release have been thoroughly described by Honegger (1978). The spores can be acicular in shape (e.g., P. neckeri) or narrowly elliptical
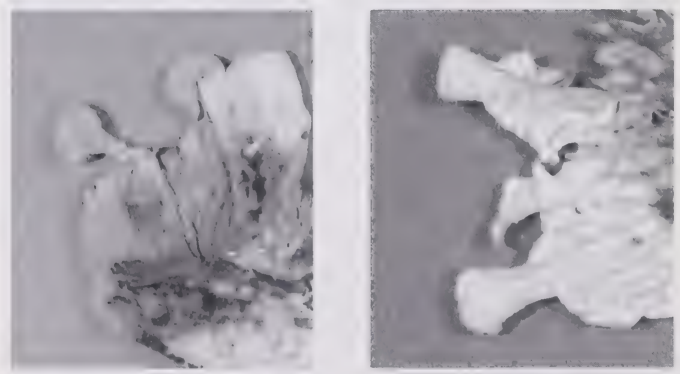

Figure 14. Lower surface of apothecia. Left - continuous cortex (Peltigera aphthosa Turner 11257, ALTA), right - patchy cortex (Peltigera leucophlebia Kennedy Sept. 6, 1961, ALTA). 
( $P$. venosa). They vary in size, from $20-125 \times 2.5-5$ $\mu \mathrm{m}$, and are most often four-celled. In some species (e.g., P. aphthosa) the protoplasm commonly appears "constricted," probably through pressure by the vacuole. In such cases the constriction resembles a septum and can be misleading when determining the number of cells per spore. Taxonomically, the use of spore characters is limited to distinguishing groups of species $(P$. horizontalis- $P$. elisabethae versus $P$. polydactyla $s$. lat.), rather than individual species.

\section{Chemistry.}

The genus Peltigera is characterized by its diverse secondary metabolites. Holtan-Hartwig (1993) in a revision of the Norwegian taxa containing secondary substances, reports 43 compounds, including 30 unidentified terpenoids and depsides. Chemical patterns can be species specific (e.g., P. neckeri) or be shared by closely related taxa (e.g., $P$. elisabethae \& $P$. horizontalis), in which case their taxonomic use is lim- ited to separating groups of species (Holtan-Hartwig 1993). In the present study, only a restricted number of taxa were analyzed by thin layer chromatography, mainly specimens of $P$. polydactyla s. lat and $P$. didactyla s. lat. More work is needed before a specific chemical description will be available and useful taxonomically for the identification of Albertan Peltigerae. Spot tests are not very useful for distinguishing species of Peltigera. The only positive test observed so far, is the $\mathrm{C}+$ or $\mathrm{KC}+$ red reaction due to the presence of gyrophoric acid in species of the $P$. polydactyla group and certain taxa or forms in the $P$. canina group. The spot test is, nevertheless, unreliable as gyrophoric acid is often only present in trace amounts. Goffinet \& Hastings (in press) suggest that this depsidone may not accumulate in the thallus because it is rapidly processed into methyl gyrophorate, which is often produced in addition to gyrophoric acid in Peltigera species. 


\section{Artificial Key to the Species}

1. Thallus homoiomerous, containing cyanobacteria, attached to the green phototype of $P$. venosa; resembling a small Leptogium; veins always absent.............. P. venosa (blue-green phototype)

Thallus heteromerous, containing green algae and/or cyanobacteria; veins often distinct $\ldots \ldots \ldots \ldots \ldots 2$

2. Photobiont green algae; cephalodia containing cyanobacteria present on lower or upper surface $\ldots \ldots \ldots 3$

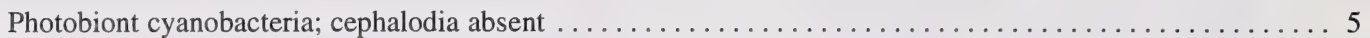

3. Thallus small, 1 to $1.5 \mathrm{~cm}$ in diameter; apothecia marginal, on non-elongated lobes and horizontal or slightly concave; cephalodia on veins on the lower surface $\ldots \ldots \ldots \ldots \ldots \ldots \ldots \ldots \ldots \ldots$. $\ldots \ldots$. $\ldots \ldots$

Thallus broad, lobes 2 to $3 \mathrm{~cm}$ wide; apothecia on elongate lobes, saddle-shaped; cephalodia

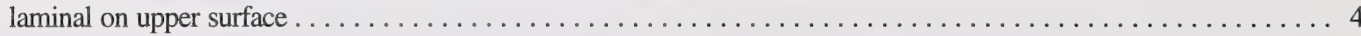

4. Lower surface with a distinct network of dark veins contrasting with whitish elongate interstices;

cortex on the underside of apothecia never continuous; thallus thin in the centre ........... leucophlebia (if lower surface has pale broad veins extending toward centre, see snow-form of $P$. aphthosa)

Lower surface with no distinct veins, or with broad anastomosing veins, separated by few pale to dark, deep, lenticular interstices, whitish near margin and black toward centre; cortex on lower surface of apothecia continuous or not; thallus thick in the centre $\ldots \ldots \ldots \ldots \ldots \ldots \ldots$. aphthosa

5. Thallus attached to lobes of $P$. aphthosa, or bearing lobules with green algae, or growing independently; cortex distinctly maculate (best seen when wet); erect hairs present on at

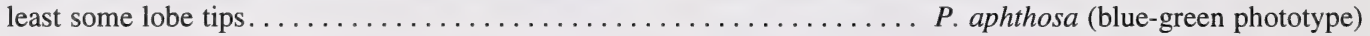

Thallus never attached to or bearing lobes containing green algae; cortex not distinctly maculate,

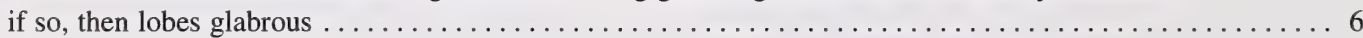

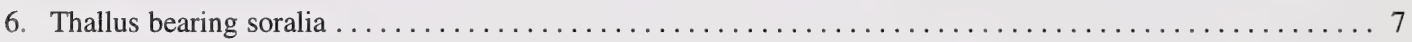

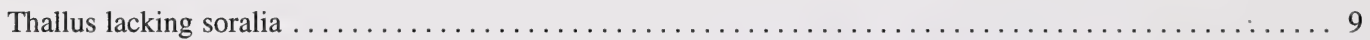

7. Soralia mainly marginal $\ldots \ldots \ldots \ldots \ldots \ldots \ldots \ldots \ldots \ldots \ldots \ldots \ldots \ldots \ldots \ldots \ldots \ldots \ldots \ldots \ldots \ldots \ldots \ldots$

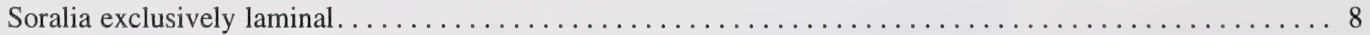

8. Thallus small, brownish-dark grey, when young usually a single deeply concave lobe; veins whitish to brownish towards centre; rhizines mostly simple; older thalli abundantly fertile with apothecia on erect elongated lobes; medulla $\mathrm{KC}-\ldots \ldots \ldots \ldots \ldots \ldots \ldots \ldots$. didactyla var. didactyla

Thallus broad, light grey, flat; lower surface with whitish veins; rhizines fibrillose; apothecia extremely rare; medulla $\mathrm{KC}+$ red (flashing, best seen when soredia are removed from young

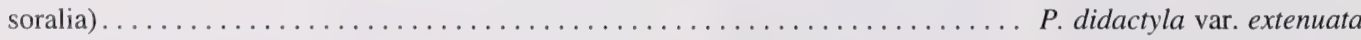

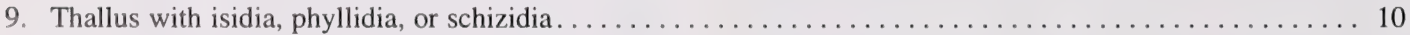

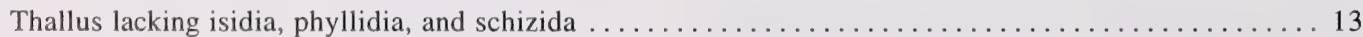


10. Thallus glabrous; lobe margin with schizidia; lower surface blackish with a few white dots, without distinct veins

Thallus tomentose; lobe margin without schizidia; lower surface with distinct white

to brown veins.

11. Thallus small, $1 \mathrm{~cm}$ wide, rarely larger then $2 \mathrm{~cm}$, concave, often unilobate; with peltate (rarely erect) isidia P. lepidophora

Thallus broad, more than $2 \mathrm{~cm}$ wide, always multilobate; with phyllidia or club-shaped to granular isidia .

12. Thallus with isidia; these exclusively laminal and diffuse, becoming dense toward lobe apices and mostly lacking toward centre; isidia globular and short, constricted at the base, occasionally somewhat squamulose toward centre of lobe; thallus flat, light grey when dry; lobe margin typically downturned

P. evansiana

Thallus with phyllidia; these in laminal clusters or in rows both along margins and cracks (lobules) toward the centre of the thallus; thallus crisped, brown when dry; lobe margin often upturned or plane

P. praetextata

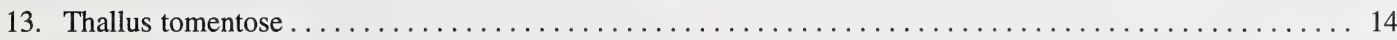

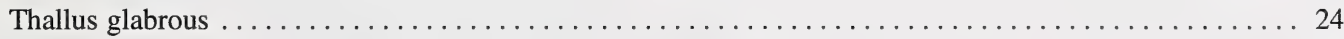

14. Tomentum of erect hairs (best seen near margin, look for sheltered lobe tips) $\ldots \ldots \ldots \ldots \ldots \ldots \ldots \ldots$

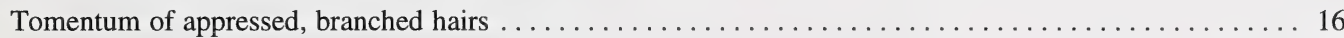

15. Lower surface with broad anastomosing veins and few if any interstices, abruptly darkening from a whitish margin; upper surface smooth $\ldots \ldots \ldots \ldots \ldots \ldots \ldots \ldots \ldots \ldots \ldots \ldots \ldots \ldots \ldots \ldots \ldots \ldots$

Lower surface with dark, distinct veins throughout; upper surface scabrous at least near lobe

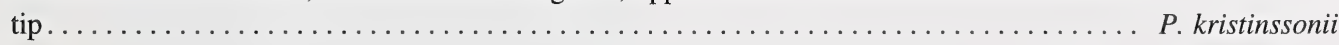

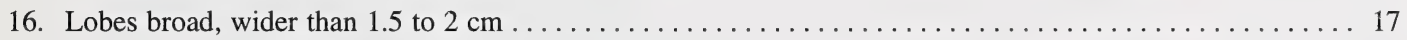

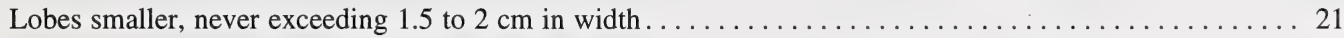

17. Lower surface with flat, soft veins, these almost as broad as interstices; interstices deep and lenticular; rhizines densely squarrosely branched P. retifoveata

Lower surface with somewhat rounded, compact veins, these much narrower than interstices; interstices diamond shaped and shallow; rhizines variously branched, if squarrosely branched then veins narrow and raised and thallus papery.

18. Veins typically very narrow, sharp and strongly raised, at least patchily covered with erect hairs, loosely reticulate, whitish throughout, rarely becoming dark brown; rhizines squarrosely branched rarely thread-like, scattered; thallus very thin, papery....................... membranacea

Veins broad and somewhat raised, never strongly so on sterile lobes, rarely covered by erect hairs and, if so, only near margin, rather neatly reticulate, pale, rusty or dark brown, if whitish then thallus thick and robust; rhizines variously branched but never squarrose, anastomosing or not; thallus variously thick, but never papery 
19. Rhizines densely branched or thread-like (near margin), at least patchily anastomosing and matforming; tomentum typically extending to centre of lobe $\ldots \ldots \ldots \ldots \ldots \ldots \ldots \ldots \ldots \ldots \ldots \ldots \ldots \ldots \ldots \ldots$

Rhizines thread-like or somewhat branched, never confluent; tomentum almost always thinning toward centre of lobe.

20. Rhizines thread-like, never branched; veins becoming distinctly rusty cinnamon-colored toward thallus center, without hairs; phyllidia absent; margin mostly plane P. cinnamomea

Rhizines thread-like or branched; veins pale to dark brown, but never cinnamon-colored, occasionally covered with erect hairs near margin; phyllidia frequent on mature lobe surface and along cracks and margin (lobules); margin wavy and often upturned

P. praetextata

21. Lower surface with black, short, densely branched, and typically anastomosing rhizines (if rhizines simple then mostly blackish); veins dark brown to almost black; upper surface with thick tomentum often extending toward lobe centre, encrusted or pruinose in the centre; apothecia saddle-

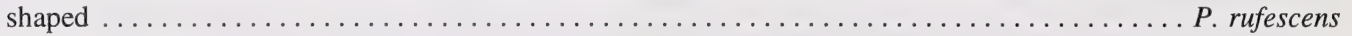

Lower surface with white to brown rhizines; veins pale throughout or darkening only gradually toward centre, scattered, if anastomosing then rhizines fibrillose; upper surface with thin tomentum gradually disappearing toward centre, never encrusted or pruinose; apothecia finger nail-shaped or

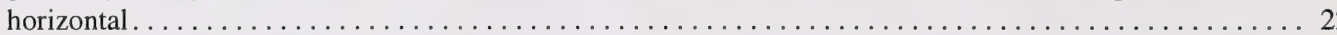

22. Lower surface with white, thick, typically strongly raised veins; apothecia plane; rare ....... P. ponojensis Lower surface with white and gradually darkening, flat to somewhat raised veins (on sterile lobes); apothecia saddle-shaped or finger nail-shaped; common

23. Thallus small, to $5 \mathrm{~cm}$ across, typically strongly concave, mostly unilobate or with erect apothecia bearing lobes, sterile branched lobes rare, when young usually a single deeply concave lobe, older thalli abundantly fertile, with apothecia bearing lobes erect and clustered as finger-like projections; soredial scars often present toward centre of main lobe, phyllidia never developed. . . . . . . didactyla var. dida

Thallus large, to $15 \mathrm{~cm}$ across, appressed, mostly abundantly branched, apothecia bearing lobes not clustered, less abundant then sterile ones; thallus often bearing phyllidia toward centre, soredial scars

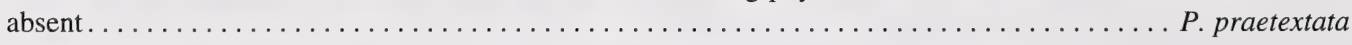
(if phyllidia absent and rhizines densely fibrillose see $P$. didactyla var. extenuata)

24. Upper surface scabrous; veins darkening gradually; rhizines penicillate $\ldots \ldots \ldots \ldots \ldots \ldots \ldots$. scabrosa Upper surface smooth, sometimes pruinose near margin; veins and rhizines various; if upper surface scabrous then rhizines thread-like and/or veins soon becoming dark brown to almost black ......... 25

25. Lower surface pale throughout or only darkening gradually toward centre; veins strongly raised...... P. sp.1 Lower surface mostly dark throughout (except near margin), if gradually darkening toward centre, then

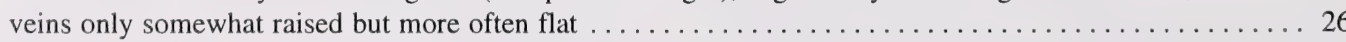

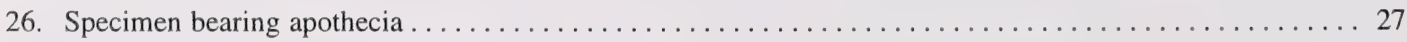

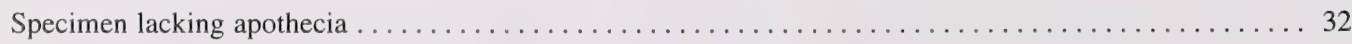


27. Apothecia horizontal; spores less then $45 \mu \mathrm{m}$ long, almost always triseptate; rhizines in concentric lines

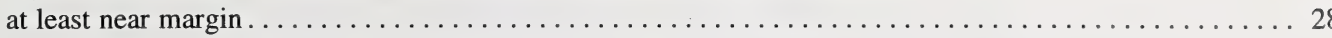

Apothecia finger nail-shaped or saddle-shaped; spores longer then $45 \mu \mathrm{m}$, tri- to pluriseptate; rhizines

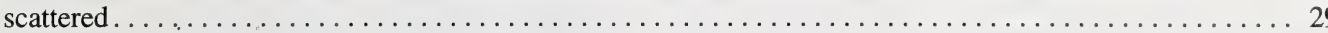

28. Lower surface with a distinct network of dark brown veins, upper surface often with pits opposite the rhizines; schizidia absent; rare $\ldots \ldots \ldots \ldots \ldots \ldots \ldots \ldots \ldots \ldots \ldots \ldots \ldots \ldots \ldots \ldots \ldots \ldots \ldots \ldots \ldots \ldots$ horizontalis

Lower surface blackish with a few white dots, without distinct veins, upper surface smooth but with numerous cracks; lobe margin with schizidia; common ...................... P. elisabethae

29. Upper surface dull, scabrous, and with sparse erect tomentum near margin (look at sheltered tips); lower surface with a distinct network of dark brown, tomentose veins; rhizines fasciculate to

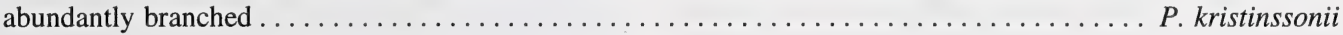

Upper surface shiny, smooth and glabrous, but sometimes pruinose; veins distinct or not, never tomentose; rhizines thread-like to penicillate, never abundantly branched

30. Thallus large, to $15 \mathrm{~cm}$ across; lobes up to $3 \mathrm{~cm}$ wide; upper surface typically dull; rhizines thread-like,

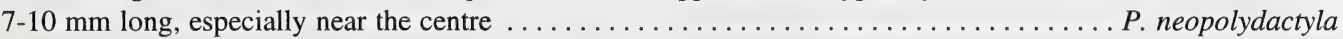

Thallus medium-sized, to $10 \mathrm{~cm}$ across; lobes less than $2 \mathrm{~cm}$ wide; upper surface typically very shiny;

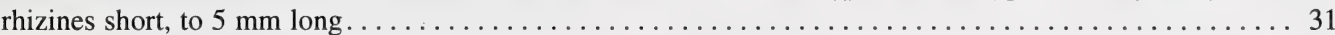

31. Apothecia brown, on elongate and somewhat canaliculate lobes; lobe margin not pruinose; veins brownish, remaining distinct almost to centre; rare .......................... polydactyla

Apothecia black, on short lobes; lobe margin often pruinose; veins blackish, broad, and often

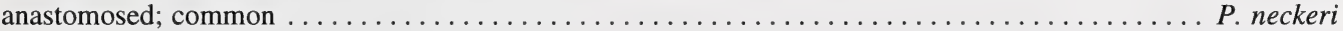

32. Rhizines near margin fasciculate and arranged in concentric lines; schizidia present or absent ....... 33

Rhizines near margin fasciculate or not, not arranged in concentric lines; schizidia always absent. ..... 34

33. Lower surface abruptly turning blackish; veins indistinct; upper surface smooth, with numerous cracks; schizidia and/or regeneration lobules; margin often pruinose $\ldots \ldots \ldots \ldots \ldots \ldots \ldots$. elisabethae

Lower surface rather gradually turning brown; veins distinct, at least toward margin; upper surface with pits opposite rhizines; cracks (except in excessively pressed specimens), schizidia, and regeneration

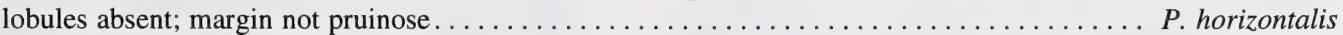

34. Upper surface scabrous, bearing erect hairs (check sheltered lobes); veins dark brown to almost black, tomentose, distinct, highly contrastive with pale interstices $\ldots \ldots \ldots \ldots \ldots \ldots \ldots \ldots \ldots \ldots$ kristinssonii

Upper surface smooth, glabrous; veins indistinct, glabrous, if contrastive with interstices then veins

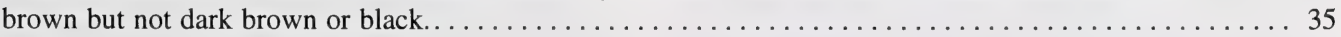

35. Upper surface dull; rhizines to $7 \mathrm{~mm}$ long, thread-like; lobes typically to $3 \mathrm{~cm}$ wide .....P. neopolydactyla Upper surface very shiny; rhizines short, to $5 \mathrm{~mm}$ long, thread-like, fasciculate, or somewhat branched;

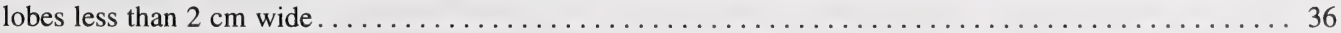

36. Lower surface with indistinct veins, soon turning blackish; cortex often pruinose near margin; common . P. neckeri Lower surface with distinct, brown veins; cortex not pruinose; rare P. polydactyla 


\section{Species Accounts}

\section{Peltigera aphthosa (L.) Willd.}

Illustrations: Figs. 15-18, map: Fig. 19.

\section{A. The green phototype}

Morphology: Thallus medium to large, loosely appressed to the substrate; lobes to $5 \mathrm{~cm}$ wide, branching, most often strongly concave, thick, brittle when dry, margin entire, rarely somewhat crenulate, plane to upturned, often bordered by a white line corresponding to the probably faster growing medulla. Upper surface typically shiny (dull in exposed habitats), apple green when wet, greenish- to bluish-grey when dry, often with brownish tint toward centre, typically wavy, covered with partly erect hairs near margin only, cephalodia to $2 \mathrm{~mm}$ wide, adnate, flat to convex, sometimes lobulate (with marginal incisions) but always attached through their whole surface to the cortex. Lower surface typically turning abruptly dark brown to blackish from a whitish cottony marginal zone, rarely pale throughout, with very broad, raised, somewhat angled, veins (ridges), separated by a few, lenticular to elliptic and deep, whitish, greyish to dark interstices, veins rarely distinct to the margin; rhizines to $5 \mathrm{~mm}$, blackish throughout, rarely pale, typically confined to mature part of the lobes, densely branched and often anastomosing. Photobiont, green algae. Apothecia common, with chestnut to dark brown disk, to $1.4 \mathrm{~cm}$ wide, with at least somewhat revolute to

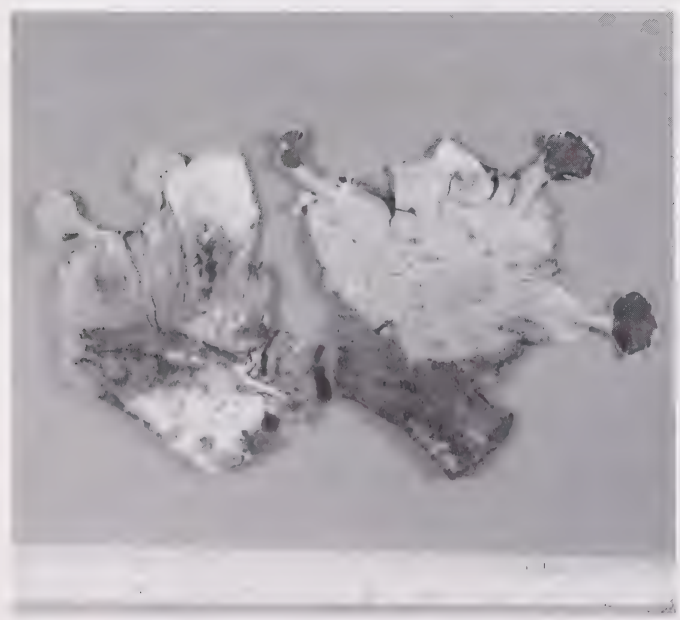

Figure 15. Peltigera aphthosa lower surface (left) and upper surface (right) of lobes and apothecia. The cephalodia appear as dots on the upper surface. (Turner 11257, ALTA.)

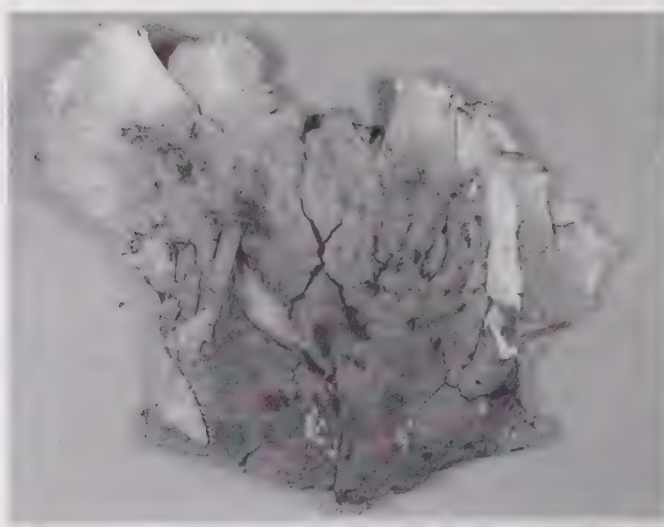

Figure 16. Peltigera aphthosa lower surface with no interstices, veins anastomosed throughout. (Ostafichuk 227-2, ALTA.)

saddle-shaped margins, on narrow, elongate lobes, lower surface continuously corticate or not, cortex pruinose-scabrous; spores acicular,.(53-) 61-75 (-86) x 3.5-5 $\mu \mathrm{m}$, mostly four-celled.

Variation: Peltigera aphthosa is among the most plastic species in the genus. Typically, in mesic habitats, the lower surface appears veinless or nearly so,

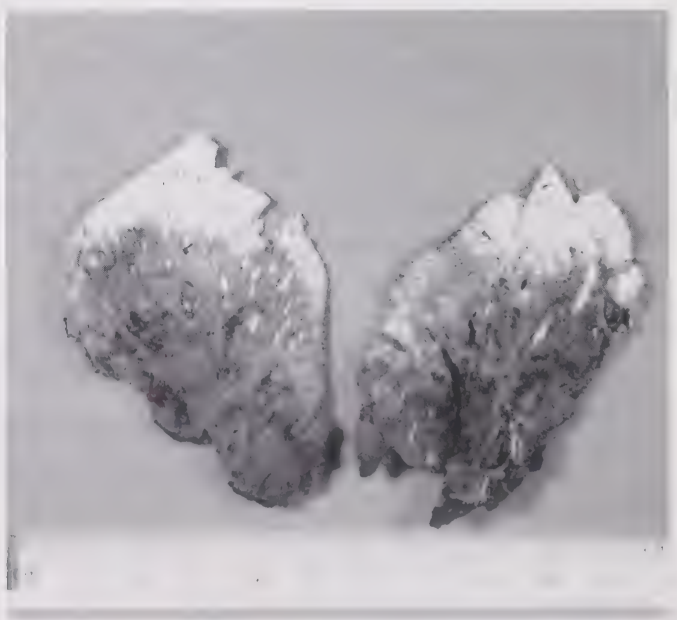

Figure 17. Peltigera aphthosa lower surface with interstices conspicuous and lenticular. (Marsh 1342, ALTA.) 


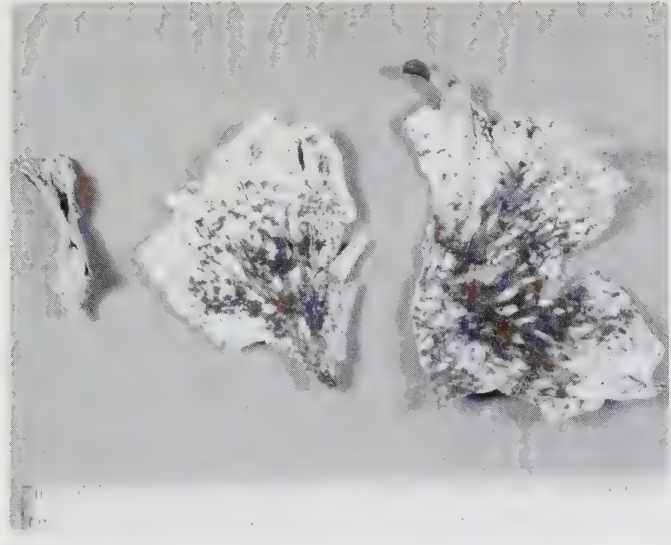

Figure 18. Peltigera aphthosa lower surface of atypical form with veins pale, rather distinct and only gradually darkening toward centre. Referred to in text as snowform. (Goffinet 1417, herb. Goffinet.)

with a distinct transition from the whitish marginal zone to the blackish central part of the thallus (Figs. 16-17). A line could almost be drawn along this transition. In habitats with heavy snow cover, however, the veins are mostly pale and extend toward the centre; they darken only gradually (Goward et al. in prep.) (Fig. 18). In Alberta, these "snow forms," which may represent a distinct taxon (Goward et al. in prep.), are restricted to the Rocky Mountains and Swan Hills. Peltigera leucophlebia is similar to these chionophilous morphotypes, but can be distinguished by its patchy lower cortex of the apothecia and its veins. These veins are typically distinct throughout the lobe and dark almost to the margin; they contrast highly with the wide and elongate interstices (see discussion under that species). Further, the two species can be segregated by the shape of the cephalodia (HoltanHartwig 1993). In P. aphthosa the cephalodia are flat to wart-shaped compared to cerebriform in P. leucophlebia. However, we have refrained from using this as a sole taxonomic character.

Thomson (1984) has suggested that $P$. leucophlebia is a variety of $P$. aphthosa ( $P$. aphthosa var. leucophlebia Nyl.) due to the transitional forms found between the two typical extremes. However, intermediate morphotypes between $P$. aphthosa and $P$. leucophlebia may represent varying degrees of introgression between these two species (Goward et al. in prep.). Further, whereas Thomson (1984) and Gowan and Brodo (1988) do not refer to the difference in the cortex layer on the lower surface of the apothecia, Vitikainen (1981) and Holtan-Hartwig (1993) consider it to be a species-specific character-the layer being continuous in $P$. aphthosa versus patchy in $P$. leuco- phlebia (Figs. $15 \& 50$ respectively). In Alberta, we have found specimens which have characters typical of $P$. aphthosa (abrupt transition in color of the lower surface, rather indistinct ridges) but with a patchy, warty cortex on the underside of the apothecia. It could either be argued that such apothecia are not yet mature, and thus the algal layer has not yet been completely developed, or that these specimens result from hybridization. Until the extent of the cortex on the lower surface of the apothecia can be related to chemical patterns, or until the development of the lower cortex is studied during apothecia maturation, we consider such forms to belong to $P$. aphthosa. Thus, in $P$. aphthosa, we consider the cortex of the lower surface of the apothecia to be typically continuous, but occasionally patchy. By contrast, it is invariably patchy in P. leucophlebia.

Ecology: Widespread and common in moist to wet boreal and montane forests. Growing in moist shrublands in boreal forest to alpine sites, Black Spruce and larch wetlands, and in moist hollows in drier forests such as spruce-pine on dunes. Commonly growing over feathermosses and often on litter, only very rarely on soil.

Distribution in Alberta: Occurring from the northern and western edge of the Central Parkland, P. aphthosa is abundant in the Foothills, Montane, Subalpine, and Alpine natural regions (Fig. 19). North from the Parklands, it has also been collected throughout the Boreal Mixedwood. In the far north, scattered collecting sites indicate its presence in Wetland Mixedwood, Peace River Woodlands, and Canadian Shield, as well as the higher elevation Boreal Highlands and Subarctic subregions. Peltigera aphthosa is probably more common in the northern part of the province than indicated. This species is among the most common Peltigera in Alberta; it is abundant over its range.

Distribution in North America: This circumpolar species is widespread throughout boreal, arctic, and alpine North America (see also map in Thomson 1984, under $P$. aphthosa var. aphthosa). Additional specimens seen (ALTA): Canada: British Columbia, Manitoba, Newfoundland, Northwest Territories, Ontario, Quebec, Saskatchewan, and the Yukon Territory; U.S.A.: Alaska, Colorado, Michigan, Minnesota, New Hampshire, Washington, and Wyoming.

\section{B. The blue-green phototype}

In Alberta, the blue-green counterpart of $P$. aphthosa is known from a single specimen collected recently in the mountains (Harris 328, UAC). The material consists of small blue-green lobes only and does not allow a formal morphological description. Neverthe- 


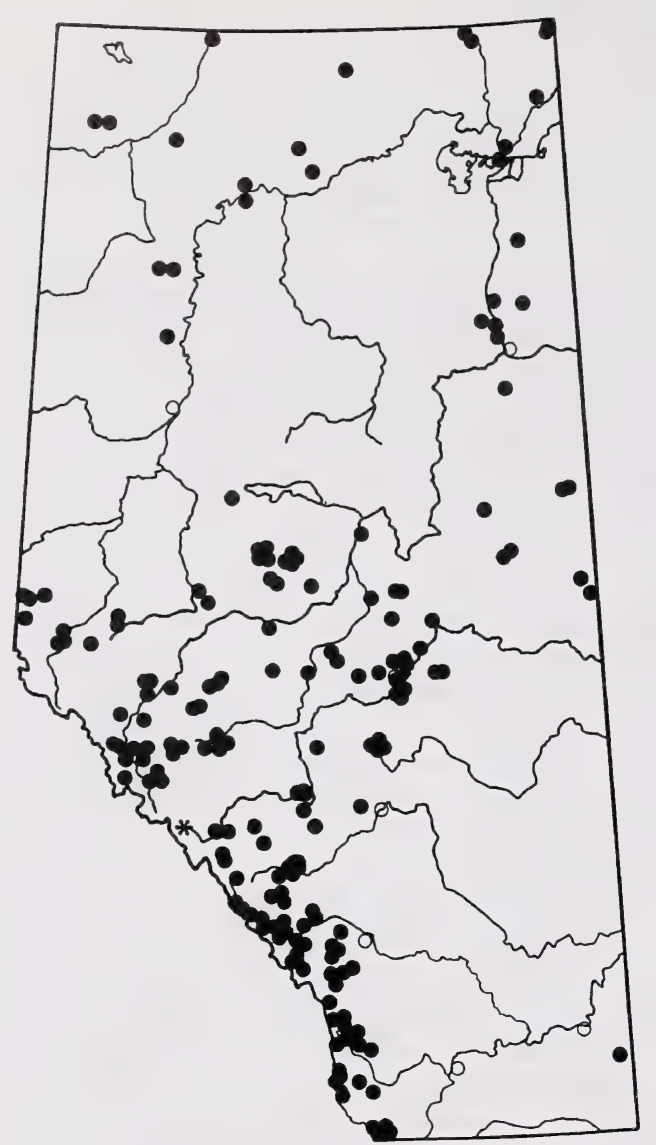

Figure 19. Distribution of Peltigera aphthosa in Alberta (solid dots: green phototype; star: blue-green phototype).

less, based on the distinct maculate cortex, there is little doubt as to the identity of the specimen. Typical material, as it is known from British Columbia, is either attached to lobes or bears lobules containing green algae (typical, green phototype of $P$. aphthosa). The blue-green lobes can either be glabrous or slightly tomentose towards the tip, in which case the glassy hairs are erect. In the former case, the phototype could be mistaken for either $P$. neckeri or $P$. elisabethae, whereas tomentose specimens would seem similar to P. malacea or P. kristinssonii. In either case, the bluegreen phototypes can be correctly identified based on the connections to green lobes or lobules, and when the thallus is independent on the distinct maculate cortex.

Distribution in Alberta: This phototype is known only from a single locality in the Montane subregion of the Rocky Mountains (Fig. 19).
Distribution in North America: Blue-green phototypes of $P$. aphthosa are so far only known from humid localities in British Columbia, Oregon, and Washington (Goward et al. in prep.). The locality in Alberta is the most continental site known for this phototype.

\section{Peltigera canina (L.) Willd.}

Illustrations: Figs. 20-22, map: Fig. 23. Appendix 1.

Morphology: Thallus medium to large, to $30 \mathrm{~cm}$ wide, rather loosely attached to the substrate; lobes to $3.5 \mathrm{~cm}$ wide, branching, flat to concave near margin, robust when dry, margin entire and downturned, rarely plane. Upper surface dull, light grey, greyish-brown, or more rarely brown, smooth, with thick, appressed tomentum typically extending toward centre of thallus, and occasionally encrusted or pruinose near centre. Lower surface pale whitish near margin, gradually turning brownish to dark brown toward centre, rarely remaining pale throughout, veins distinct, glabrous, broad and flat, often raised near margin, interstices whitish, elongate to diamond-shaped; rhizines to $8 \mathrm{~mm}$, concolorous with veins, thread-like near margin but typically soon abundantly branching (bushy), sometimes only apically (Fig. 4), or penicillate, only observed once as being tomentose, often anastomosing near margins. Photobiont, cyanobacteria. Apothecia common, disk chestnut brown, between 4 and $9 \mathrm{~mm}$ wide, rarely larger $(12 \mathrm{~mm})$, saddle-shaped, on narrow

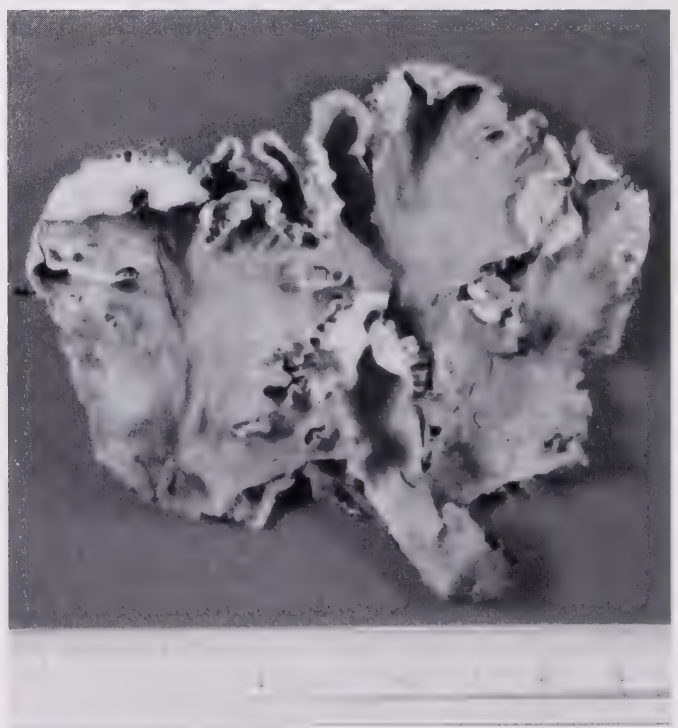

Figure 20. Peltigera canina habit. The lobes are strongly concave with a downturned margin. (Goffinet C90.4.172, herb. Goffinet.) 


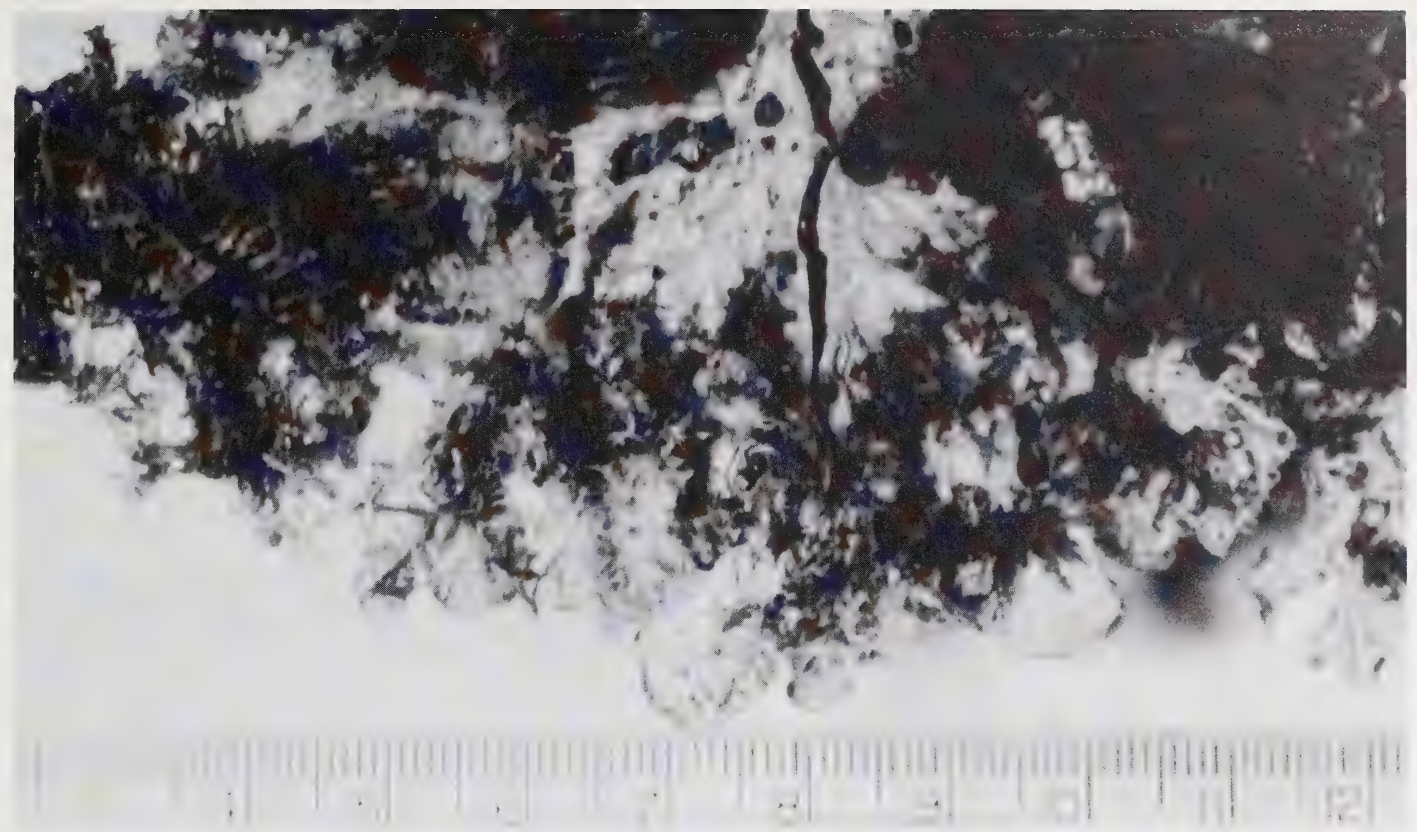

Figure 21. Peltigera canina lower surface. It has pale veins and scattered, branched rhizines near the margin. (Sérusiaux July 1990, herb. Goffinet.)
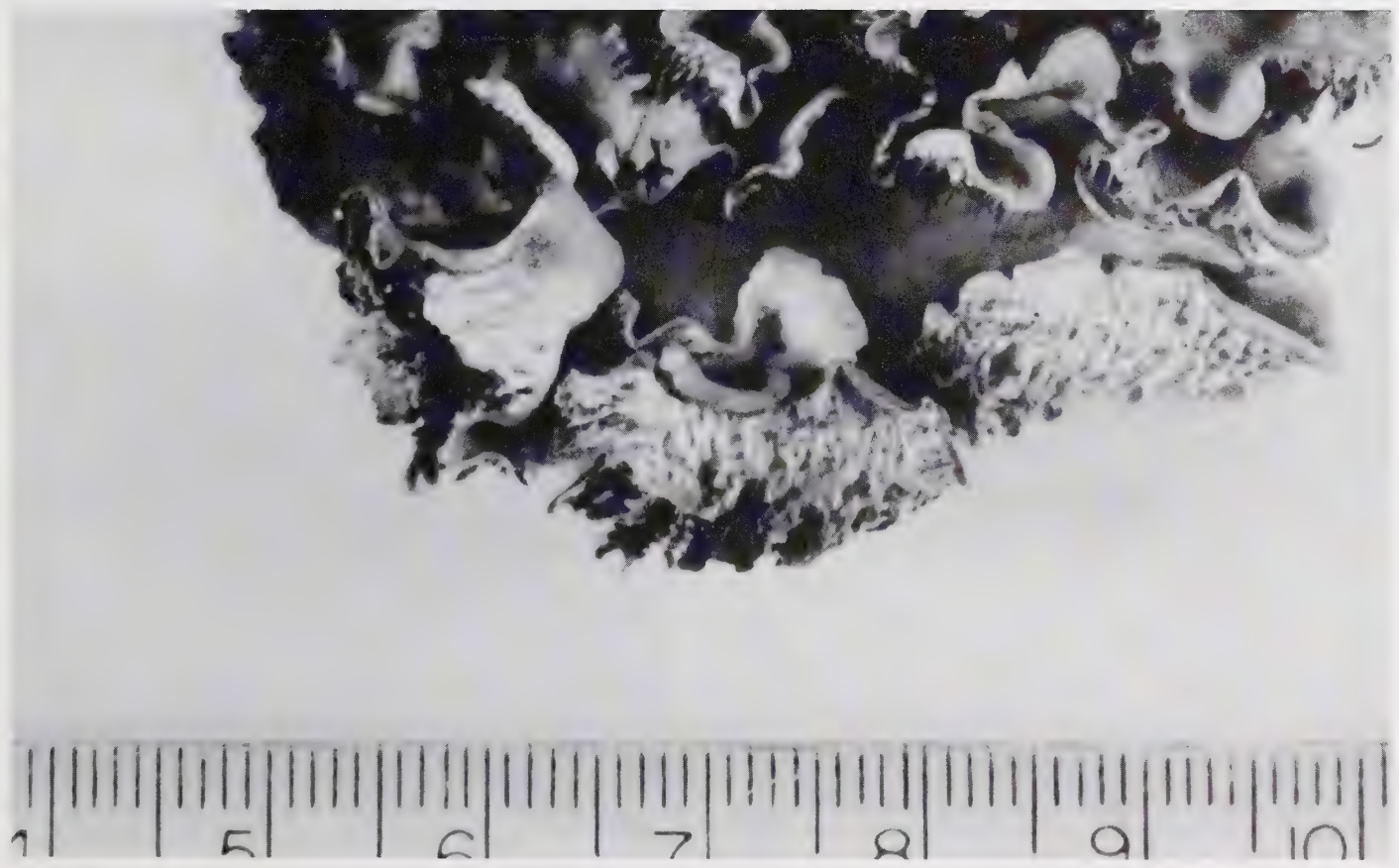

Figure 22. Peltigera canina lower surface near margin. Note the variation in the degree of branching and color of the rhizines; scattered and whitish on the right and anastomosed and dark on the left. The veins of the apothecia bearing lobes are strong and ropy. (Goffinet 1557-2, herb, Goffinet.) 
elongate lobes; spores acicular (39-) 44-54 (-59) x 3-4 $\mu \mathrm{m}$, invariably four-celled.

Variation: The Peltigera canina group s. lat. includes eight species. Most of these show high phenotypic plasticity making it the most difficult group taxonomically. Peltigera retifoveata (with its foveate lower surface) and $P$. didactyla (typically bearing soredia) are easily recognized. The remaining taxa $(P$. canina, $P$. cinnamomea, $P$. membranacea, $P$. ponojensis $P$. praetextata, and $P$. rufescens) are often split between two groups according to the size of their lobes. This character, however, is unreliable when immature specimens are collected. The species differ significantly in

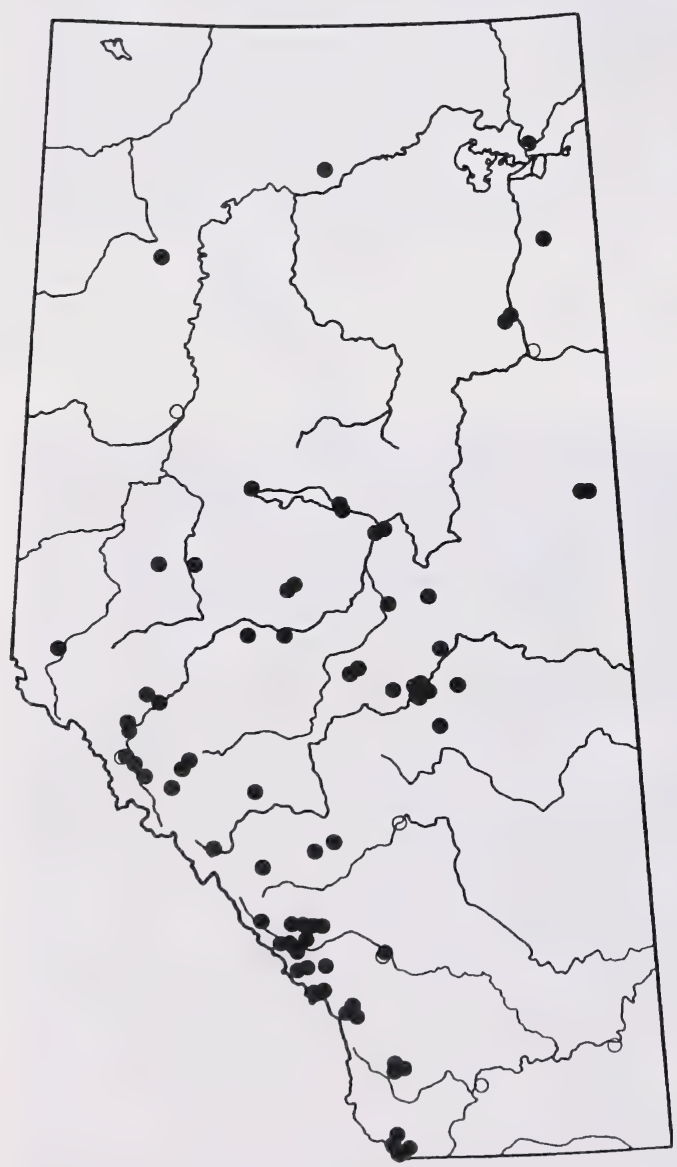

Figure 23. Distribution of Peltigera canina in Alberta. the morphology of their lower surface, and further, with field experience, habitat and growth form can often prove useful for separating the species (Appendix 1).

Typical material of $P$. canina differs from related species by its downturned margin, the low and glabrous veins, and the abundantly branched and anastomosing rhizines (Figs. $21 \& 22$ ). Peltigera canina is most commonly mistaken for $P$. rufescens. The latter species, however, has an upturned margin, typically dark and abundantly branched rhizines even near the margin, and its lobes never extend beyond $1.5 \mathrm{~cm}$. As is probably true for all species of Peltigera, P. canina can sometimes produce regeneration lobuli. In Alberta, these were observed only once (Ostafichuk 260-8, ALTA), but characters such as the branching of the rhizines allowed for no confusion with $P$. praetextata (see discussion under that species). Another collection from the alpine zone (Pegg B88.2.41 PMAE) had strongly raised veins as well as strongly tomentose rhizines. This collection was nevertheless kept as $P$. canina because of its broad veins and thick lobes, characters that distinguish it from $P$. membranacea.

Ecology: Occurring in dry to moist sites ranging from roadside embankments to pine-spruce forests. Common on litter and mosses in pine, pine-spruce, and White Spruce-Balsam Fir forests. Also on dry soil and burned or rotten wood. Occasionally occurring on moist litter in alpine shrublands, and rarely in Black Spruce and Aspen Poplar forests.

Distribution in Alberta: This species has been most commonly collected along the northern edge of the Central Parkland and in the southern part of the Boreal Mixedwood (Fig. 23). It extends westwards into the Foothills, Montane, and Subalpine subregions, occasionally reaching upwards into the Alpine. Peltigera canina appears to be uncommon north of Lesser Slave Lake. There are a few sites in the low elevational Wetland Mixedwood, Peace River Lowlands, and $\mathrm{Ca}$ nadian Shield regions, but it is apparently unknown in the Boreal Highlands and Subarctic of northern Alberta. Peltigera canina is common over its range.

Distribution in North America: This circumpolar species is widespread throughout North America. Additional specimens seen (ALTA): Canada: British Columbia, Manitoba, Northwest Territories, Quebec, Saskatchewan, and the Yukon Territory; U.S.A.: Alaska, Minnesota, New Mexico (herb. Goffinet) and Wyoming. 


\section{Peltigera cinnamomea Goward} ined.

Illustrations: Figs. 24-25, map: Fig. 26. Appendix 1.

Morphology: Thallus large, to $30 \mathrm{~cm}$ across, loosely appressed to the substrate; lobes to $3 \mathrm{~cm}$ wide, branching, wavy, flat to concave near margin, fragile when dry, margin entire and downturned, rarely plane. $U p$ per surface shiny to rarely dull, greyish-brown to light brown, typically with some cinnamon colored patches, smooth, tomentum restricted to margin. Lower surface pale whitish near margin, gradually darkening and becoming cinnamon colored, veins distinct, narrow and

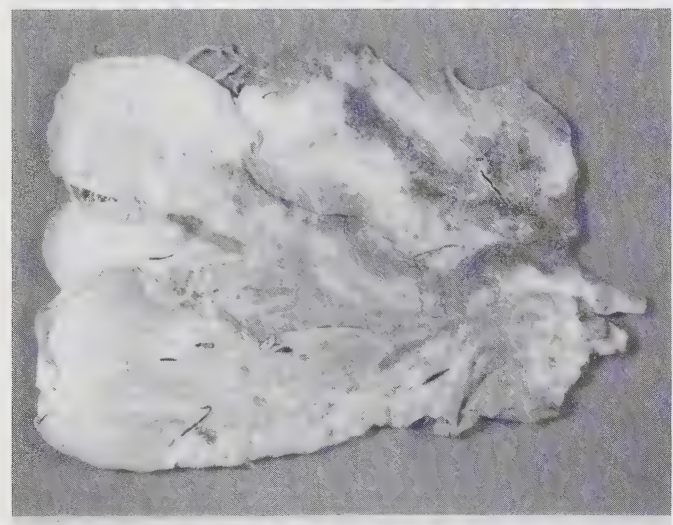

Figure 24. Peltigera cinnamonea upper surface. (Seymour Sept. 1966, ALTA.)

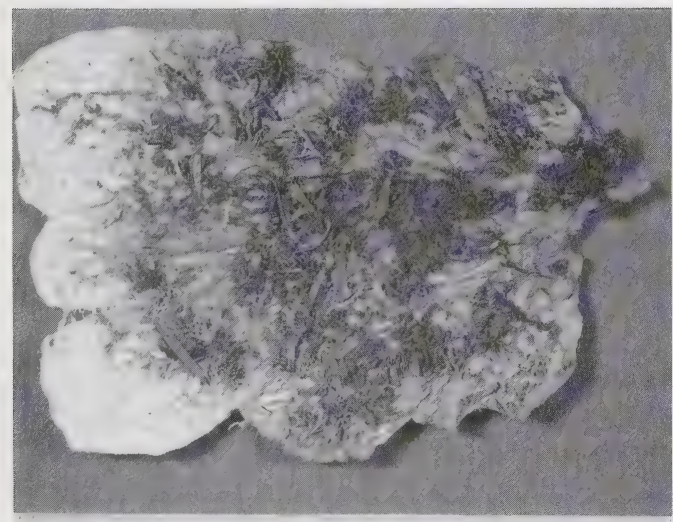

Figure 25. Peltigera cinnamomea lower surface. (Seymour Sept. 1966, ALTA.) slightly raised near margin becoming broad and flat toward centre, interstices concolorous with veins, diamond-shaped to elongate; rhizines to $5 \mathrm{~mm}$, pale to light brown, thread-like to sometimes apically fibrillose but otherwise unbranched. Photobiont, cyanobacteria. Apothecia common, disk chestnut brown, to 8 $\mathrm{mm}$ wide, slightly saddle-shaped, on narrow, elongate and somewhat canaliculate lobes; spores acicular, (38-) $40-50(-55) \times 3-5 \mu \mathrm{m}$ (50 spores measured), invariably four-celled.

Note: Peltigera cinnamomea has not yet been validly described, and is thus taxonomically an invalid name.

Variation: This species differs from $P$. membranacea and $P$. praetextata by the lack of tomentum on its veins. However, some specimens of $P$. praetextata have glabrous veins. Peltigera cinnamomea can be segregated from these both by the color of the lower

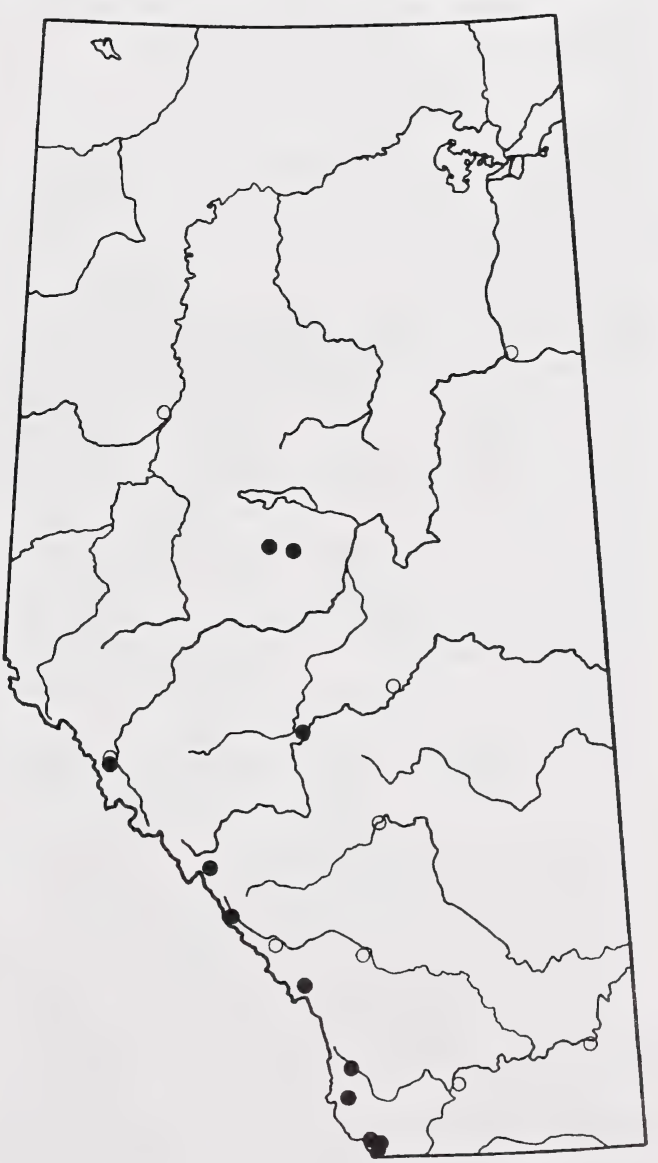

Figure 26. Distribution of Peltigera cinnamomea in Alberta. 
surface, which is never dark brown in $P$. cinnamomea, and by its plane margin which contrasts with the rather wavy upturned margin of $P$. praetextata. Peltigera cinnamomea differs from $P$. canina by having strictly simple and sparse rhizines, and tomentum that does not extend toward the centre of the upper cortex (Figs. 24-25; Appendix 1).

Ecology: Occurring in the upper Foothills to Subalpine in spruce and fir forests where it grows most commonly on litter and/or mosses. It is also occasionally found on rotten wood.

Distribution in Alberta: Peltigera cinnamomea is largely restricted to foothills and mountain habitats with long-lasting snow cover (Fig. 26). The species is uncommon in Alberta.

Distribution in North America: Peltigera cinnamomea is currently known only from the Pacific Northwest and Alberta. Additional specimens seen (ALTA): Canada: British Columbia; U.S.A.: Washington.

\section{Peltigera collina (Ach.) Schrad.}

\section{Illustrations: Fig. 27, map: Fig. 28.}

Morphology: Thallus medium, to $10 \mathrm{~cm}$ across, closely attached to the substrate; lobes small, about $1 \mathrm{~cm}$ broad, rarely 1.5 to $2 \mathrm{~cm}$, branching, rather thick and robust, margin plane and often dissected. Upper surface brownish-grey when dry, bluish to dark blue when moist, smooth to rarely slightly scabrous near margin, glabrous, margin rarely pruinose, ascending; soredia bluish-grey, sometimes developing into isidia, marginal but some also laminal, maculiform, and along cracks. Lower surface with ochraceous to brown, flat, anastomosing veins, with white interstices; rhizines to $4 \mathrm{~mm}$, brown, scattered to confluent, aciculate to slightly branched. Photobiont, cyanobacteria. Apothecia rare, disk dark brown to black, to $3 \mathrm{~mm}$ long, finger nail-shaped, on short, narrow lobes, almost sessile; spores acicular, (48) 55-70 (84) x 3-4 $\mu \mathrm{m}$, mostly four-celled (rarely to eight).

Variation: Peltigera collina is usually easily recognized by its marginal soredia (these were developed in all examined Albertan material). In the absence of soredia, however, it may resemble $P$. elisabethae or $P$. neckeri by the color of the cortex and the marginal pruinosity. Peltigera collina differs from the former by the absence of schizidia, and also by having a distinct network of brown veins, short finger nail-shaped apothecia, and a dull upper surface (Fig. 27). Peltigera neckeri has a very shiny thallus and the blackish veins are often confluent and indistinct. Thomson (1950) and Krog (1968) described $P$. collina as seemingly quite variable with regards to the color of the thallus and the presence of soredia. In Alaska, it is frequently fertile (Krog 1968). Alberta specimens from Glenevis (Pegg 1385, PMAE) and Hinton (Marsh JE788, ALTA) are abundantly fertile, but this appears to be atypical.

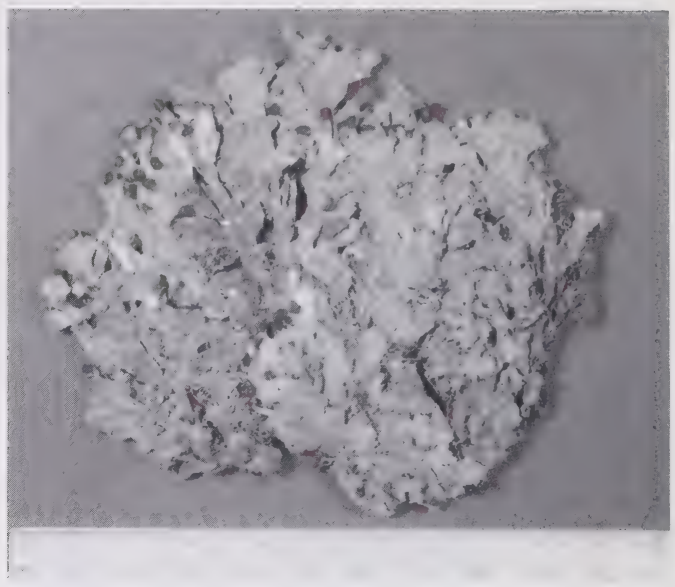

Figure 27. Peltigera collina upper surface with cracks and scattered atypical laminal soredia. (Pegg s.n., B88.2.55, PMAE.)

Ecology: Peltigera collina occurs on litter or rotten wood in Subalpine Lodgepole Pine-spruce-Subalpine Fir forests. It is occasionally found growing in similar habitats in the southern Boreal Mixedwood subregion. It is among the taxa considered characteristic of old woodlands in Europe (Coppins 1976). In moist oak woodlands in Oregon it is a major component of the epiphytic flora on moderately old branches (Stone 1989).

Distribution in Alberta: Peltigera collina is mainly found in the Rocky Mountains but protrudes eastward along the southern edge of the boreal forest (Fig. 28). The species is extremely rare in Alberta.

Distribution in North America: This typically oceanic (Wirth 1987), circumpolar species shows a predominantly western North America-western Europe distribution, but is also reported from Newfoundland, Ontario, Quebec, Greenland, and Iceland (Thomson 1984). Additional specimens seen (ALTA): Canada: British Columbia and the Yukon Territory; U.S.A.: Washington. 


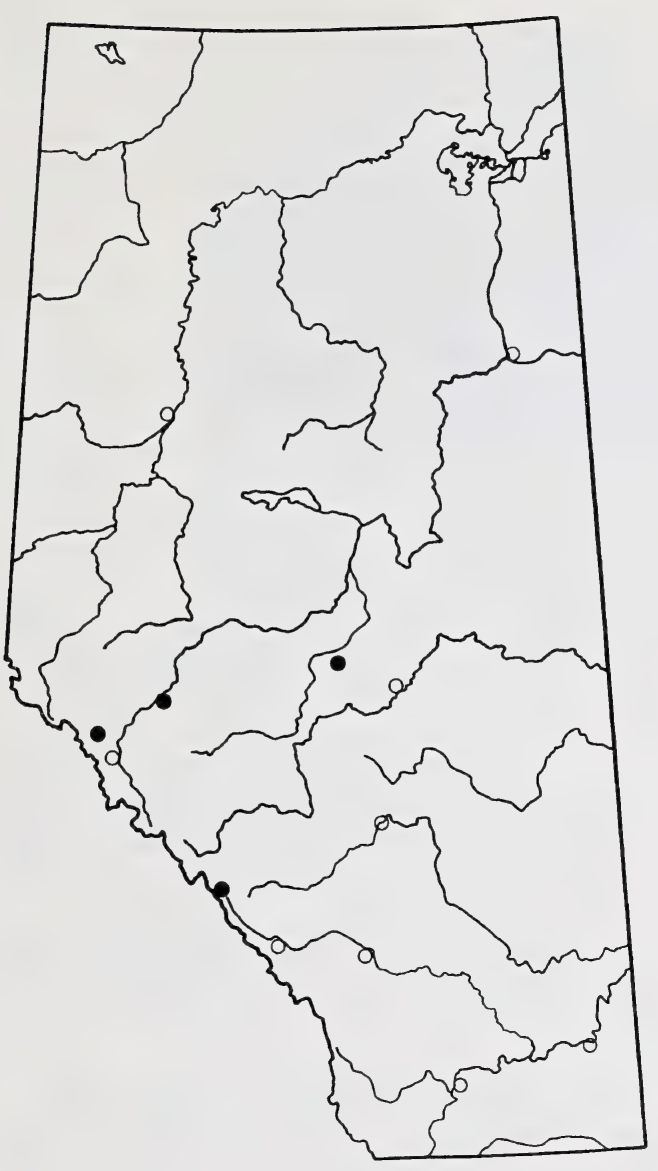

Figure 28. Distribution of Peltigera collina in Alberta.

\section{Peltigera didactyla (With.) Laundon var. didactyla}

Illustrations: Fig. 29, map: Fig. 30.

Appendix 1.

Morphology: Thallus small, to $5 \mathrm{~cm}$ broad; lobes to $1 \mathrm{~cm}$ broad, somewhat branching in mesic conditions, concave or flat with plane to slightly downturned, entire margins, thin, fragile when dry. Upper surface greyish-brown to dark brown when dry, with thick appressed tomentum often becoming loose and detached from cortex, glabrous toward the centre, sometimes tomentum sparse and restricted to lobe tip or, more rarely, absent, with maculiform, sometimes weakly isidiferous and confluent, $2 \mathrm{~mm}$ wide soralia. Lower surface whitish sometimes becoming greyish to brown toward centre, veins flat and narrowly reticulate, with whitish, rounded, lenticular or irregular interstices; rhizines to $5 \mathrm{~mm}$, white, simple to somewhat fibrillose often restricted to mature part of lobes, becoming darker and sparser toward centre. Photobiont, cyanobacteria. Apothecia common, disk chestnut to dark brown, to $6 \mathrm{~mm}$ wide, finger nail-shaped to saddleshaped, on erect, narrow, elongate lobes; spores acicular, (42-) 47-58 (-67) x 2.5-3.5 $\mu \mathrm{m}$, invariably fourcelled.

Variation: Recently, Weber (1990) reported P. erumpens (Taylor) Elenkin as new for North America. This species is characterized by a small unilobate, tomentose thallus bearing laminal soredia and no apothecia. However, both field (Dahl 1950, under $P$. spuria) and laboratory (Stocker-Wörgötter and Türk 1990) observations suggest that such forms represent only a developmental stage of $P$. didactyla. Therefore, such specimens do not deserve taxonomic recognition and $P$. erumpens should be kept as a synonym of $P$. didactyla as was suggested earlier by $\mathrm{Vi-}$ tikainen (1981).

We have proposed another sorediate taxon, $P$. didactyla var. extenuata to account for the morphological, ecological, and chemical divergences found within $P$. didactyla s. lat. (Goffinet and Hastings in press). Variety extenuata grows in forested sites and most often develops broad, spreading lobes bearing numerous and abundantly fibrillose rhizines, whereas var. didactyla occurs mainly in dry habitats where its thallus often remains unilobate (unless apothecia are produced) and its lobes are strongly concave and attached to the substrate by scattered central rhizines. In addition, var. $e x$ tenuata typically produces methyl gyrophorate and gyrophoric acid (the latter often in trace amounts, or occasionally seemingly absent); the production of the latter tridepside results in a characteristic $\mathrm{KC}+$ red (flashing) reaction of the medulla. As mentioned earlier, the amount of gyrophoric acid can be variable, probably because of the metabolic link of the two chemicals. As a result the $\mathrm{C}+$ or $\mathrm{KC}+$ red spot test is seemingly negative. Methyl gyrophorate, however, appears to be constant among all specimens of $P$. didactyla var. extenuata, whereas both chemicals are invariably absent from the var. didactyla. However, some specimens could not be placed satisfactorily in either variety. We argue (Goffinet and Hastings in press) that such specimens could be the result of hybridization. This is likely to occur in localities where the two taxa are sympatric, considering that their predominant way of propagation involves soredia, and that fusion of different soredia is required to initiate thallus formation (Stocker-Wörgötter \& Türk 1990).

Fertile specimens of var. didactyla may be mistaken for fertile $P$. rufescens, as both develop erect apothecia 


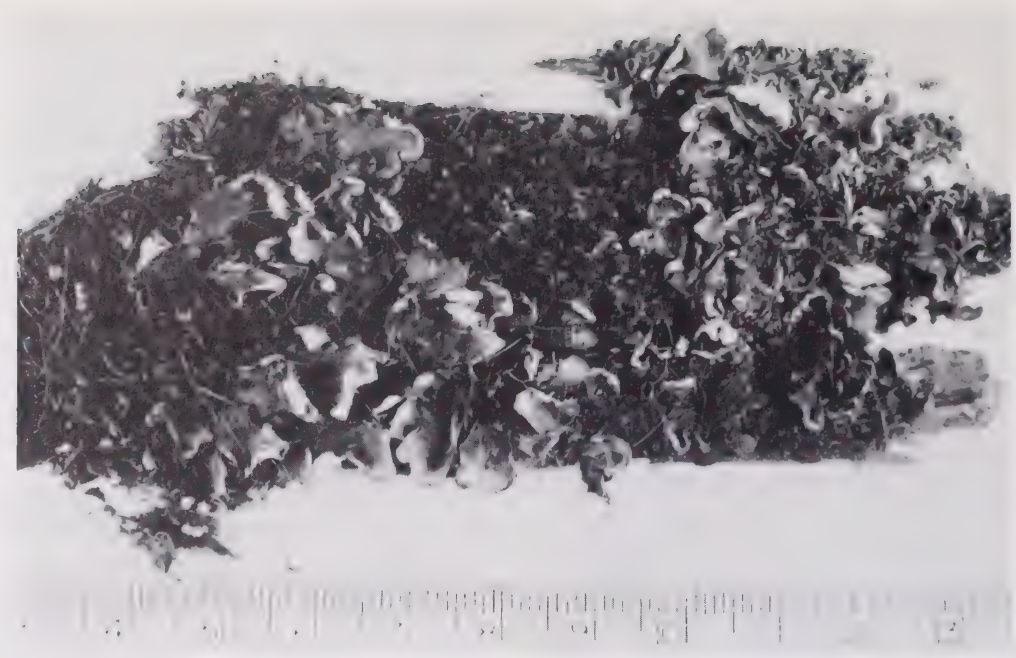

Figure 29. Peltigera didactyla var. didactyla habit. It has erect apothecia bearing lobes. (Goffinet 1846, herb. Gooffinet.)

bearing lobes supported by strong, ropy, whitish veins. The latter species however, invariably lacks soredia or their scars, and has, at least on the lower surface of mature sterile lobes, dark, abundantly branched rhizines. Further, in $P$. rufescens, the mature part of the lobes is often covered by a white crust

Ecology: Occurring in a wide range of dry to mesic forest sites but almost always in disturbed sites such as trail edges and roadcuts. Also found on sand, fine gravel, and boulders.

Distribution in Alberta: Peltigera didactyla var. didactyla is most common in the Central Parkland subregion (Fig. 30). To the north it occurs in scattered localities in the Boreal Mixedwood and to the west it occurs in the Foothills, Montane, and upwards into the Subalpine subregions. It has also been collected in the southeast corner of the province in Montane uplands of the Cypress Hills and even in the Mixedgrass subregion. This variety in common in Alberta.

Distribution in North America: This ubiquitous, cosmopolitan species is widespread throughout North America (see specimen data in Thomson 1950 under P. canina var. spuria and $P$. canina var. spuria $\mathrm{f}$. sorediata). Additional specimens seen (ALTA \& CANL): Canada: New Brunswick, Newfoundland, Nova Scotia, Ontario, Prince Edward Island, Quebec, Saskatchewan, and the Yukon Territory; U.S.A.: Washington.

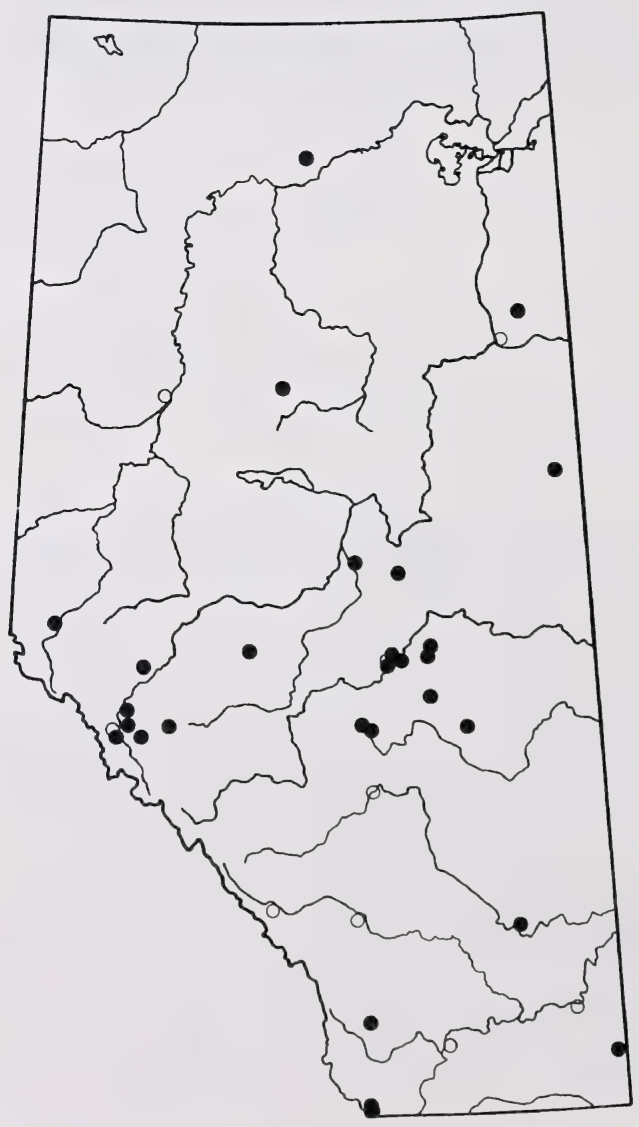

Figure 30. Distribution of Peltigera didactyla var. didactyla in Alberta. 


\section{Peltigera didactyla (With.) Laundon var. extenuata (Nyl. ex Vainio) Goffinet \& Hastings}

\section{Illustrations: Figs. 31-32, map: Fig. 33. Appendix 1.}

Morphology: Thallus medium-sized, to $8 \mathrm{~cm}$ broad; lobes to $1-1.5 \mathrm{~cm}$ broad, concave or flat, with plane to slightly upturned margins, thin and fragile, with maculiform, sometimes confluent, $2 \mathrm{~mm}$ wide soralia, developing isidia even in early stages. Upper surface with thick appressed tomentum often becoming loose and detached from cortex, glabrous toward the centre; color of dry thallus light to greyish-brown. Lower surface whitish becoming greyish to brown toward the centre, veins flat and narrow with large whitish rounded to slightly elongate interstices; rhizines to 5 $\mathrm{mm}$, white, fibrillose, rarely simple or slightly branched, forming a dense mat near margin, becoming darker and sparser toward centre. Photobiont, cyanobacteria. Apothecia rare (only one apothecia seen), on short elongate lobes, finger nail-shaped, to $5 \mathrm{~mm}$ long; spores acicular, "(many spores not clearly septate), 41-60 x 3-4 $\mu \mathrm{m}$ " (Goffinet \& Hastings in press).

Note: the new combination $P$. didactyla var. extenuat $a$ has been proposed by Goffinet and Hastings (in press).

Variation: This variety is best recognized by its broad lobes, the numerous, fibrillose, whitish rhizines, and veins that remain pale throughout. Further, the thallus is branched and the mature parts of the lobes do not disintegrate as they often do in lobed, fertile material of var. didactyla. By contrast, sterile thalli of the latter variety often remain unilobate, small, and bear scat-

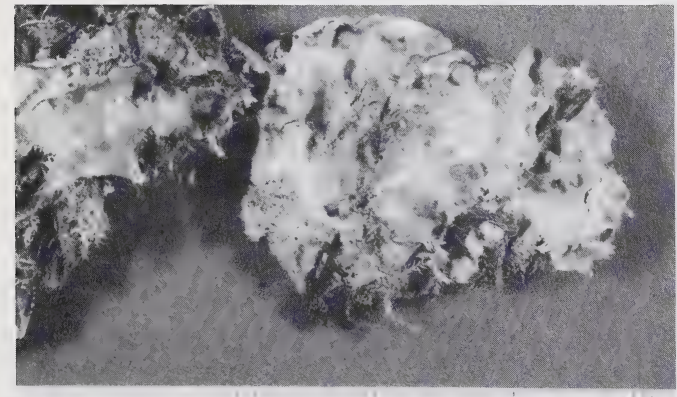

Figure 31. Peltigera didactyla var. extenuata upper surface. (Hastings C90.5.20b, PMAE.) tered rather thread-like rhizines mostly confined to the centre of the lower surface (for further discussion see var. didactyla). Variety extenuata produces soralia almost invariably; so far only a single esorediate thallus has been found. The latter was somewhat similar to $P$. praetextata but was segregated by its characteristic fibrillose, pale rhizines and the $\mathrm{KC}+$ red reaction of the medulla.

Ecology: Peltigera didactyla var. extenuata occurs in mesic to moist sites on mosses or on mosses over rotten wood. In the boreal forest it is found in sites ranging from Black Spruce-Swamp Birch wetlands, larch fens, and lakeside willow swamps. In the mountains it grows in Lodgepole Pine-White Spruce forests up to the alpine tundra. Only rarely does it grow on mineral soil.

Distribution in Alberta: This variety has been collected in a number of localities scattered throughout northern and western Alberta (Fig. 33). It is probably most common in the Boreal Mixedwood subregion. To the north, it has been collected in the Subarctic and Canadian Shield. Towards the mountains, it has been collected in the Foothills, Montane, and in moist sites in the Subalpine and Alpine subregions. This variety is common throughout its range.

Distribution in North America: This circumboreal variety is widespread throughout boreal North America. Its distribution is documented in Goffinet and Hastings (in press). Additional specimens seen (ALTA \& CANL): Canada: British Columbia, Labrador, New Brunswick, Newfoundland, Ontario, Prince Edward Island, Quebec, Saskatchewan, and the Yukon Territory; U.S.A.: Colorado.

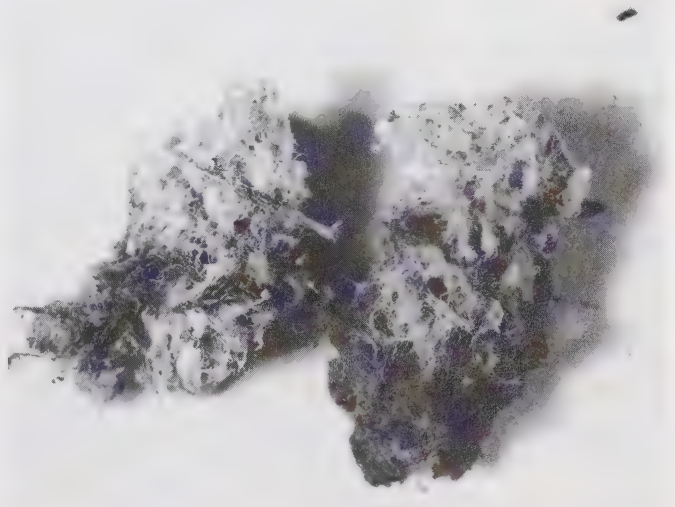

Figure 32. Peltigera didactyla var extenuata lower surface, note the fibrillose rhizines. (Hastings C 90.5.20b, PMAE.) 


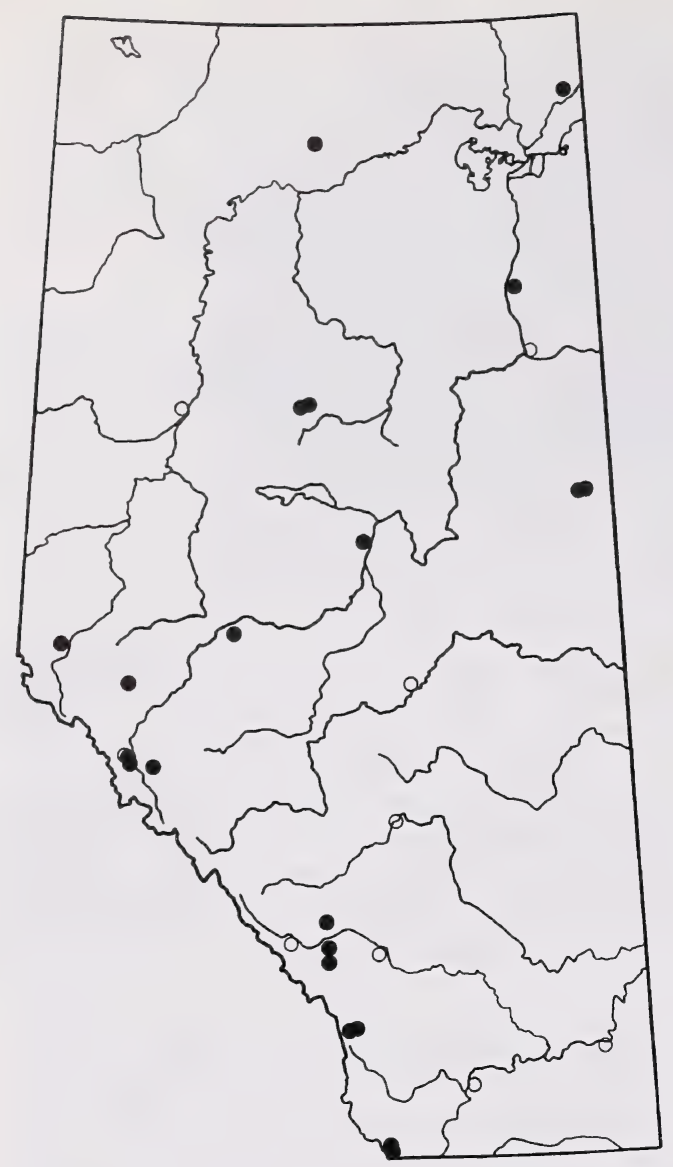

Figure 33. Distribution of Peltigera didactyla var. extenuata in Alberta.

\section{Peltigera elisabethae Gyelnik}

Illustrations: Figs. 34-35, map: Fig. 36.

Appendix 2.

Morphology: Thallus medium to large, moderately to closely attached to the substrate; lobes 1 to $3 \mathrm{~cm}$, branching, crisped or flat, rather thick, robust when dry, margin entire and plane. Upper surface grey to brownish-grey toward centre when dry (sometimes with a bluish tint when growing along streams in extremely wet habitats) and dark brown to blackish when wet, shiny, glabrous, smooth, often pruinose toward margin, with numerous cracks exposing the white medulla; regeneration lobules isidia-like, knobby to slightly flattened, developing along cracks, schizidia often present along margin and cracks. Lower surface cottony, appearing veinless, abrupt transition from a whitish to ochraceous margin to a dark brown to black inner part, only a few light, deep, elongate to rounded interstices near margin; rhizines to $5 \mathrm{~mm}$, dark brown, fasciculate, short, sparse, in concentric lines. Photobiont, cyanobacteria. Apothecia occasional, disk brown to black, to $7 \mathrm{~mm}$ across, horizontal or with slightly recurved margins but never strongly finger nailshaped, on short lobes; spores long-elliptical, (27-) 30$41(-47)$ x 4-6 $\mu \mathrm{m}$, invariably four-celled (90 spores measured).

Variation: Peltigera elisabethae is most closely related to $P$. horizontalis; both have horizontal apothecia producing small, four-celled spores. However, $P$. elisabethae is distinguished by its broad anastomosing veins, giving the appearance of a veinless lower surface (Fig. 35), and characteristic marginal schizidia (Fig. 14). In addition, $P$. horizontalis is never pruinose. Peltigera pacifica Vitik. is another glabrous species developing "isidioid propagules" (Vitikainen 1985). It differs from $P$. elisabethae by its distinct veins, phyllidia, longer spores, and by its chemistry. Peltigera pacifica is, at present, known mainly from coastal British Columbia but might "extend farther inland in oceanic areas in North America" (Vitikainen 1985). Based on the lower surface, $P$. elisabethae can also be mistaken for P. malacea. However, P. malacea lacks vegetative propagules and develops erect tomentum near the margin. When sterile, $P$. elisabethae is similar to $P$. neckeri. The latter, however, develops no schizidia, has a black lower surface with conspicuous pale interstices, at least near the margins, and its rhizines are not arranged in concentric lines (compare Figs. 35 \& 62; for further comparisons see Appendix 2). When fertile, $P$. elisabethae can be distinguished from the latter three species by its shorter spores which almost never exceed $45 \mu \mathrm{m}$ in length (two spores out of 90 were $46 \& 47 \mu \mathrm{m}$ long). For further discussion see $P$. collina and $P$. polydactyla.

Following Thomson's (1950) treatment, specimens of $P$. elisabethae bearing regeneration lobules, would key to $P$. horizontalis var. zopfii (Gyelnik) Thomson. Pruinose thalli would be identified as $P$. horizontalis var. pruinosa Gyelnik. Ostafichuk (1966) adopted the same taxonomy and most specimens he named $P$. horizontalis var. zopfii (ALTA) are P. elisabethae. The name "zopfii" actually applies to forms of $P$. horizontalis bearing regeneration lobuli, and has consequently been reduced to synonymy with the latter (Clauzade and Roux 1985; see discussion under $P$. horizontalis). 


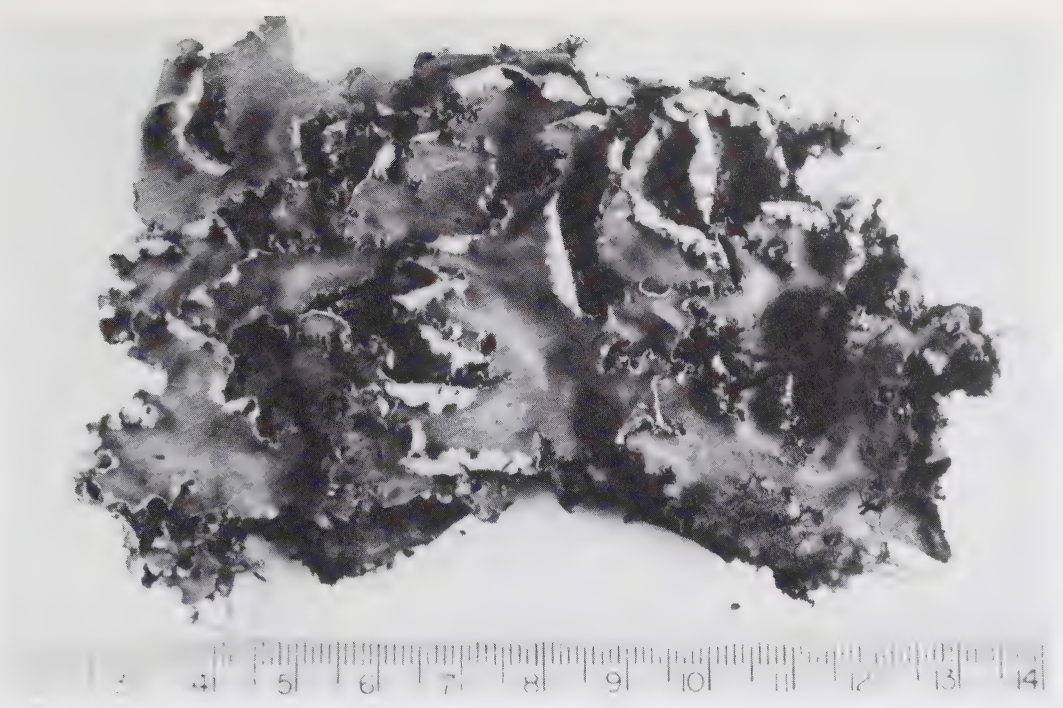

Figure 34. Peltigera elisabethae habit. (Goffinet 3083, herb. Goffinet.)

Ecology: Most commonly occurring on mosses, litter, and rotten wood in mesic, mixed White SpruceAspen Poplar forests to mature White Spruce/ Ledum/feathermoss stands. Growing in similar microhabitats in foothill and mountain Lodgepole PineWhite Spruce forests. Rarely and sporadically growing on moist soil in more open areas such as roadcuts through the forest, alluvium along river channels, or on open but moist rocky areas in the subalpine.

Distribution in Alberta: Peltigera elisabethae is common from the northern and western portions of the Central Parkland, northwards through the Boreal
Mixedwood, and into the Wetland Mixedwood (Fig. 36). It has been collected in the Peace River Parkland and Peace River Lowlands. Westwards from the Central Parkland, it ranges through the Foothills and Montane subregions. It reaches into the Subalpine in moist sites. In southeast Alberta it has been collected in the Cypress Hills. Peltigera elisabethae is common over its range.

Distribution in North America: The distribution of this species is not well documented for North America as it was, until recently, not distinguished from $P$. horizontalis. The species is probably widespread

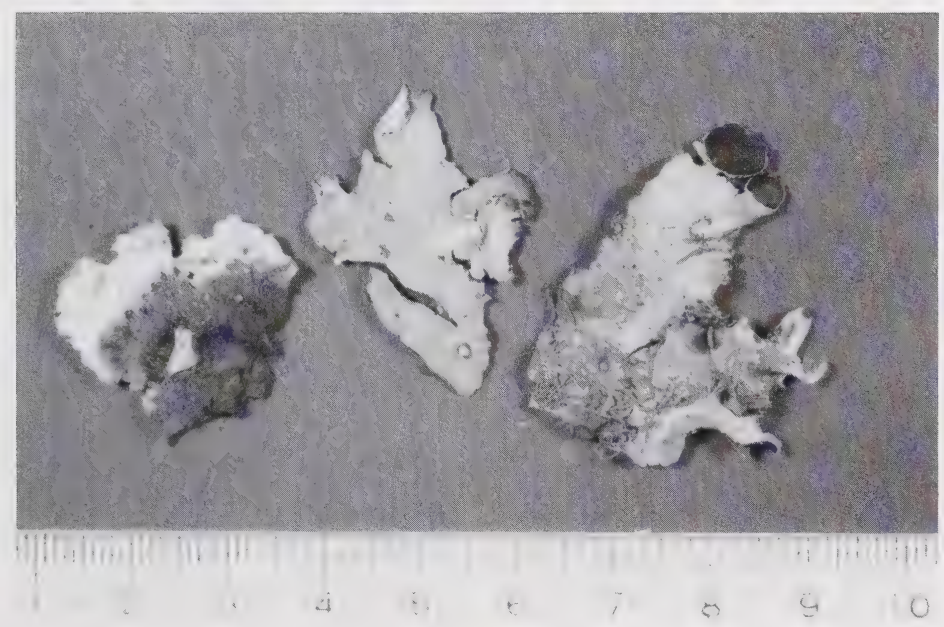

Figure 35. Peltigera elisabethae. Left - lower surface showing concentric arrangement of rhizines (dark dots), and anastomosed veins giving a veinless appearance. Middle - upper surface with cracks and schizidia. Right - fertile lobe with horizontal apothecia. (Goffinet C90.4.70, PMAE.) 


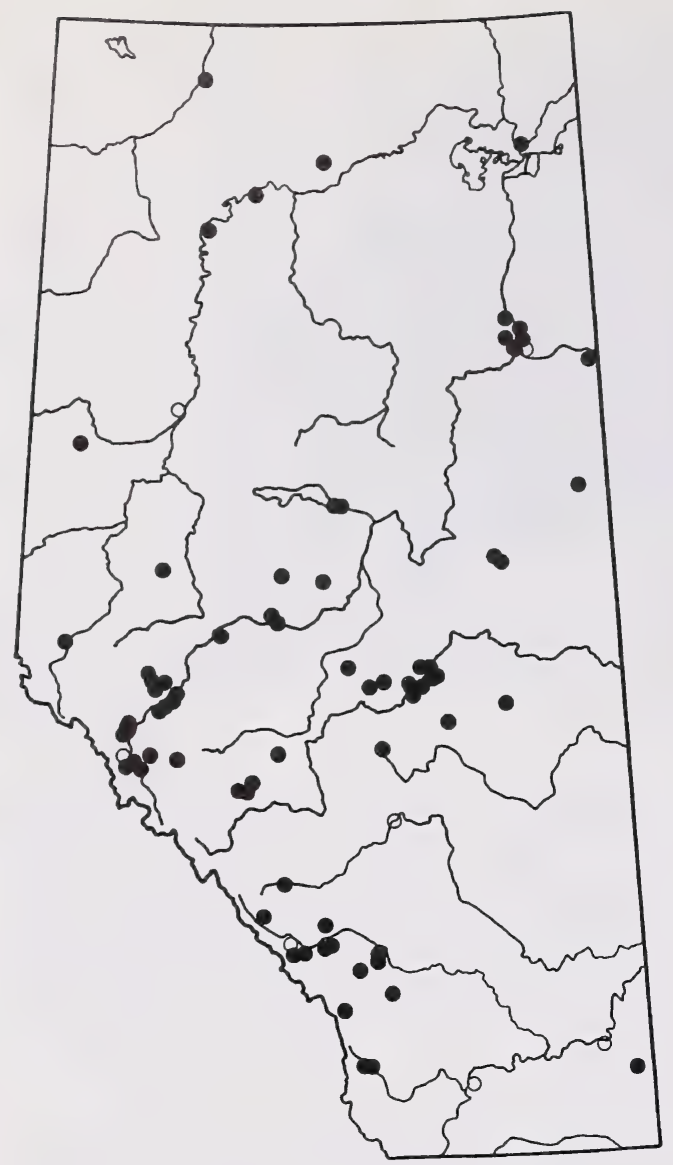

Figure 36. Distribution of Peltigera elisabethae in Alberta.

throughout boreal, alpine, and arctic North America as is suggested by its northern range in Europe (Vitikainen 1987, Wirth 1987). Additional specimens seen (ALTA): Canada: British Columbia, Northwest Territories, Ontario, Quebec, Saskatchewan, and the Yukon Territory; U.S.A.: Colorado, Michigan, Minnesota, New Mexico (herb. Goffinet), and South Dakota.

\section{Peltigera evansiana Gyelnik}

\section{Illustrations: Figs. 37-38, map: Fig. 39.}

Morphology: Thallus medium, several $\mathrm{cm}$ across, often loosely attached to the substrate; lobes to 2 rarely $3 \mathrm{~cm}$ wide, branching, flat or slightly ascending, thin, fragile when dry, margin entire, plane to upturned. Upper surface light grey to dark greyish- brown when dry, dark brown when wet, tomentose, strongly pruinose near margin, to rarely slightly scabrous near edge, covered toward lobe tip with erect globular, or sometimes coralloid isidia and occasionally with dorsiventral isidia toward mature part of lobes. Lower surface with sparse, low, narrow, whitish to ochraceous veins, becoming brown toward centre; rhizines to $6 \mathrm{~mm}$, white or brown toward centre, simple, rarely fibrillose. Photobiont, cyanobacteria. Apothecia rare, disk light to chestnut brown, to $4 \mathrm{~mm}$ long, slightly saddle-shaped, on short lobes; spores acicular, (39-) 43-55 (-58) x 2.5-4 $\mu \mathrm{m}$, mostly fourcelled, but pentaseptate spores occasionally seen.

Variation: Some herbarium specimens were identified as $P$. lepidophora, which resembles $P$. evansiana by having laminal isidia. In $P$. lepidophora the isidia are typically peltate versus being erect, granular, or club-shaped to coralloid in $P$. evansiana. In both taxa, isidia on mature parts of lobes can become somewhat atypical, i.e., erect and dorsiventral respectively. However, in Alberta, dorsiventral isidia have been seen only on a single specimen of $P$. evansiana (Fig. 38). Peltigera praetextata differs from $P$. evansiana by its invariably dorsiventral and erect phyllidia that are restricted to mature parts of the lobes. When dry, $P$. evansiana is easily recognized because "the isidia stand out darkly against the greyish tomentum-covered upper side of the thallus" as the algae shine through the rather thin cortex of the isidia (Lindahl 1960) (Fig. 37). The species has been considered glabrous by some authors (e.g., Thomson 1950). This confusion arose from the marginally restricted tomentum which is often hidden in a pruinose layer. These hairs seem to be necessary for the development of the isidia on the upper cortex (Lindahl 1960).

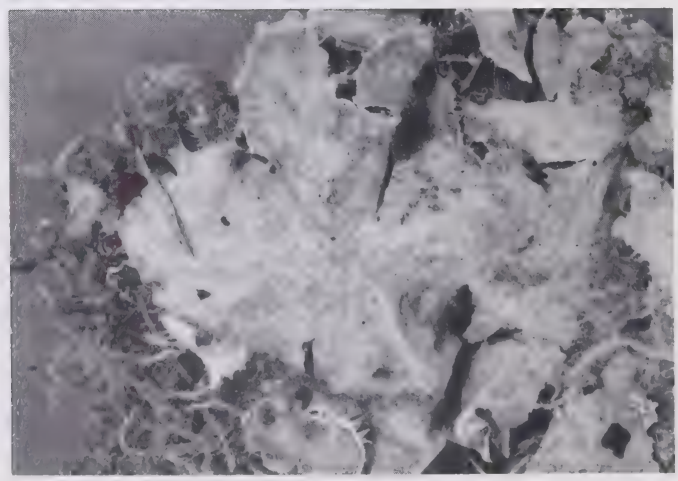

Figure 37. Peltigera evansiana habit. The granular isidia appear as small dots. (Lindsay B77.24.30, PMAE.) 


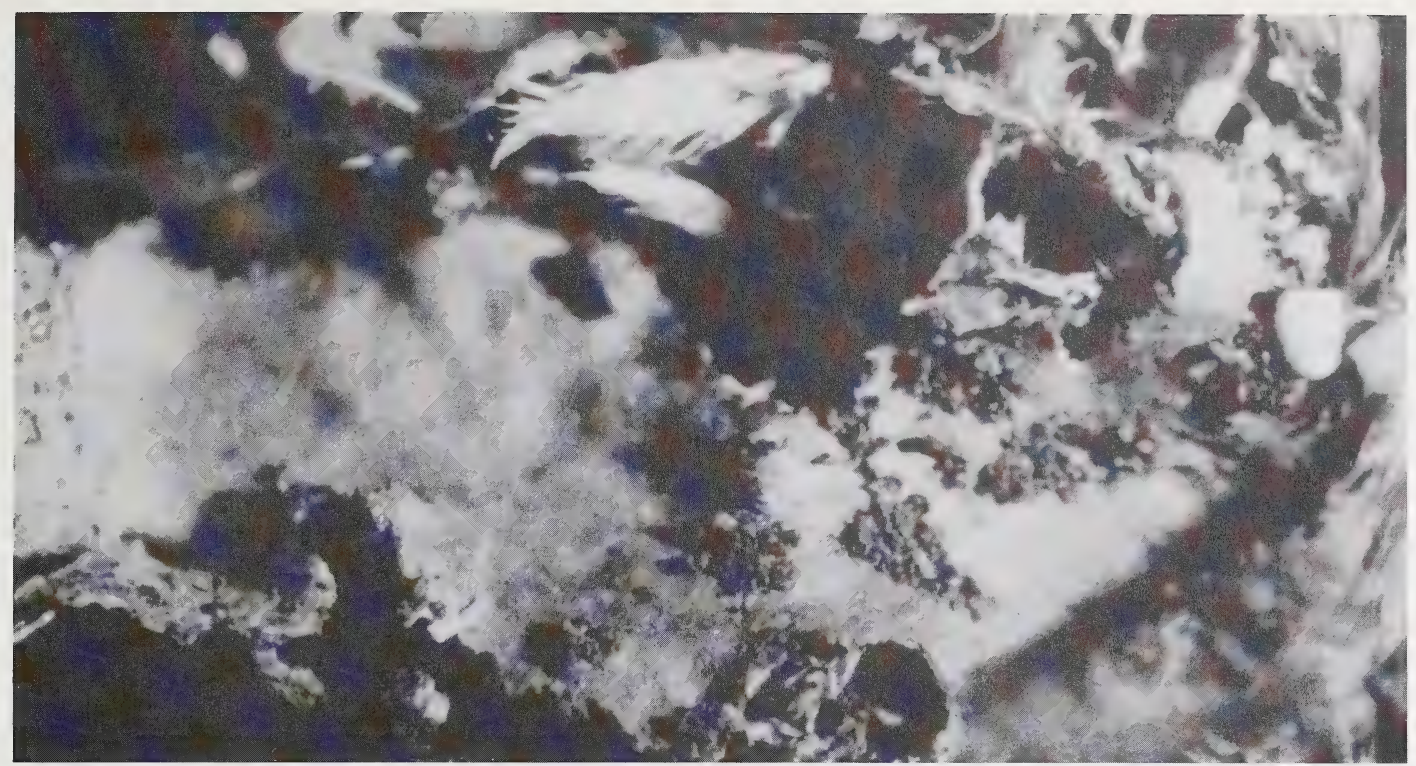

Figure 38. Variation in shape of isidia in $P$. evansiana. They are club-shaped to the left, near the lobe tip and squamulose-peltate near the centre of the lobe. (Crites 12 June 1993, herb. Goffinet.)

Ecology: Peltigera evansiana grows most commonly on rotten wood, moss covered rotten wood, or moss covered tree roots in Aspen Poplar, Balsam Poplar, or mixed Aspen Poplar-White Spruce forests. It occurs rarely in White Spruce-Balsam Fir forests. Gyelnik (1931a) and Thomson (1950) mentioned it as also growing over saxicolous mosses.

Distribution in Alberta: This species is known only from the northern edge of the Central Parkland subregion and from a few scattered localities in the southern part of the Boreal Mixedwood (Fig. 39). Turner collected numerous specimens around Fort Saskatchewan, but in the last 30 years it has only been collected occasionally in the Edmonton region. The species is rare but locally abundant.

Distribution in North America: This species was originally described by Gyelnik (1931a) from New England and was known only from North America (where it is mainly eastern in distribution, Thomson 1950) until its discovery in Eurasia (Blum et al. 1975, XiLing 1986). In western North America it occurs in Alberta and in boreal British Columbia (Noble et al. 1987), but is rare in both provinces. Additional specimens seen (ALTA): Canada: Ontario; U.S.A.: Michigan, Minnesota, and New York.

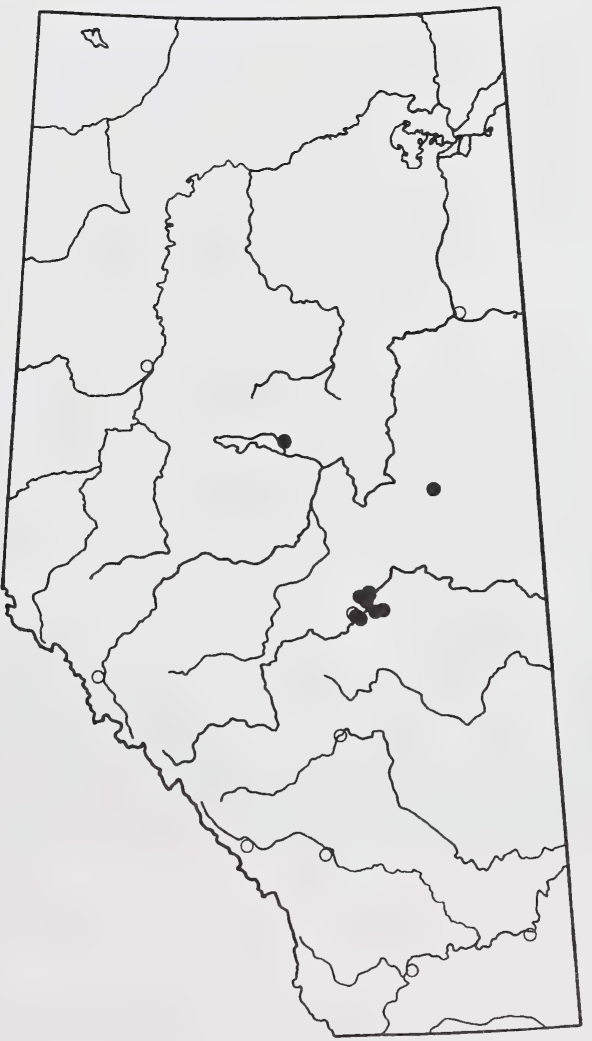

Figure 39. Distribution of Peltigera evansiana in Alberta. 


\section{Peltigera horizontalis (Huds.)}

\section{Baumg.}

Illustrations: Figs. 40-41, map: Fig. 42.

Appendix 2.

Morphology: Thallus medium, rather firmly attached to the substrate; lobes to $2 \mathrm{~cm}$ broad, branching, moderately thin, fragile when dry, margin entire, usually plane, but sometimes also with narrow crisped lobes. Upper surface smooth, glabrous, somewhat shiny, not pruinose, bluish to brown-grey to chestnut brown, dark when moist, often pitted near margin (these pits are low depressions of the thallus found opposite the rhizines). Lower surface with a distinct network of ochraceous marginal veins becoming dark brown and anastomosing toward centre, with distinct, elongate, light interstices at least toward margin; rhizines sparse, to $5 \mathrm{~mm}$, brown, fasciculate, in concentric lines at least near margin. Photobiont, cyanobacteria. Apothecia apparently frequent (all four specimens from Alberta were fertile), disk chestnut brown, horizontal, to $1 \mathrm{~cm}$ across, on short lobes; spores long-elliptical to (22-) 29-39 (-44) x 4-6 $\mu \mathrm{m}$, four-celled except for one spore which was three-celled (90 spores measured).

Variation: Peltigera horizontalis can be easily recognized by its horizontal apothecia in combination with the distinct network of veins (Figs. 40 \& 41). As was noted while revising the genus in Belgium (Goffinet et al. in prep.), some thalli of $P$. horizontalis do produce laminal regeneration lobules (e.g., Ostafichuk 530, ALTA). These specimens can still be differentiated from the closely related $P$. elisabethae by the distinctly veined

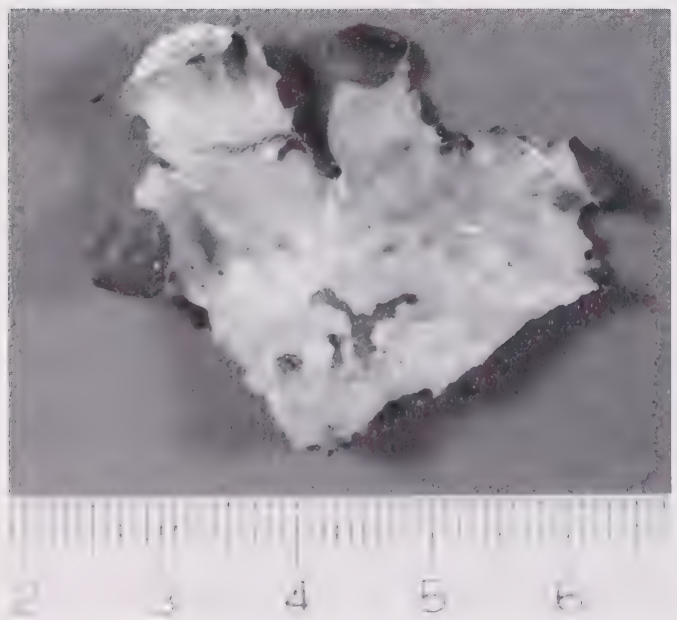

Figure 40. Peltigera horizontalis upper surface of fertile lobe. The apothecia are flat and the pits occur along a concentric line opposite the rhizines. (Goffinet 1315, herb. Goffinet.) lower surface and absence of schizidia (see $P$. elisabethae). Based only on his description, it appears that Gyelnik (1927) considered these lobulate forms as a separate taxa, $P$. zopfii. We consider this latter species to represent only a regeneration form of $P$. horizontalis. It does not, therefore, deserve taxonomic recognition. We agree with the synonymy of zopfii and horizontalis as proposed by Clauzade and Roux (1985; see also note under $P$. elisabethae).

In the past, sterile material of $P$. horizontalis was often mistaken for $P$. polydactyla or even thought to be unidentifiable. However, when sterile, the two species can be distinguished as follows: $P$. horizontalis has rhizines that are arranged along concentric lines and its thallus often bears marginal "pits" opposite the rhizines (Fig. 40); P. polydactyla has rhizines that are randomly distributed and has a smooth upper surface. When fertile, the two species differ by the shape of the apothecia. They are typically horizontal in $P$. hori$z$ zontalis versus finger nail-shaped in $P$. polydactyla. In $P$. horizontalis the supporting lobe is short and rather plane, versus elongate and canaliculate in $P$. polydactyla (see Appendix 2 for further comparisons).

Ecology: Peltigera horizontalis grows on terricolous mosses in mixed moist forests. According to Rose (1976), P . horizontalis appears "to be a faithful species to old hardwood forest in lowland Britain." The species was recently collected in Edmonton (Hastings C93.6.3, PMAE), where large thalli grew over mosses in an Aspen Poplar-White Spruce woodland in a moist and steep ravine.

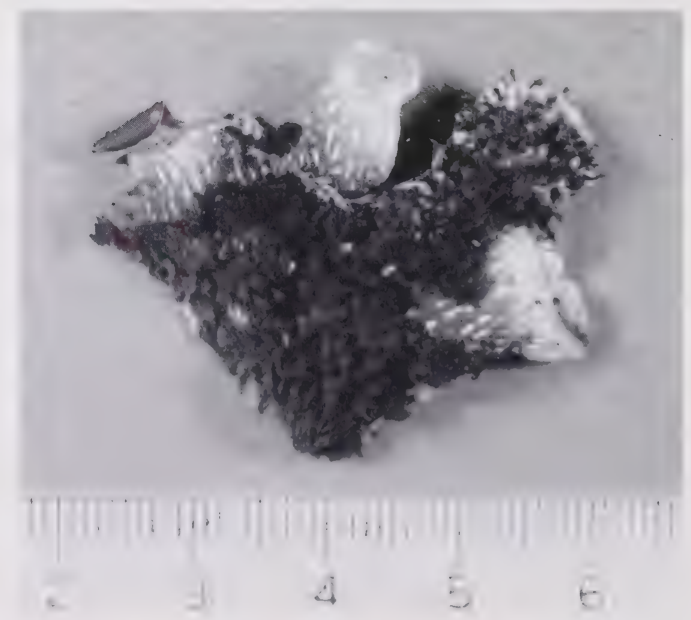

Figure 41. Peltigera horizontalis lower surface. The veins are distinct and the rhizines are aligned. (Goffinet 1315, herb. Goffinet.) 
Distribution in Alberta: Peltigera horizontalis is known from scattered localities in the Central Parkland, Foothills, and Subalpine subregions (Fig. 42). The species is extremely rare in Alberta; only four collections (five specimens) are known. It has been collected only once since 1971 .

Distribution in North America: In light of recent taxonomic changes, the distribution of this species is not well known. Therefore, descriptions given by Thomson (1950, 1984) and Krog (1968) should be considered suspect for they certainly include $P$. elisabethae. From Europe, however, we know that the species is missing from arctic and boreal regions (Wirth 1987). Additional specimens seen (ALTA): Canada: British Columbia; U.S.A.: Michigan, New Mexico (herb. Goffinet; dupl. ALTA) and New Hampshire.

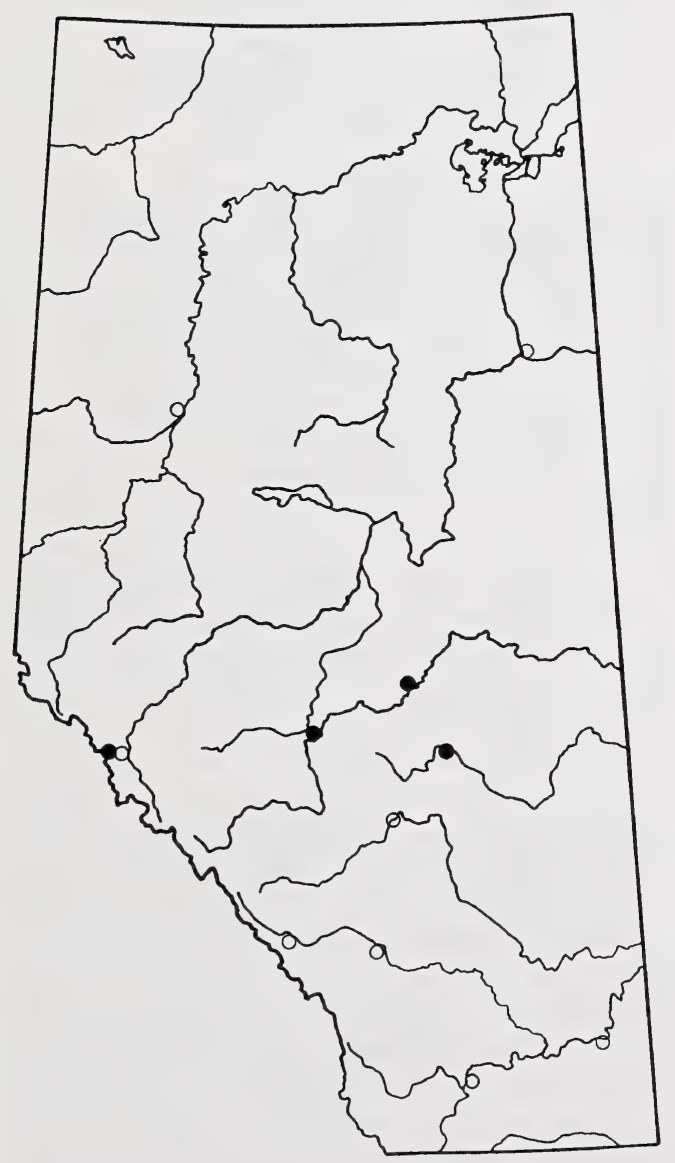

Figure 42. Distribution of Peltigera horizontalis in Alberta.

\section{Peltigera kristinssonii Vitik.}

Illustrations: Figs. 43-44; map: Fig. 45.

Morphology: Thallus medium, several $\mathrm{cm}$ across, often closely attached to the substrate; lobes 1 to $1.5 \mathrm{~cm}$ wide, branching, moderately thin, robust when dry, with entire margins. Upper surface light brown, greybrown or bluish-grey "often with yellowish tint" (Vitikainen 1985), erect tomentum near margin, scabrous at least toward edge, smooth in the centre. Lower surface ochraceous at the margins with a distinct network of dark brown, tomentose, flat to slightly raised veins contrasting with pale, conspicuous, elliptical, sharp interstices; rhizines to $3 \mathrm{~mm}$, dark brown, fasciculate to mainly squarrosely branched. Photobiont, cyanobacteria. Apothecia rare, disk dark brown, "with revolute margins, to $8-10 \mathrm{~mm}$ in diameter, on slightly ascending lobes; spores (40-) 44-59 (-73) x (2.6-) 3-4 (-5.2) $\mu \mathrm{m}$, four-celled" (Vitikainen 1985).

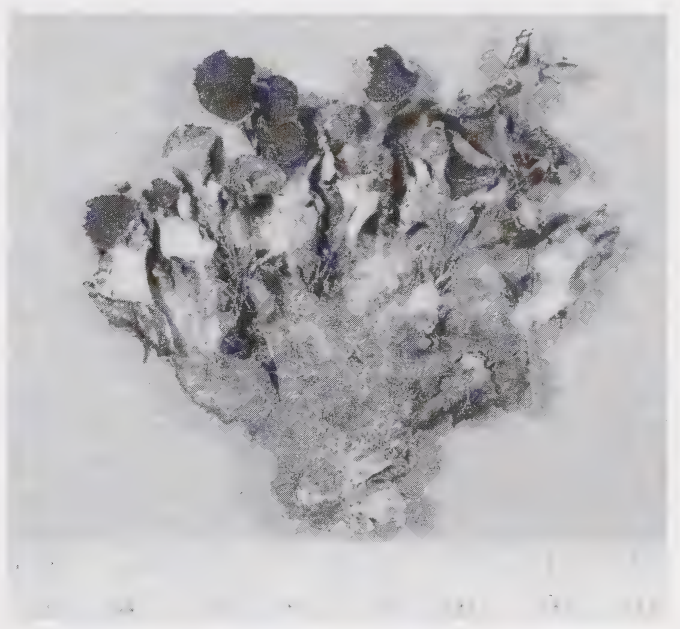

Figure 43. Peltigera kristinssonii habit. (Hastings C89.12.22, PMAE.)

Variation: Peltigera kristinssonii has been described recently by Vitikainen (1985). By its erect tomentum it might be mistaken for $P$. malacea, from which it differs by its lower surface bearing distinct veins (Fig. 44), by lacking chemical compounds, and by its squarrosely branched rhizines. Sometimes the tomenturn is very sparse and $P$. kristinssonii would then key out in the $P$. polydactyla group. However, the distinct network of dark tomentose veins throughoutand the scabrous upper surface (at least near the margin), segregates it from the $P$. polydactyla group. Specimens that are only slightly scabrous look similar to $P$. rufescens; they also share a lack of lichen substances. However, 


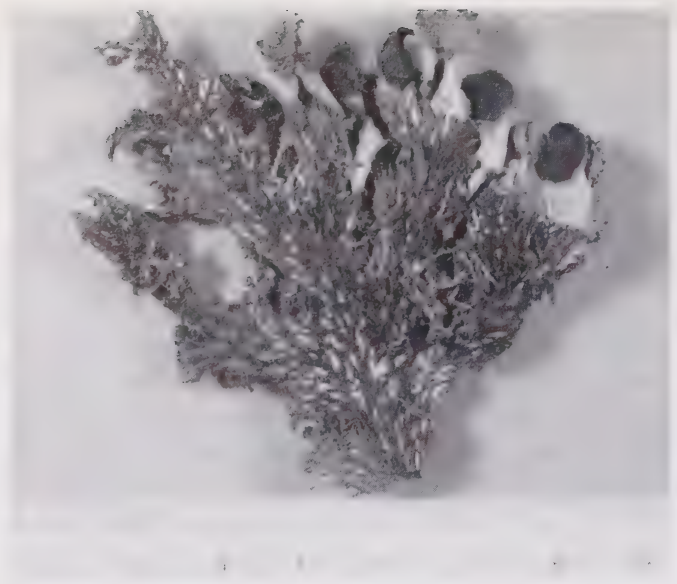

Figure 44. Peltigera kristinssonii lower surface. The distinct dark veins contrast with the pale interstices throughout. (Hastings C89.12.22, PMAE.)

P. kristinssonii can be distinguished based on its erect versus appressed tomentum, tomentose veins, and its scattered fasciculate to squarrosely branched rhizines.

Thomson (1984) referred specimens that have the combination of erect marginal hairs and a scabrous upper cortex to $P$. occidentalis (Dahl) Krist. However, as discussed by Vitikainen (1985), P. occidentalis and $P$. kristinssonii represent two distinct taxa that differ by their morphology and their chemistry. Peltigera occidentalis has a glabrous upper surface and produces several depsides and hopane triterpenoids. Peltigera kristinsonii has a tomentose and scabrouse upper surface and lacks lichen substances. Based on his morphological data, the collections examined by Thomson (1984) actually belong to $P$. kristinssonii. Further, the chemistry he reports for $P$. occidentalis was probably based on data provided by Ohlsson (1973) but the specimens referred to as $P$. occidentalis in that publication actually belong to $P$. retifoveata (Vitikainen 1985; see under "Excluded species" for further discussion on $P$. occidentalis).

Ecology: Peltigera kristinsonii is found on rocks, mosses, and humus in moist to dry habitats ranging from upland White Spruce forests and Lodgepole Pine woodlands to exposed sandstone and shale outcrops and solifluction lobes in the alpine.

Distribution in Alberta: Peltigera kristinssonii is a mountain-dwelling species. It is known only from the Montane, Subalpine, and Alpine subregions (Fig. 45). The species is uncommon over its range.

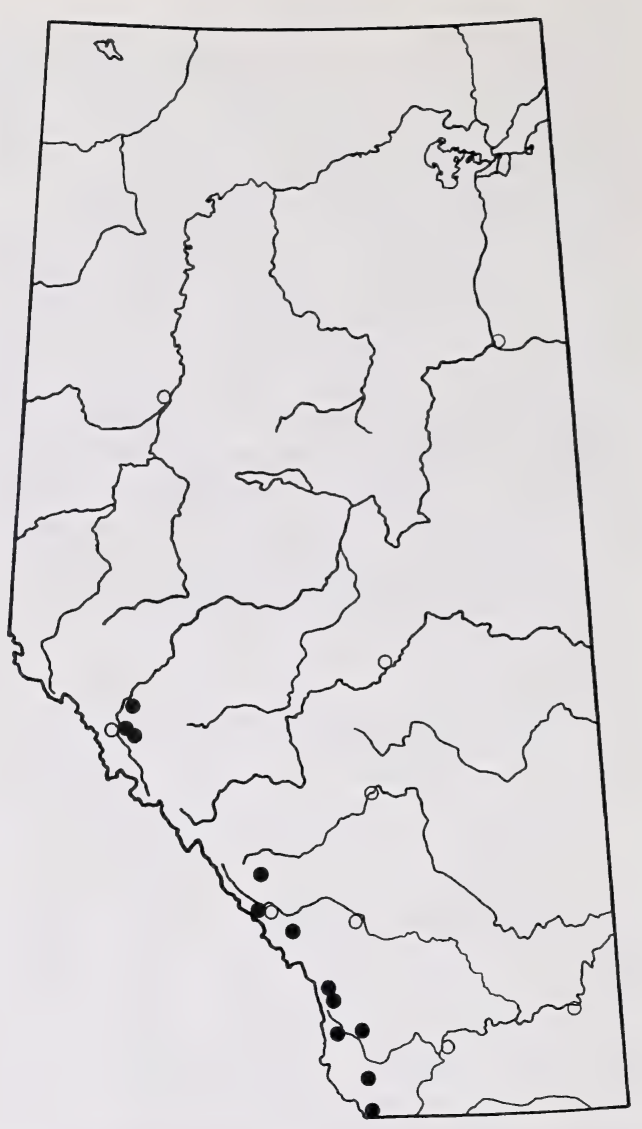

Figure 45. Distribution of Peltigera kristinssonii in Alberta.

Distribution in North America: Peltigera kristinssonii is distributed in the arctic and boreal zones and in their altitudinal counterparts in North America (Vitikainen 1985). Additional specimens seen (ALTA): U.S.A.: Colorado and Washington.

\section{Peltigera lepidophora (Nyl. ex Vainio) Bitter}

\section{Illustration: Fig. 46, map: Fig. 47.}

Morphology: Thallus small, rarely larger than $2-3 \mathrm{~cm}$, more or less rounded, firmly attached to the substrate; lobes rarely to $2 \mathrm{~cm}$, rarely branching, strongly concave, rather robust when dry, margin entire and rather plane. Upper surface light to dark brown, tomentose, dull, covered with peltate or rarely erect dorsiventral isidia (never globular or coralloid). Lower surface light, ochraceous at the margins, brown toward centre, veins flat and somewhat anastomosing; rhizines to 2 


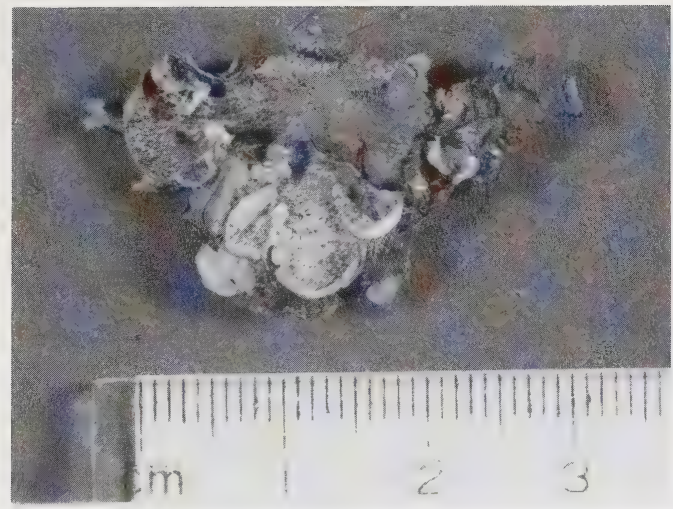

Figure 46. Peltigera lepidophora habit. The isidia appear as dark dots. (Ostafichuk 3598, ALTA.)

$\mathrm{mm}$, pale, simple to fibrillose. Photobiont, cyanobacteria. Apothecia unknown in Alberta, but described as being "small, 1.5-4.5 mm across on extended lobules, the margins crenate; disk brown; ...spores acicular, 5585 x 4-4.5 $\mu \mathrm{m}$ " (Thomson 1950, 1984).

Variation: Peltigera lepidophora, like $P$. evansiana, has laminal isidia and is tomentose. However, unlike the latter species, its isidia are peltate and never globular and coralloid. Further, the thallus of $P$. lepidophora is often unilobate or hardly branched, small and strongly concave (Fig. 46). It commonly grows with $P$. didactyla, which is also deeply concave and often unilobate, but the latter bears laminal soredia.

Ecology: This xerophytic lichen is most common along roadcuts and other dry habitats. It grows on mosses over soil, on sandy soil, and on quartzitic sandstone boulders from open grasslands, Aspen Poplar and pine forests on dunes, to exposed, rocky alpine tundra. It is occasionally found on exposed peat.

Distribution in Alberta: Most commonly occurring in more upland sites, $P$. lepidophora is found from the Foothills and Montane upwards into the Alpine subregions (Fig. 47). However, it has been collected occasionally in the southern part of the Boreal Mixedwood and in the Central Parkland. At present, this species is not known to occur north of the town of Whitecourt. However, Peltigera lepidophora is easily overlooked in the field and may be more common than is known currently.

Distribution in North America: Even though it has not been collected north of Whitecourt in Alberta, it shows a circumpolar arctic to temperate distribution in North America (Thomson 1984). Additional specimen seen (ALTA): Canada: British Columbia.

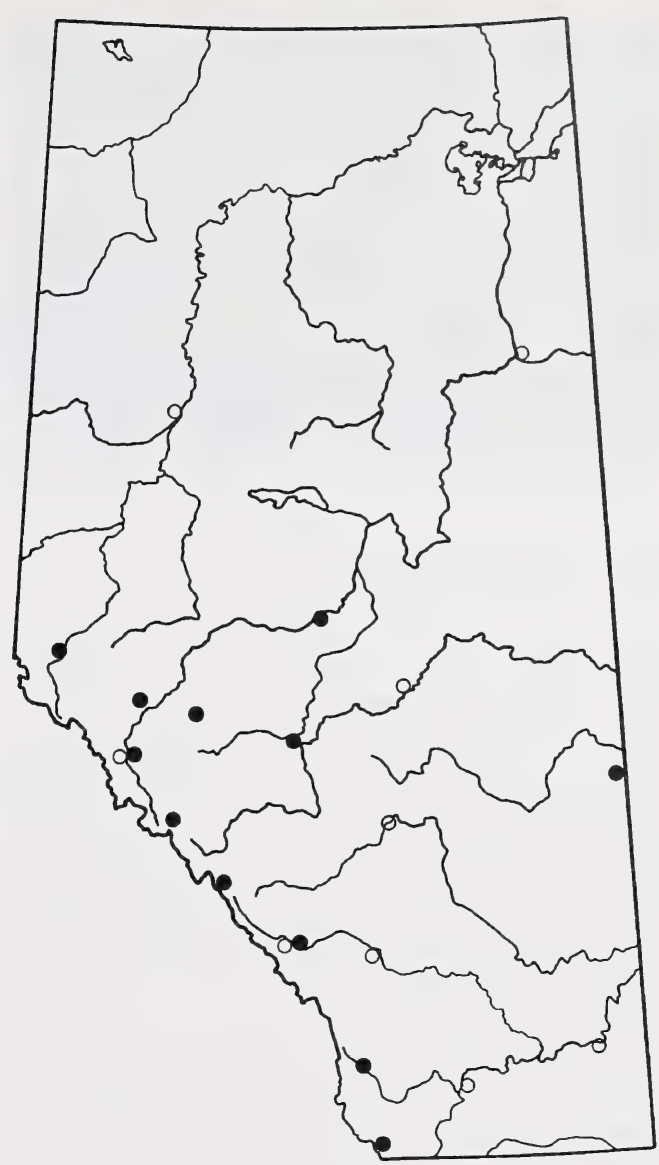

Figure 47. Distribution of Peltigera lepidophora in Alberta.

\section{Peltigera leucophlebia (Nyl.) Gyelnik}

Illustrations: Figs. 48-52, map: Fig. 53.

Morphology: Thallus medium to large, loosely appressed to the substrate; lobes to $3 \mathrm{~cm}$ wide, branching, mostly spreading and flat, thin, fragile when dry, margin crisp to crenulate, flat to upright, rarely bordered by a white line. Upper surface typically shiny (dull in exposed habitats), apple green when wet, greenish-grey when dry, often with brownish tint toward centre, typically wavy, covered with partly erect hairs only near margin, cephalodia to $2 \mathrm{~mm}$ wide, adnate, convex, and most often cerebriform, attached through their whole surface to the cortex. Lower surface with raised and rounded or flat, smooth veins becoming gradually dark brown to blackish toward 


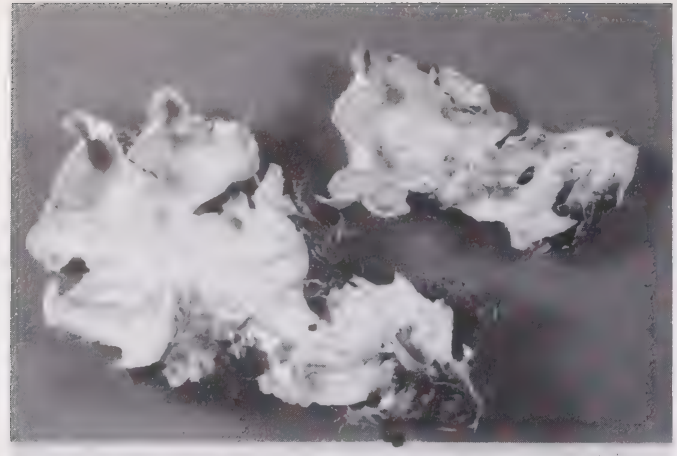

Figure 48. Peltigera leucophlebia habit. (Sérusiaux 10955, herb. Goffinet, duplicate LG.)

centre, these distinct throughout the lobe, typically highly contrastive, at least near margin with pale elongate, elliptical interstices; rhizines to $5 \mathrm{~mm}$, blackish throughout, scattered, densely branched and often anastomosing. Photobiont, green algae. Apothecia common, with chestnut to dark brown disk, to $1.2 \mathrm{~cm}$ wide, with revolute margins, on narrow and somewhat elongate lobes, lower surface with patchy smooth cortex or cortex lacking; spores acicular, (48-) 51-65 $(-74) \times 3.5-5 \mu \mathrm{m}$, mostly four-celled.

Variation: Peltigera leucophlebia is typically characterized by the mostly cerebriform cephalodia, the apothecia which are only discontinuously corticate on their lower surface, and by the highly conspicuous veins contrasting with the pale interstices almost throughout the lobes (Figs. 49-50). Specimens with

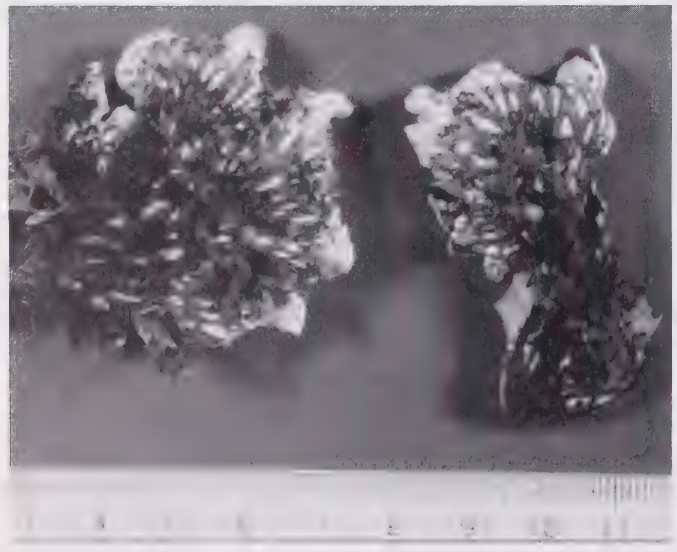

Figure 49. Peltigera leucophlebia. Typical lower surface with distinct veins throughout. (Sérusiaux 10955, herb. Goffinet, duplicate LG.)

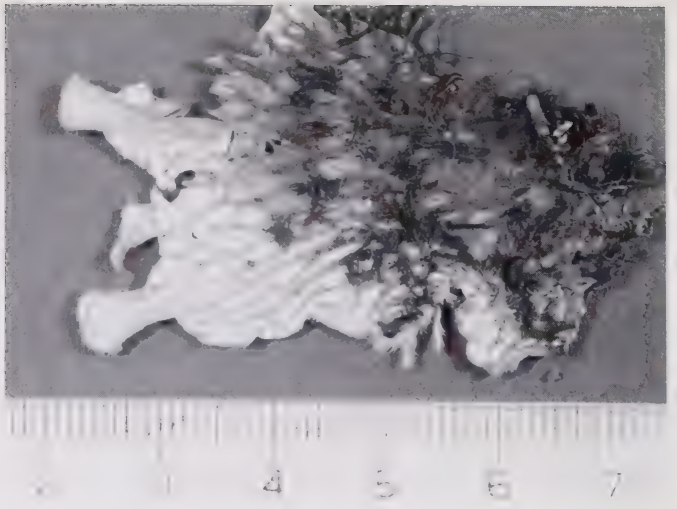

Figure 50. Peltigera leucophlebia lower surface. Note the patchy cortex on the lower surface of the apothecia. (Kennedy Sept. 6, 1961, ALTA.)

this pattern of veination on the lower surface are uncommon in Alberta, but the species can still be distinguished from $P$. aphthosa by its usually rather crenulate margin (Fig. 52) and thin and fragile lobes. Some forms of $P$. aphthosa have a lower surface which becomes only gradually darker toward the centre, with a broad, pale marginal zone, much like $P$. leucophlebia (compare Figs. 18 \& 50). Such specimens are only known from localities with a heavy snow cover and can be distinguished by the continuous cortex on the lower surface of the apothecia (all such specimens show this character) and by its veins which are indistinct throughout and not contrastive with the interstices (see $P$. aphthosa for further discussion).

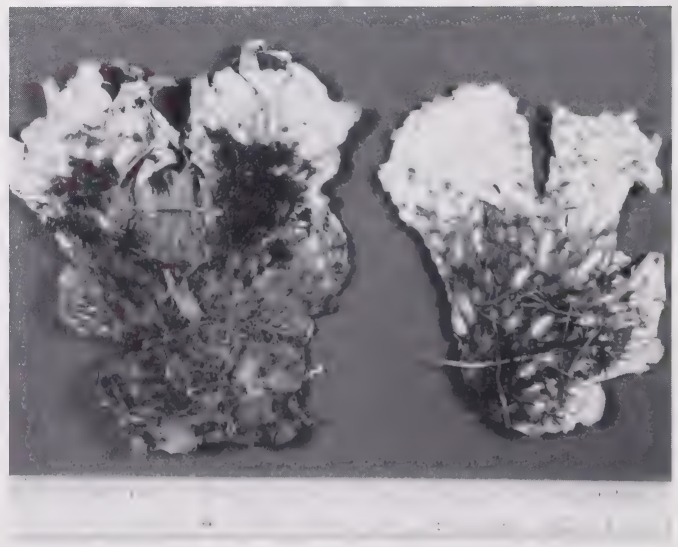

Figure 51. Peltigera leucophlebia lower surface, showing degree of variation in differentiation of veins within a single specimen. (Kennedy Sept. 6, 1961, ALTA.) 


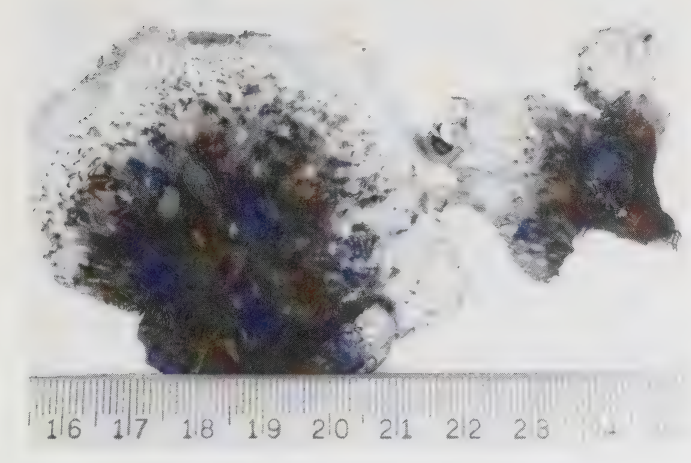

Figure 52. Peltigera leucophlebia lower surface. Note the crenulate margin of the sterile lobe. (Goffinet C90.4.223, PMAE.)

Ecology: Mostly occurring on mosses or litter in wet to moist forests. In the boreal forest it ranges from Black Spruce/Ledum wetlands to mesophytic Aspen Poplar-White Spruce forests. In mountainous areas it occurs in mesic Lodgepole Pine woodlands to subalpine Engelmann Spruce-Subalpine Fir forests. Occasionally, it is found in the alpine tundra where it grows both on mosses over soil and, more rarely, directly on soil. It is a rare inhabitant of xeric Jackpinelichen woodlands in the northeast corner of the province.

Distribution in Alberta: Peltigera leucophlebia is found most commonly in the foothills and mountain areas (Fig. 53). It has been collected in a few localities in the Boreal Mixedwood and to the north in the subarctic of the Caribou Mountains and on the Canadian Shield. This species is common over its range.

Distribution in North America: This circumpolar species is widespread in the boreal, arctic, and alpine of North America (see map in Thomson 1984, under P. aphthosa var. variolosa). Additional specimens seen (ALTA): Canada: British Columbia, Manitoba, Northwest Territories, Saskatchewan, and the Yukon Territory; U.S.A.: Colorado, New Mexico (herb. Goffinet), and Wyoming.

\section{Peltigera malacea (Ach.) Funk.}

Illustrations: Figs. 53-54, map: Fig. 56.

Morphology: Thallus moderately attached to the substrate, often thick and robust when dry; in dry habitats (rocks or roadsides) small to medium with lobes about $1 \mathrm{~cm}$ broad, branching, short and mostly erect and disintegrating in the centre, margin entire and strongly

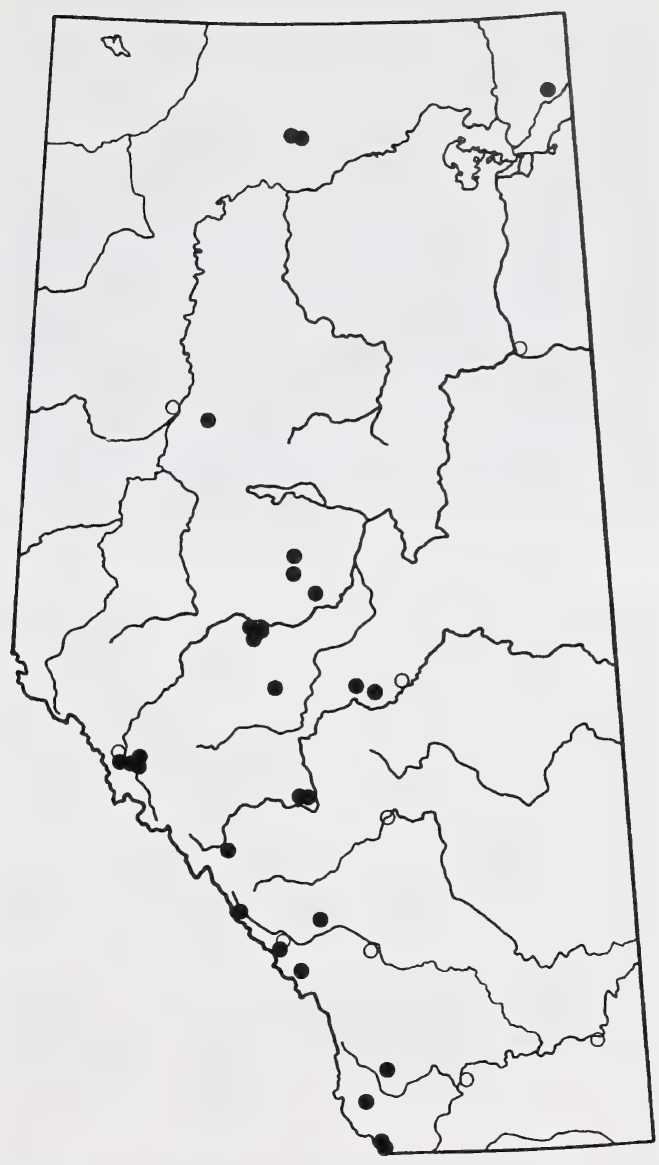

Figure 53. Distribution of Peltigera leucophlebia in Alberta.

upturned; upper surface brown to dark brown, dull; in moist habitats (bogs) medium to large with lobes to 3 $\mathrm{cm}$ wide, branching, margin entire and flat; upper surface grey to bluish-grey when dry and turning deep green when wet, dull. Upper surface always with erect tomentum near margin, sometimes pruinose. Lower surface lacking distinct veins, cottony, whitish, ochraceous to yellowish near margin, becoming abruptly black toward centre; rhizines poorly differentiated, to $2 \mathrm{~mm}$, black, sparse, fasciculate. Photobiont, cyanobacteria. Apothecia common, disk brown to blackish brown, to $5 \mathrm{~mm}$ across, saddle-shaped, on erect, narrow, and elongate lobes; spores acicular, (42-) 52-57 (-79) $\times 3.5-5.5 \mu \mathrm{m}$, invariably four-celled (90 spores measured).

Variation: By the strongly anastomosing veins (only a few, if any, clear elongate interstices are apparent on 


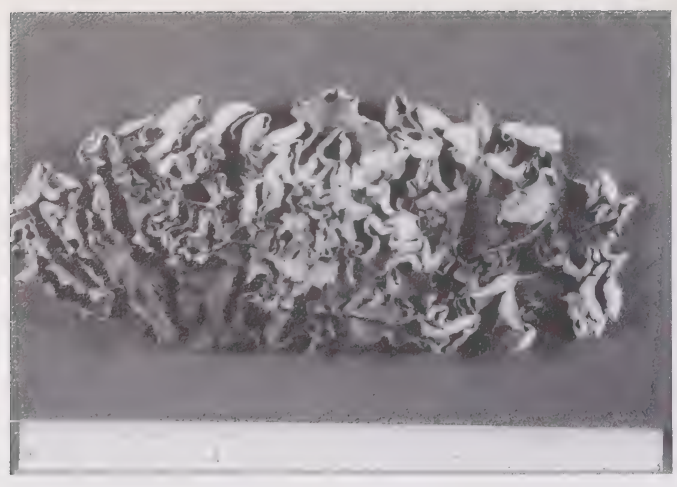

Figure 54. Peltigera malacea typical habit in xeric habitats. (Scotter 60768, ALTA.)

the dark brown to black lower surface, Fig. 55) and the erect marginal hairs, $P$. malacea resembles $P$. aphthosa but is clearly differentiated by its blue-green photobiont. The seemingly veinless lower surface is similar to that of $P$. elisabethae, which, however, lacks tomentum and has vegetative propagules. Peltigera kristinssonii also has erect tomentum near the margin, but it differs by its lower surface having distinct chestnut brown tomentose veins and a scabrous upper marginal cortex. In his treatment, Thomson (1950) recognized two infraspecific taxa. The variety polyphylla Flot. apud Sturm, was characterized by erect, thick, overlapping lobes; the combination is not retained here as it probably represents a xero-ecotype of the species (Fig. 54). The second infraspecific taxa, forma prolifera Thomson, was based on Gyelnik's (1931a and 1932) descriptions of the "isidiate" $P$. avenosa which actually represents the blue-green phototype

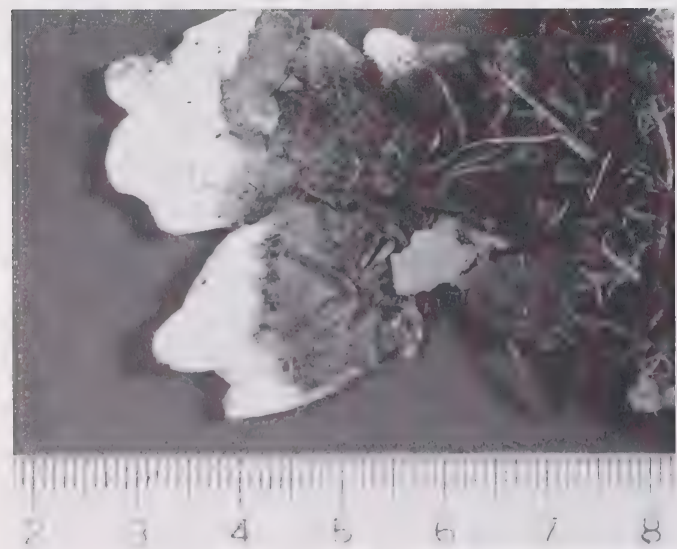

Figure 55. Peltigera malacea lower surface. There is an abrupt transition between the pale margins and the blackish, mature parts of lobes. The anastomosed veins give the appearance of a veinless lower surface. (Vitikainen 10957, ALTA.) of $P$. britannica Holtan-Hartwig \& Tønsberg (Goward et al. in prep.; see also Tønsberg \& Holtan-Hartwig 1983).

When growing in mesic to somewhat xeric conditions $P$. malacea is often found among acrocarpous and feather mosses. Maybe, due to the competition from these, the lobes are mostly erect and often disintegrate in the centre. By contrast, in moist conditions, i.e., in peatlands, it develops large, spreading lobes and its thallus remains intact.

Ecology: Peltigera malacea occurs in a wide range of habitats from wet subarctic Black Spruce bogs, mesic mixed Aspen Poplar-White Spruce forests, and open pine forests on dunes. It is also common in pine forests in the foothills and mountains, subalpine spruce-Subalpine Fir forests, and dry, rocky alpine sites. Most commonly it grows on litter, but is also

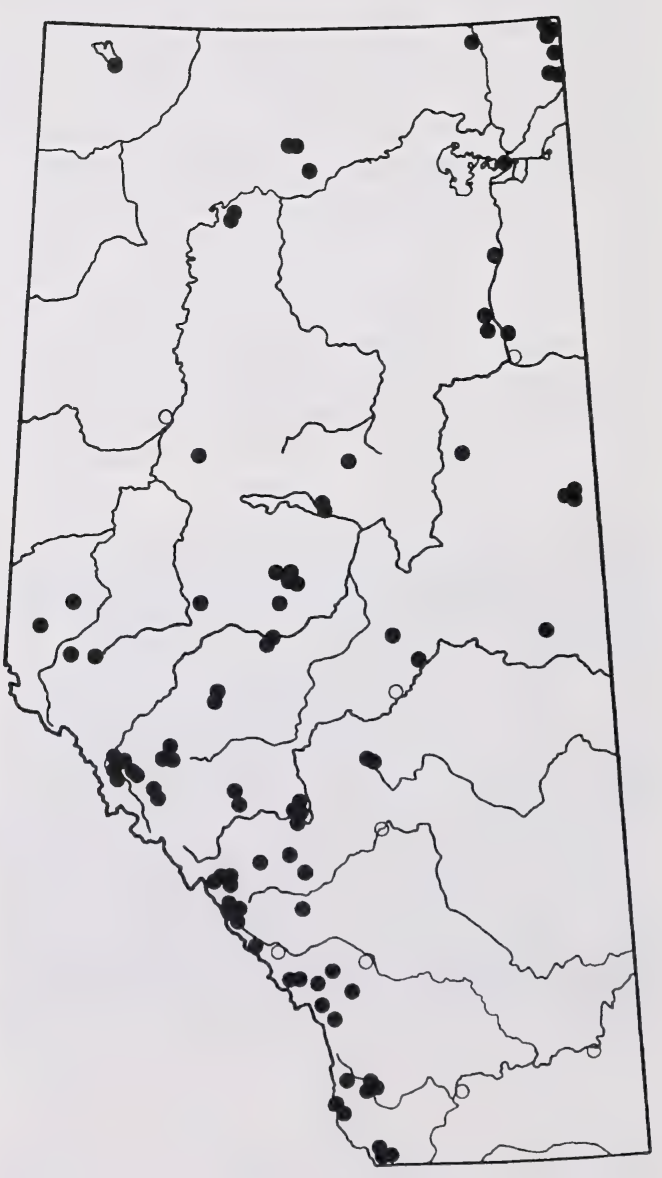

Figure 56. Distribution of Peltigera malacea in Alberta. 
often found on mosses and occasionally even on exposed dry sand on dunes, or rocks in the alpine tundra.

Distribution in Alberta: This eurytopic species grows throughout the forested and alpine natural regions in the province, being absent only from the grasslands (Fig. 56). It appears to be most common in the Boreal Mixedwood and Foothills subregions. The species is common over its range.

Distribution in North America: Krog (1968) reports $P$. malacea to be "a high arctic-temperate, circumpolar species." Thomson (1984) adds that it is, however, rare in the Arctic Islands. Additional specimens seen (ALTA): Canada: British Columbia, Manitoba, Quebec, Northwest Territories, Saskatchewan, and the Yukon Territory; U.S.A.: Alaska, Colorado, and Washington.

\section{Peltigera membranacea (Ach.) Nyl.}

\section{Illustrations: Figs. 57-59, map: Fig. 60. Appendix 1.}

Morphology: Thallus medium to large, rather loosely attached to the substrate; lobes 2 to $3 \mathrm{~cm}$ broad, branching, sometimes concave, very thin, fragile when dry, margin entire and downturned. Upper surface grey, rarely with brownish tint, smooth, tomentum usually restricted to margin. Lower surface with distinct, narrow, raised, and tomentose veins throughout, these typically whitish but sometimes darkening and becoming almost blackish (rare) toward centre, interstices wide, diamond-shaped to polygonal; rhizines to $8 \mathrm{~mm}$, typically whitish, but commonly brownish or even blackish, simple to more often densely and short squarrosely branched. Photobiont, cyanobacteria. Apothecia occasional, on elongate lobes, disk hazelnut brown, to $8 \mathrm{~mm}$ long, with somewhat revolute margins, on short lobes; spores acicular, (31-) 41-61 (-76) x 3-4 $\mu \mathrm{m}$, mostly four-celled, occasionally more than tri-septate.

Variation: Peltigera membranacea belongs to the $P$. canina group but differs from these related species by its narrow, widely reticulate veins (Fig. 58) and its membranous lobes with downturned margins. Peltigera canina also has downturned lobe tips but differs by its thick and robust thallus, the absence of tomentum on veins, and its mostly branched, dark rhizines that are at least patchily anastomosing. Peltigera praetextata also has long, simple rhizines but differs from $P$. membranacea by a network of usually flat and brown veins and a typically upturned margin. In addition, its

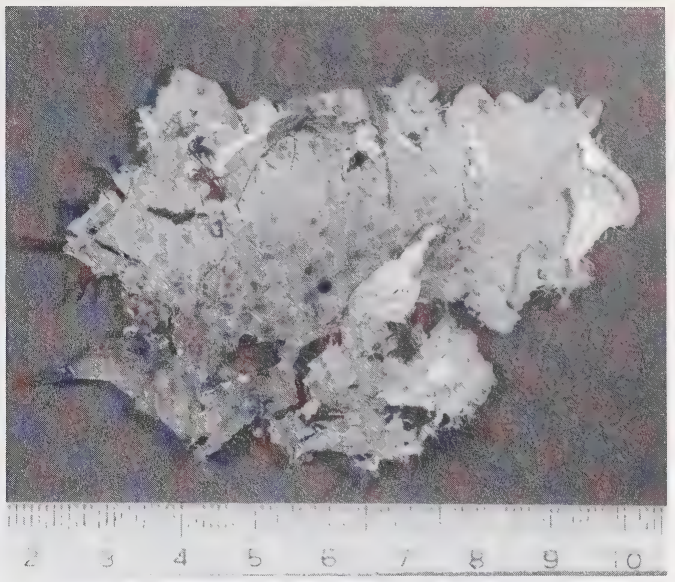

Figure 57. Peltigera membranacea upper surface. (Goffinet 412, herb. Goffinet.)

upper cortex often bears phyllidia, which are never developed in $P$. membranacea (Appendix 1). We have included in the present concept of $P$. membranacea specimens with veins forming an atypically neat reticulate network (Fig. 59 right) and rhizines squarrosely to abundantly branched (bushy); in such cases, the thallus is papery and the veins and rhizines are either dark brown or whitish, and tomentose almost throughout. The taxonomic placement of such specimens remains uncertain, and these morphologically intermediate thalli might be of hybrid origin.

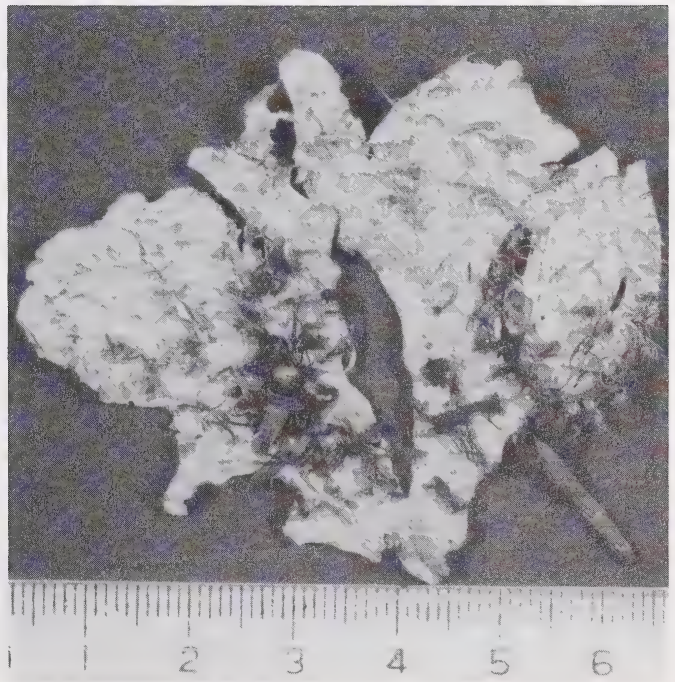

Figure 58. Peltigera membranacea lower surface. The distinct, narrow veins form a loosely reticulate network. (Goffinet 412, herb. Goffinet.) 


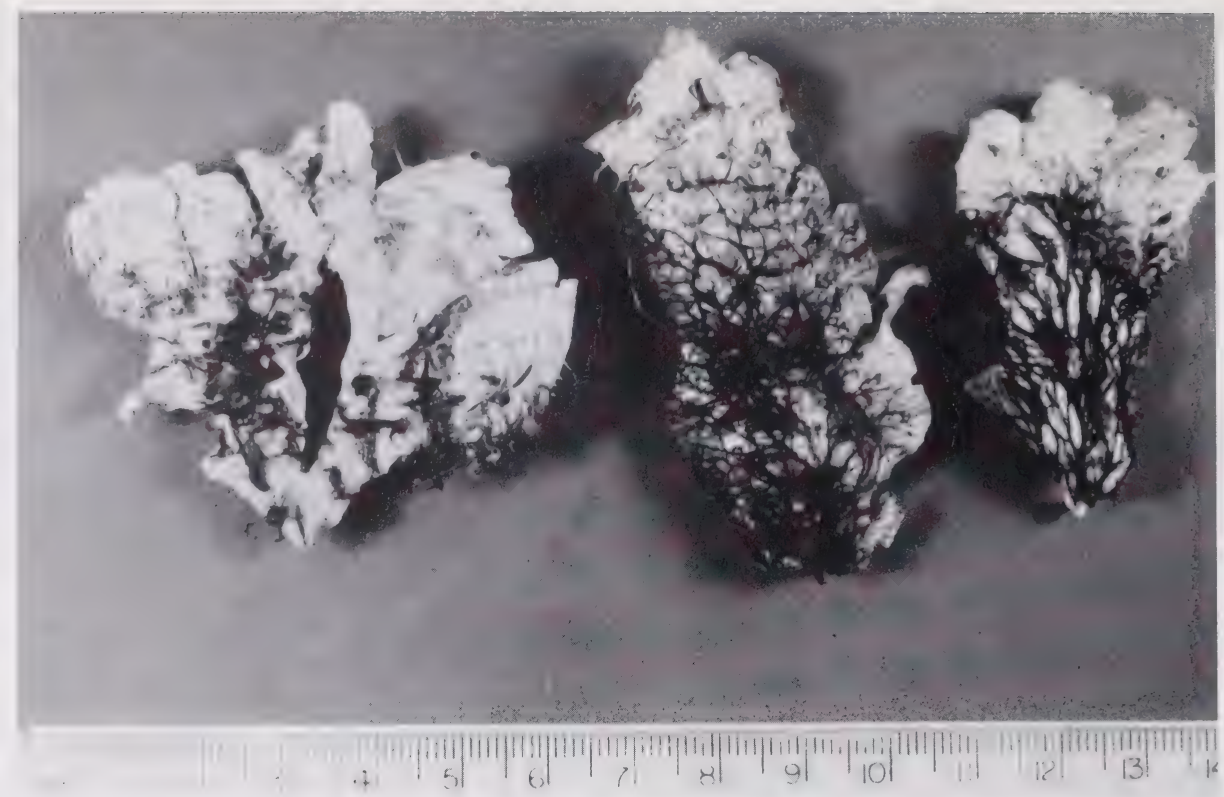

Figure 59. Peltigera membranacea variation in color of veins. (left to right: Goffinet 412 , Goffinet 1505, both herb. Goffinet; Goffinet C90.4.176, PMAE.)

Ecology: Peltigera membranacea occurs most commonly on mosses or humus in mesic, mixed White Spruce-Aspen Poplar forests. It also grows on mosses in mesic to moist sites in subalpine spruce-Subalpine Fir forests and in mesic alpine tundra meadows. Occasionally it is found on rotten logs in mesic forests and, more rarely, directly on mineral soil.

Distribution in Alberta: This lichen is widely distributed but uncommon in Alberta; it appears to be found mostly in moist sites within the Boreal Mixedwood subregion (Fig. 60). It also occurs within the Subarctic subregion on the Caribou Mountains and in the Peace River Lowlands. Towards the west it has been collected in the Foothills, Montane, and Subalpine subregions.

Distribution in North America: Peltigera membranacea is known from a few continental localities but has an essentially oceanic to suboceanic distribution in North America and Europe (Ahti and Vitikainen 1977, Thomson 1950 and 1984, Vitikainen 1987). Additional specimens seen (ALTA): Canada: British Columbia, Newfoundland, and Nova Scotia; U.S.A.: Alaska, California, Idaho, and Oregon.

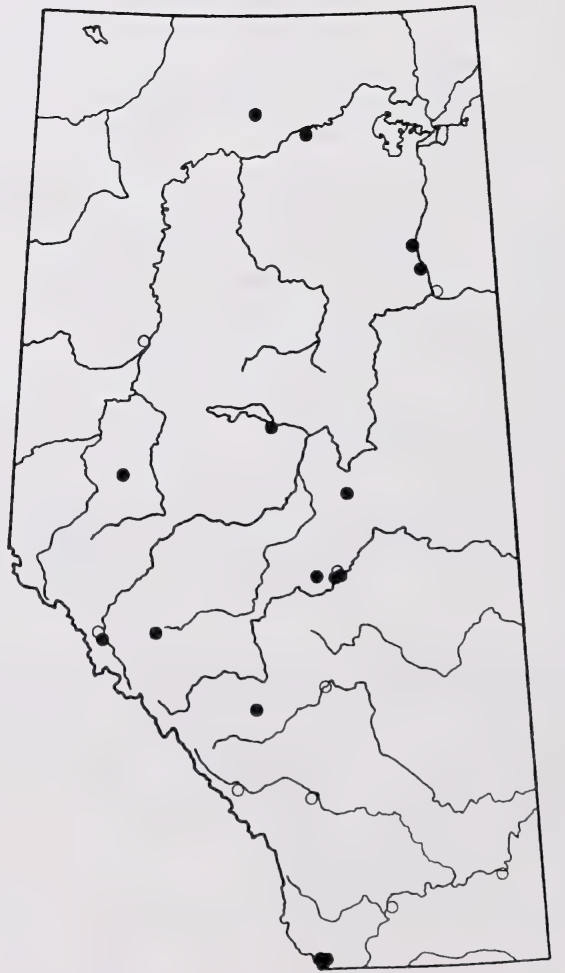

Figure 60. Distribution of Peltigera membranacea in Alberta. 


\section{Peltigera neckeri Hepp. ex Müll.} Arg.

\section{Illustrations: Figs. 61-62, map: Fig. 63. Appendix 2.}

Morphology: Thallus medium, several $\mathrm{cm}$ across, moderately appressed to the substrate; lobes to $1.5 \mathrm{~cm}$ broad, rarely $2 \mathrm{~cm}$, branching, rather thin, fragile when dry, margin plane to raised and slightly dissected. Upper surface usually with numerous cracks, dull to rarely shiny, occasionally somewhat maculate, grey to greyish-brown to sometimes bluish-grey, rarely entirely brown, smooth and glabrous, margin often pruinose. Lower surface ochraceous near margin, but often turning quickly dark brown, veins broad, more or less distinct only near margin, may be absent, some white interstices often remaining in the centre (the whitish margin can be broad in some specimens); rhizines to $5 \mathrm{~mm}$, dark brown rarely pale near margin, short fasciculate to almost simple, often sparse and almost absent. Photobiont, cyanobacteria. Apothecia frequent, disk black, strongly finger nail-shaped, rarely reaching $6 \mathrm{~mm}$ in length $(8 \mathrm{~mm}$ in the Yukon Territory material), on short lobes, appearing almost sessile; spores acicular, (34-) 44-59 (-68) x 3-4 $\mu \mathrm{m}$, mostly four-celled but occasionally six-celled (90 spores measured).

Variation: Peltigera neckeri was recently reinstated and distinguished from $P$. polydactyla based on its distinct morphology (Vitikainen 1981) and chemistry (White and James 1985, see Appendix 2 for further comparisons). The species does not vary greatly, it is best characterized by its black apothecia that are supported by short, narrow lobes (Fig. 62). Peltigera neckeri can be confused with $P$. elisabethae when

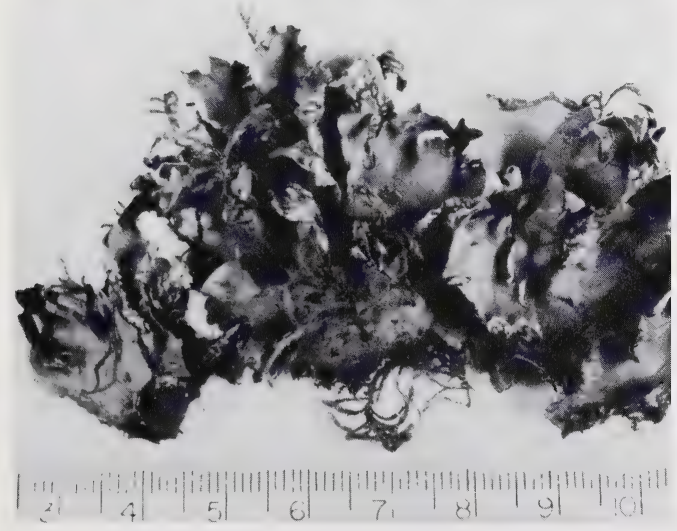

Figure 61. Peltigera neckeri habit. (Goffinet 3469, herb. Goffinet.) sterile; both have often pruinose margins, a seemingly veinless lower surface (Fig. 62), and numerous cracks on the upper cortex. However, the lobe margin of $P$. elisabethae may bear schizidia, and lobules are often developed along the cracks. Peltigera neckeri invariably lacks specialized vegetative propagules and rarely produces regeneration lobules. When fertile, $P$. neckeri differs from $P$. elisabethae by its apothecia with revolute margins and spores that are longer than $45 \mu \mathrm{m}$. The two species also differ chemically (Goward et al. in prep., Holtan-Hartwig 1993).

Because of its usually indistinct veins, $P$. neckeri collections will key to $P$. polydactyla var. crassoides Gyelnik in both Thomson's (1950) and Ostafichuk's (1966) monographs. Both authors stress the similarities between specimens of $P$. polydactyla var. crassoides and $P$. malacea. Considering that $P$. neckeri has a lower surface with indistinct veins, this may indicate that their collections actually belong to P. neckeri. Ahti and Vitikainen (1977) and Vitikainen (1981) considered the combination $P$. polydactyla var. crassoides to be synonymous with $P$. lactucifolia (With.) Laundon (=P. hymenina (Ach.) Del.). This species, however, differs from $P$. neckeri by its ochraceous, anastomosing veins and by its brown apothecia supported by moderately long lobes. This contrasts with the black and almost sessile apothecia in P. neckeri. Peltigera lactucifolia is currently known only from the eastern coast of North America (Ahti and Vitikainen 1977) and from scattered hyper-maritime localities in British Columbia (Goward et al. in prep.).

Recently, Holtan-Hartwig (1988) described P. frippii from Norway. It differs from $P$. neckeri by its distinctly maculate upper cortex, crisped and narrow lobes, rather distinct veins, and chemistry. The species

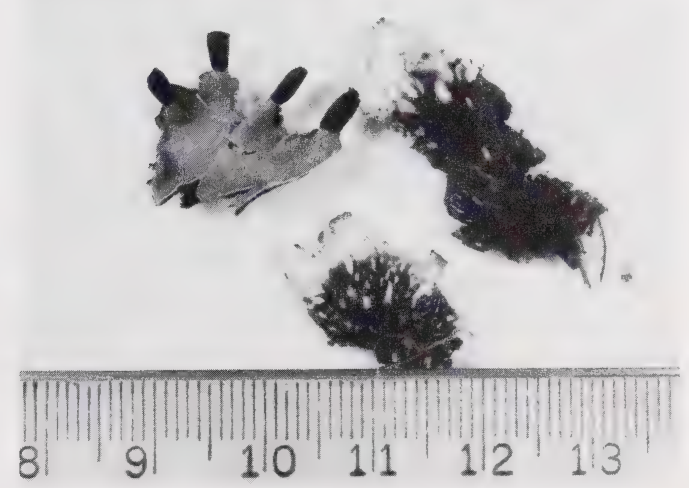

Figure 62. Peltigera neckeri. Left: upper surface, note the small, blackish apothecia on short, narrow lobes. Middle and right: lower surface, note the broad veins and the few whitish interstices. (Hastings C91.5.54, PMAE.) 
is currently not known from North America but it may be expected from higher elevations or latitudes.

Ecology: Peltigera neckeri occurs most commonly on mosses or humus in mesic, mixed White SpruceAspen Poplar stands in the boreal forest, and occasionally on rotten logs in mature Aspen Poplar forests. In drier sites, it grows on humus and in the shade. It is fairly common on mosses and humus in mountainous Lodgepole Pine forests; rarely in similar microhabitats in the alpine tundra.

Distribution in Alberta: Peltigera neckeri is here reported as new to Alberta. Most collections of $P$. neckeri are from the Central Parkland and Boreal Mixedwood subregions in the central part of the province (Fig. 63). It also occurs commonly in the Foothills, Montane, and Subalpine subregions. Towards the north, it has been collected at low elevations near the

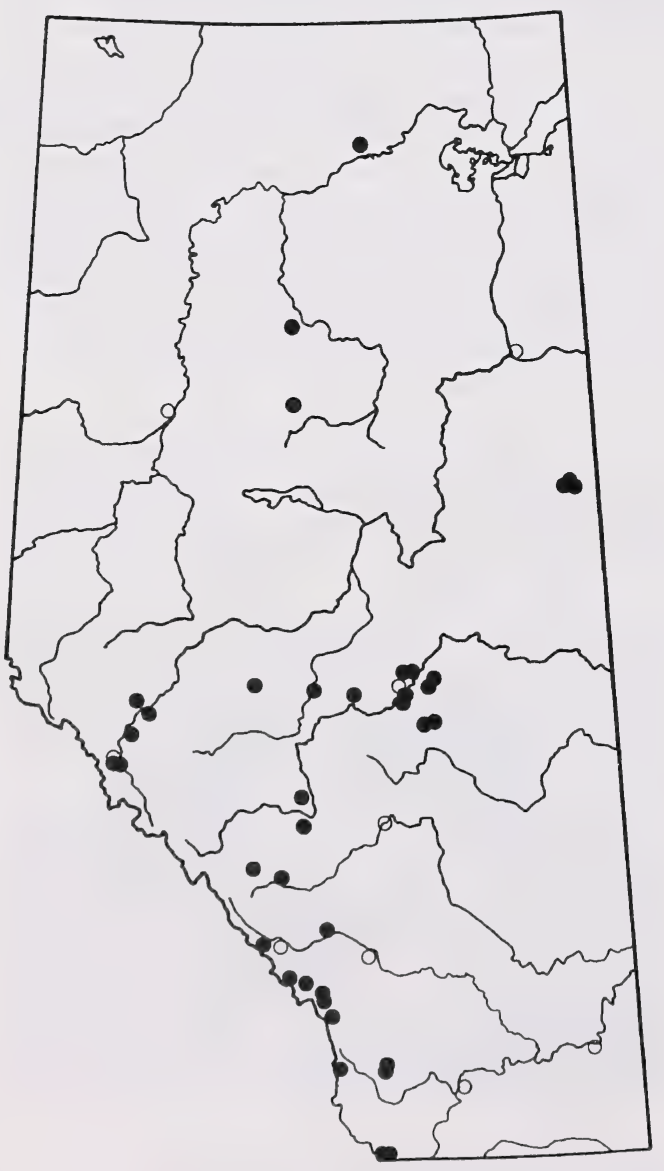

Figure 63. Distribution of Peltigera neckeri in Alberta
Buffalo Head Hills and Caribou Mountains. It is common over its range.

Distribution in North America: The distribution of this species is not well documented for North America but can be expected to follow a ubiquitous pattern similar to that observed in Europe (Vitikainen 1987). Additional specimens seen (ALTA): Canada: Ontario, and the Yukon Territory; U.S.A.: Minnesota and South Dakota.

\section{Peltigera neopolydactyla (Gyelnik) Gyelnik}

Illustrations: Figs. 64-66, map: Fig. 67. Appendix 2.

Morphology: Thallus large, to $15 \mathrm{~cm}$ across, often loosely attached to the substrate; lobes 3 to $4 \mathrm{~cm}$ wide, light brown to grey when dry, branching, moderately thin, robust to fragile when dry, margin entire, plane and somewhat crenulate. Upper surface smooth, glabrous, dull, faintly pruinose near margin, grey, bluishgrey to brownish-grey when wet, often brown toward centre when dry. Lower surface with ochraceous to dark brown broad veins anastomosing toward centre, interstices pale, rounded to elongate; rhizines particularly long in the centre to $7 \mathrm{~mm}$, dark brown, simple, rarely fasciculate, somewhat branched towards centre. Photobiont, cyanobacteria. Apothecia common, disk chestnut brown, saddle-shaped, small, to $4 \mathrm{~mm}$ long, on narrow lobes rarely longer than $5 \mathrm{~mm}$; spores acicular, (50-) 65-81 (-90) $\times 3-4 \mu \mathrm{m}$, four-celled to ten-celled (in one specimen, all spores were fourcelled, whereas another had mostly spores with more than four cells; 90 spores measured).

Variation: Peltigera neopolydactyla can be distinguished by its large size; none of the other glabrous species develop lobes reaching 3 to $4 \mathrm{~cm}$ across (Fig. 64). However, one should always consider the possibility of small specimens representing young thalli; these can still be correctly identified based on the rhizines reaching $7 \mathrm{~mm}$ in length (check near mature part of lobes). We found most collections of this species under $P$. polydactyla, which differs from typical $P$. neopolydactyla by its narrow lobes, narrow veins, and short rhizines. It has also often been mistaken for $P$. scabrosa, from which $P$. neopolydactyla differs by its smooth upper surface and the absence of short, fasciculate, dark brown, marginal rhizines. Some specimens from the west coast have a slightly scabrous upper cortex (Goward et al. in prep.), but this variation is not known from Alberta. The lower surface of Peltigera neopolydactyla varies considerably: it can be pale 


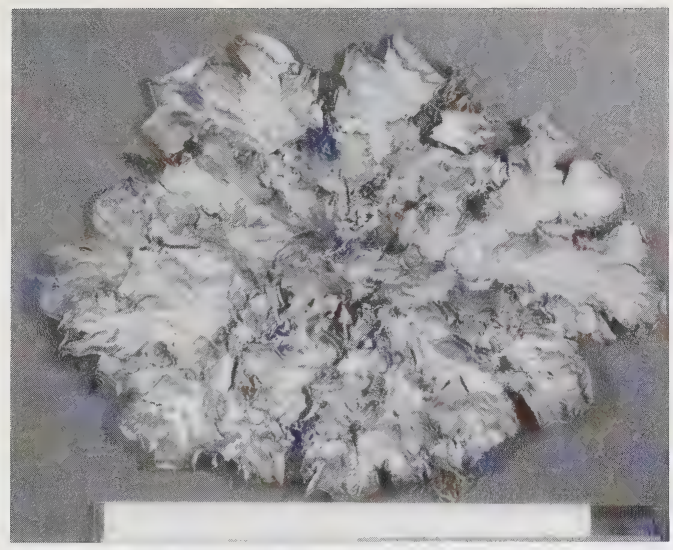

Figure 64. Peltigera neopolydactyla habit. (Horton 1755, ALTA.)

brown or ochraceous throughout or show an abrupt transition between a pale margin and a dark brown centre; the veins can be anastomosing near the margin or remain distinct almost throughout (Figs. 65-66). If Thomson's (1950) taxonomic concepts are followed, Albertan specimens would be identified as $P$. polydactyla var. dolichorrhiza Nyl. Ahti and Vitikainen (1977), however, point out that this taxon represents an entity different from $P$. neopolydactyla and subsequently rejected this variety from the North American flora. Whereas Albertan specimens of $P$. neopolydactyla are relatively homogenous, collections from British Columbia suggest that further studies may lead to the recognition of several taxa based on divergent morphology and chemical patterns (Goward et al. in prep.).

Ecology: This species prefers microhabitats with mesic to wet moisture regimes. It grows commonly

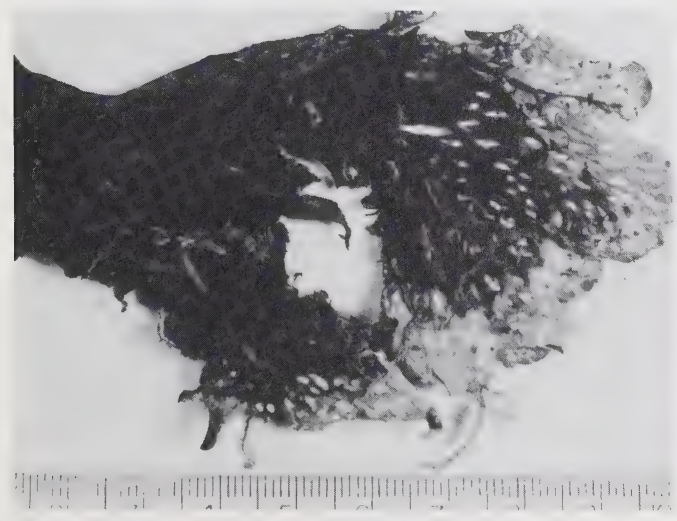

Figure 65. Peltigera neopolydactyla lower surface. (Horton 3510, ALTA.)

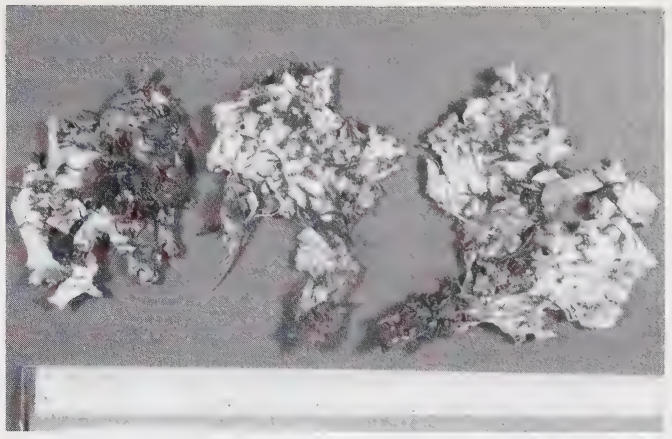

Figure 66. Peitigera neopolydactyla lower surface. There is considerable variation in the distinctness of the veins. (Vitt s.n., April 25 1984, ALTA.)

over mosses, humus, or on rotting logs in Black Spruce wetlands ranging from moderately rich to poor fens, and bogs. It is occasionally found on rotting logs in mesic montane forests and in wet alpine meadows where it grows on mosses.

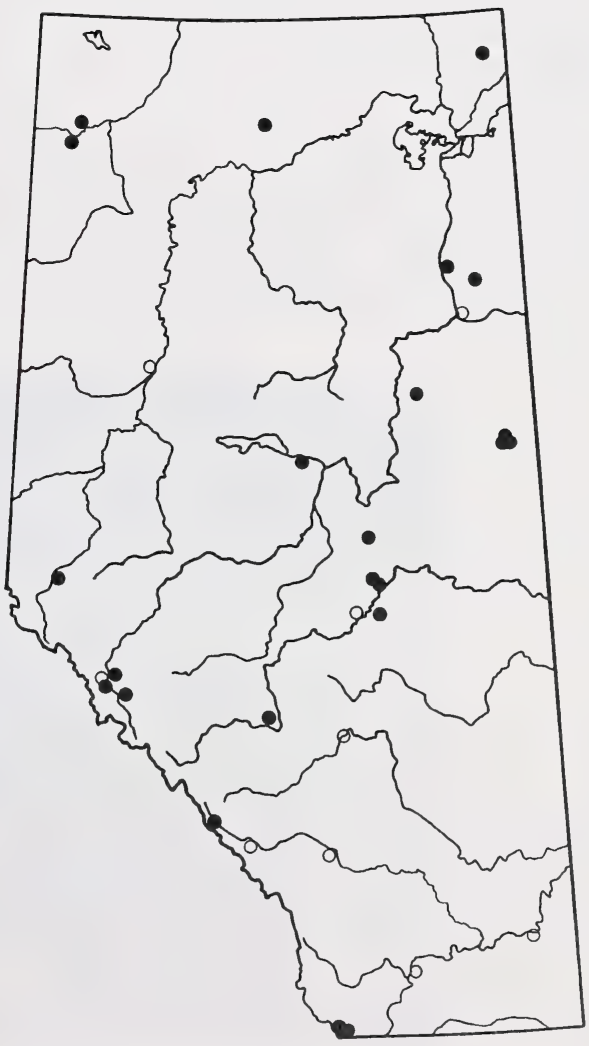

Figure 67. Distribution of Peltigera neopolydactyla in Alberta. 
Distribution in Alberta: Peltigera neopolydactyla has been collected in scattered localities in the northern Central Parkland, Boreal Mixedwood, Subarctic, and Canadian Shield subregions (Fig. 67). Towards the west, it has been collected in the Foothills and Montane subregions upwards in elevation to lower parts of the Alpine. The species is common over its range.

Distribution in North America: This species has been recently reported from several provinces in Canada (Brodo et al. 1987), extending its range throughout northern North America from Alaska and Washington to Newfoundland and New York. Further taxonomic investigation may lead to the recognition of additional taxa and thus to a revision of the presently known range. Additional specimens seen (ALTA): Canada: British Columbia, Labrador, Newfoundland, Northwest Territories, and Saskatchewan; U.S.A.: Michigan, Minnesota, New York, and Washington.

\section{Peltigera polydactyla (Neck.) Hoffm.}

\section{Illustrations: Figs. 68-70, map: Fig. 71. Appendix 2.}

Morphology. Thallus medium, to $10 \mathrm{~cm}$ across, rather firmly attached to the substrate; lobes to $1 \mathrm{~cm}$ wide, branching, thin, fragile when dry, margin plane to upturned, irregular, crisped, becoming almost squamulose. Upper surface light brown when dry, smooth, very shiny, glabrous, not pruinose, with cracks, vege- tative propagulae lacking, but short knobby regeneration lobules sometimes present. Lower surface with distinct veins near margins, abruptly turning dark brown and anastomosing toward centre, interstices pale, roundish to elongate; rhizines to $4 \mathrm{~mm}$, dark brown, simple to somewhat branched apically, confluent near margin. Photobiont, cyanobacteria. Apothecia strongly finger nail-shaped, disk brown to dark brown, to $7 \mathrm{~mm}$ long, on ascending and somewhat canaliculate lobes reaching $1 \mathrm{~cm}$ in length, spores acicular, (51-) $58-70(-75)$ x 3-4 $\mu \mathrm{m}$, invariably four-celled (60 spores from two apothecia were measured; in the apothecia from the third specimen only immature spores with no clear septa were found).

Variation. Peltigera polydactyla was reported as widespread in Alberta by Thomson (1950, 1984), Ostafichuk (1966), and Vitt et al. (1988). Most Albertan specimens examined, however, belong to $P$. neopolydactyla, $P$. neckeri, or P. elisabethae. The former has broad lobes reaching 3-4 $\mathrm{cm}$ across, the broad veins vary in color and pattern, but the rhizines are always simple and to $7 \mathrm{~mm}$ long. Peltigera neckeri and $P$. elisabethae segregate by their blackish lower surface appearing veinless and with few pale interstices, and by a rather greyish upper cortex which is often pruinose near the margin (see Appendix 2 for further comparisons). The three specimens of $P$. polydactyla known so far from Alberta have numerous apothecia. Peltigera polydactyla can be distinguished from $P$. elisabethae and $P$. horizontalis by its strongly finger nail-shaped disk, and from $P$. neckeri by its long, narrow, apothecia-bearing lobes. When sterile, $P$. poly-

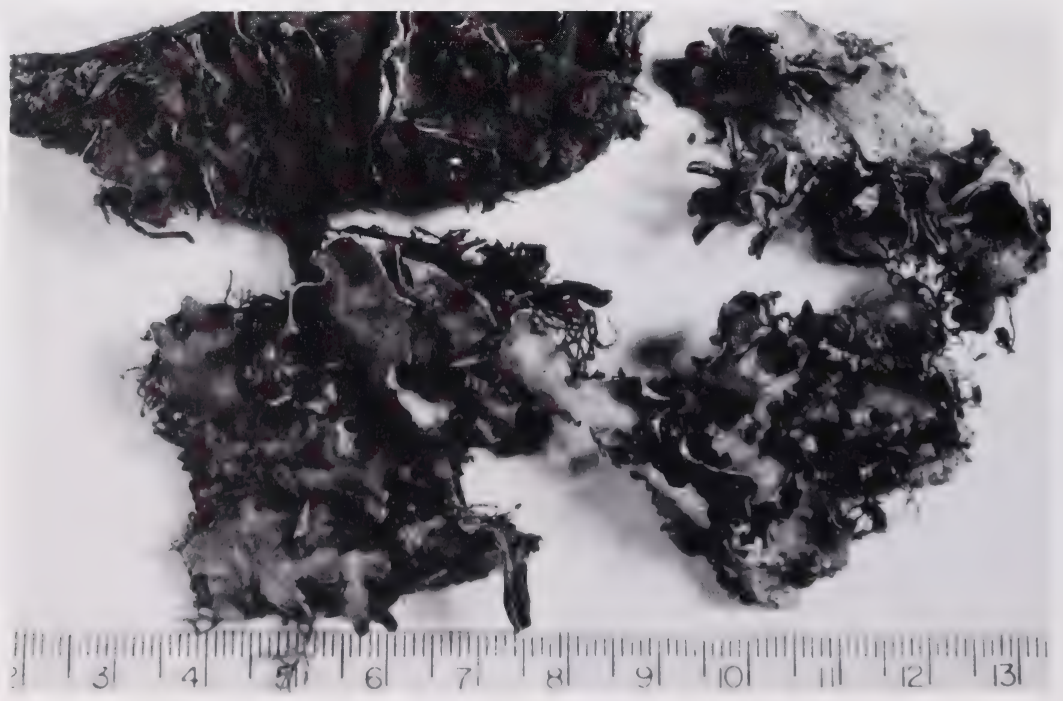

Figure 68. Peltigera polydactyla habit. The margins are upturned and the apothecia bearing-lobes are upright and narrowly elongate. (Goffinet 3246, ALTA.) 


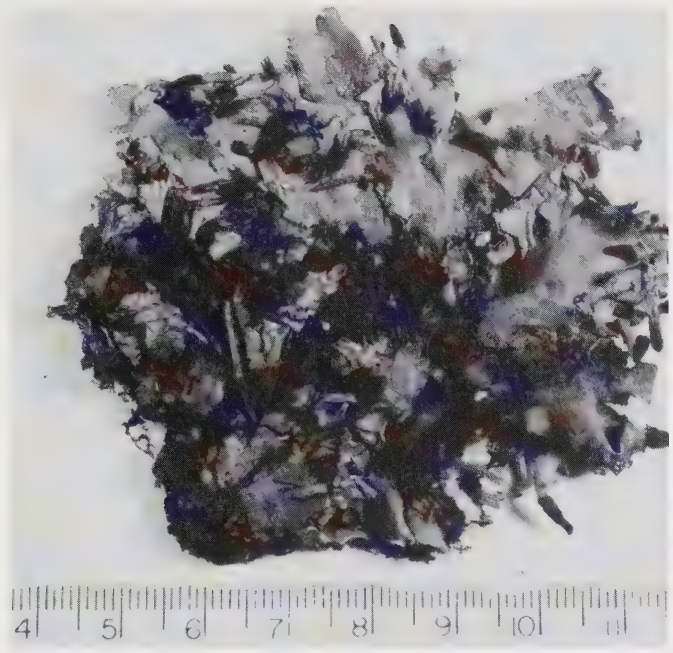

Figure 69. Peltigera polydactyla upper surface. (Scotter 46009, ALTA.)

dactyla is most similar to $P$. horizontalis (they have long been considered indistinguishable from each other when sterile) but differs by its crisped margin, lack of sub-marginal depressions on the upper surface, and scattered rhizines (Appendix 2).

Ecology. The three specimens known from Alberta were collected in mesic forests with poplar and White Spruce; they were growing over humicolous mosses.

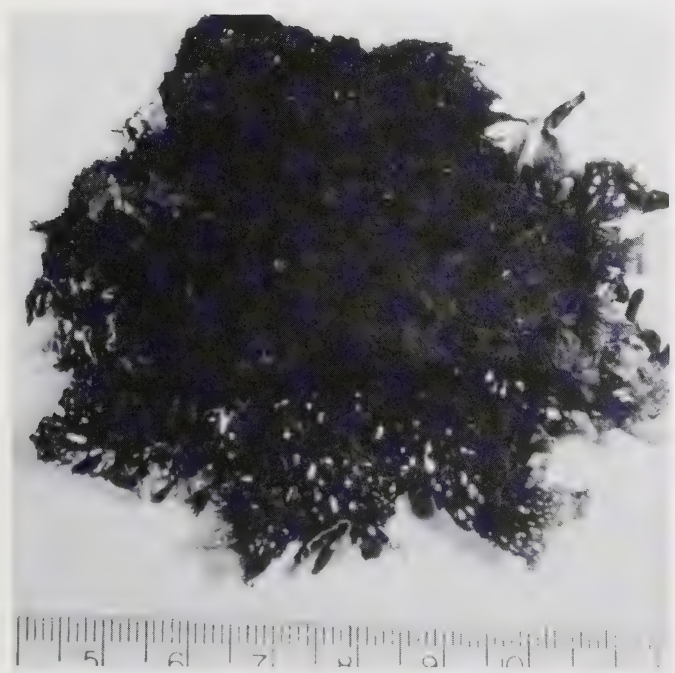

Figure 70. Peltigera polydactyla lower surface. Note the distinct veins. (Scotter 46009, ALTA.)
Distribution in Alberta: This rare species is known from only three localities, all between Edmonton and Lesser Slave Lake (Fig. 71). Two sites are in the Boreal Mixedwood and one is in the Central Parkland.

Distribution in North America. The distribution of this species is not well documented for North America as the mapped records certainly include specimens of $P$. neckeri, $P$. neopolydactyla, and $P$. lactucifolia. In Canada, $P$. polydactyla seems, so far, to have a temperate, oceanic distribution; the Albertan collections are the most continental localities yet recorded with certainty. Additional specimens seen (ALTA): Canada: British Columbia and Ontario. U.S.A.: Colorado (herb. Goffinet), Minnesota, and New Mexico (herb. Goffinet).

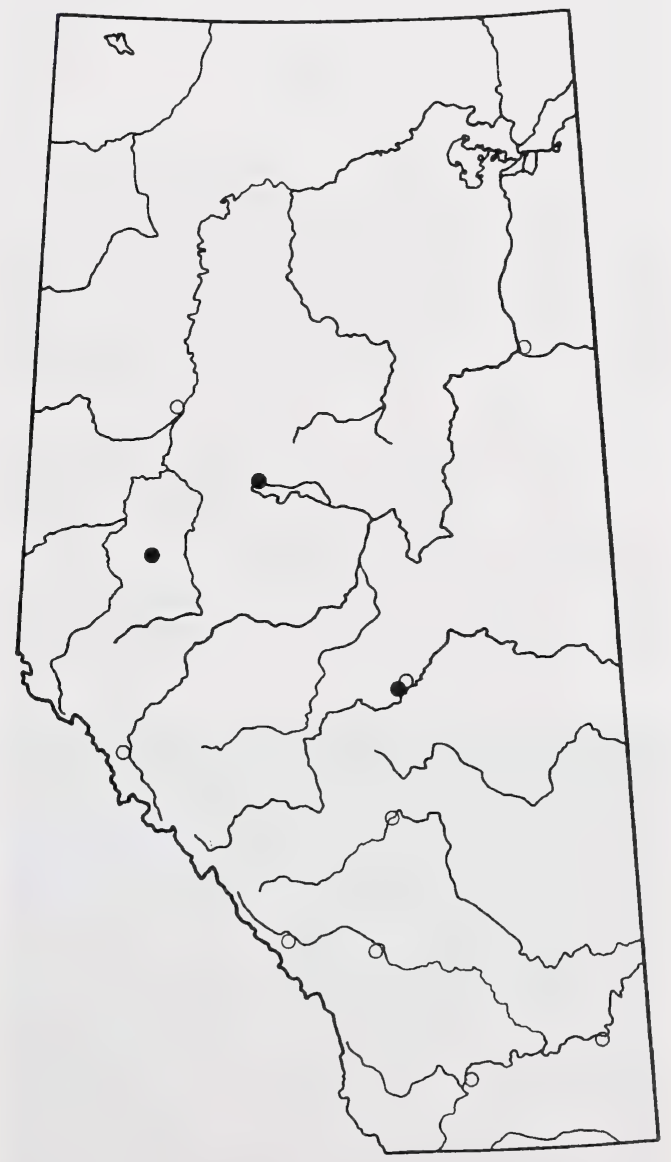

Figure 71. Distribution of Peltigera polydactyla in Alberta. 


\section{Peltigera ponojensis Gyelnik}

Illustrations: Figs. 72-73, map: Fig. 73.

Appendix 1.

Morphology: Thallus small to medium, rarely reaching $10 \mathrm{~cm}$, appressed to the substrate; lobes to $1 \mathrm{~cm}$ wide, branching, flat to crisped, thin, fragile when dry, margin entire, typically upturned, sometimes appearing somewhat lobulate. Upper surface grey, tan to brownish-grey, dull, tomentum typically restricted to the margin but sometimes extending toward centre, Lower surface with prominent and raised, glabrous veins, these pale rarely darkening gradually toward centre; rhizines to $7 \mathrm{~mm}$, pale to brown, simple to scarcely branched, not confluent. Photobiont, cyanobacteria. Apothecia rare (only one fertile specimen seen), disk chestnut brown, to $1.3 \mathrm{~cm}$ wide, flat or with somewhat revolute margins, on short lobes; spores acicular, (38-) 41-54 (-60) x 3-4 $\mu \mathrm{m}$ (20 spores measured), invariably four-celled.

Variation: Peltigera ponojensis can be mistaken for $P$. rufescens as both are tomentose and form small thalli. However, the two species can be distinguished by the following characters: $P$. ponojensis has a pale lower surface with simple rhizines and the tomentum on the upper cortex typically thins toward the centre of the lobes (Figs. $72 \& 73$ ); P. rufescens has a blackish lower surface with branched and confluent rhizines (if rhizines simple, then blackish), and its upper cortex is typically covered by a thick tomentum and a white crust in the centre. Peltigera ponojensis can also be mistaken for small specimens of $P$. praetextata, but can be separated by the absence of phyllidia, the invariably glabrous ropy veins, and its rather xeric habitat preferences (Appendix 1). In his original descrip-

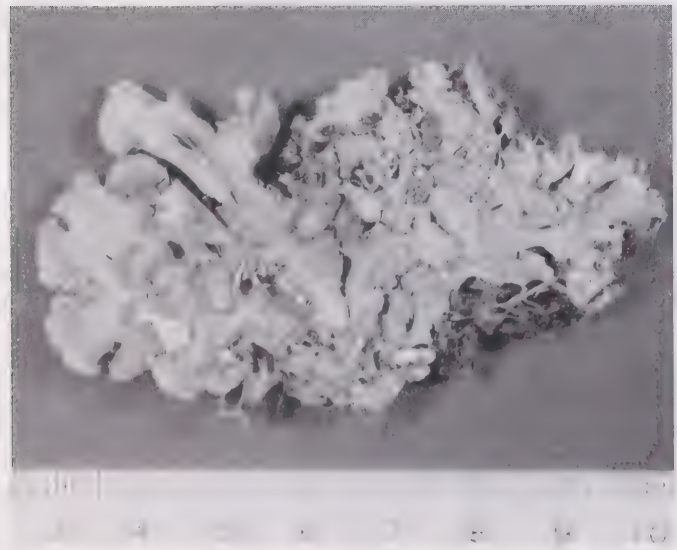

Figure 72. Peltigera ponojensis upper surface. (Pegg 1324, PMAE.) tion, Gyelnik (1931b) considered $P$. ponojensis as closely related to $P$. didactyla (under $P$. spuria which, at that time, was considered to be a non-sorediate but fertile species with erect tomentose lobes). Although both taxa belong to the $P$. canina group, the modern concept of $P$. didactyla distinguishes them on the basis of the presence of soralia (or their scars) which are absent in $P$. ponojensis, the veins of the sterile lobes (raised in $P$. ponojensis and flat in $P$. didactyla), and the shape of the apothecia (wide and plane in $P$. ponojensis versus narrow and finger nail-shaped to saddleshaped in $P$. didactyla).

Ecology: Peltigera ponojensis grows on soil and humus in exposed and cold microsites including open areas in forests, trail edges, and on boulders and rockslides. It is found in a variety of habitat types ranging from Black Spruce wetlands and Aspen Poplar forests to exposed rock outcrops in the alpine tundra.

Distribution in Alberta: The distribution of this species appears to be controlled by the availability of a very specific microhabitat. It occurs in the Central and Peace River Parklands, Boreal Mixedwood, Foothills, and Alpine subregions but only in exposed, cold sites (Fig. 74). It can be characterized as a widespread but rare species.

Distribution in North America: Based on numerous collections, Brodo et al. (1987) reported $P$. ponojensis from most of northern North America. However, further taxonomic research is expected to lead to the recognition of an additional taxon (see Peltigera sp. 1) thus reducing the range of $P$. ponojensis in North America. Additional specimen seen (ALTA): U.S.A.: Arizona.

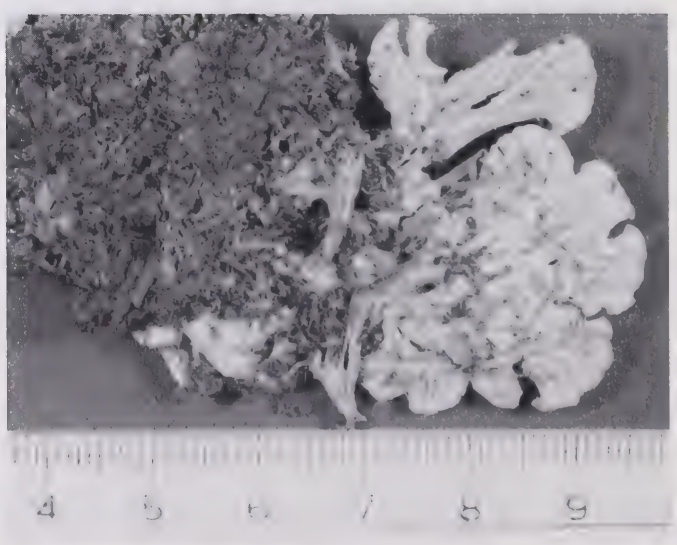

Figure 73. Peltigera ponojensis lower surface. The veins remain pale throughout. (Pegg C88.2.57, PMAE.) 


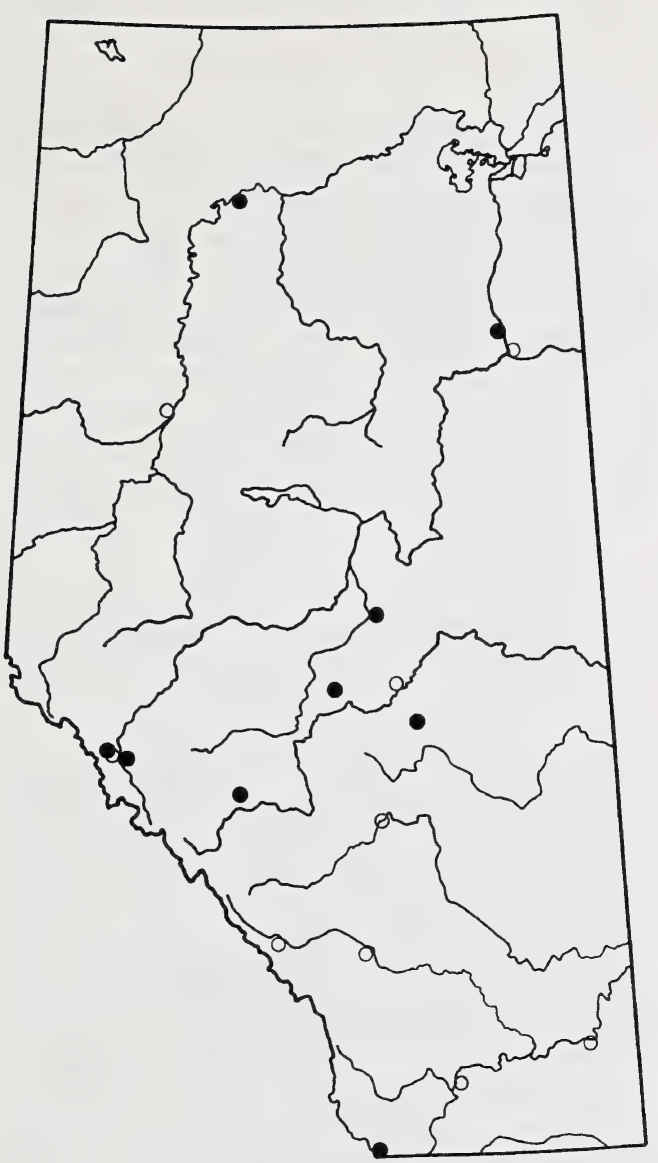

Figure 74. Distribution of Peltigera ponojensis in Alberta.

\section{Peltigera praetextata (Sommerf.) Zopf}

\section{Illustrations: Figs. 75-76, map: Fig. 77. Appendix 1.}

Morphology: Thallus large, to $15 \mathrm{~cm}$ across, firmly attached to the substrate; lobes 0.7 to $2.0 \mathrm{~cm}$ wide, abundantly branching, margins somewhat dissected, plane to upturned and crenulate or sometimes somewhat downturned, thin, fragile when dry. Upper surface light to dark brown, smooth, dull, with appressed tomentum lacking toward centre, often with numerous cracks, phyllidia and lobules common, clustered on lobe surface or developing along cracks and margins. Lower surface with distinct network of brownish, somewhat raised to centrally flat veins, these some-

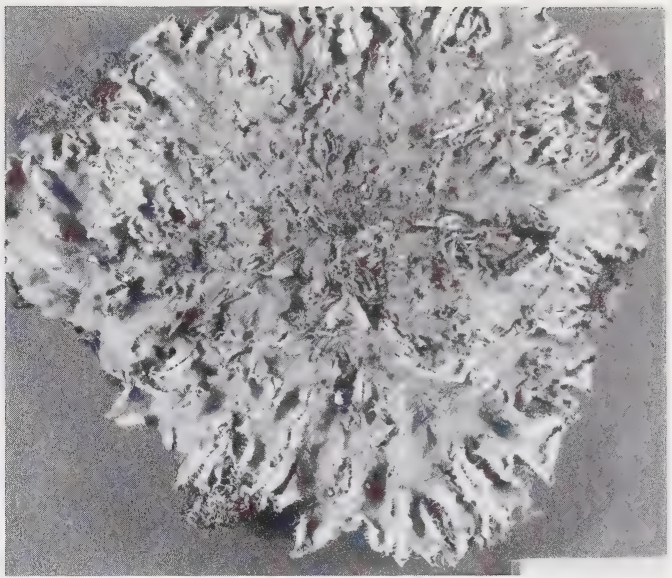

Figure 75. Peltigera praetextata habit (Hastings C91.5.10, PMAE.)

times covered with erect hairs near margin and overlapping toward centre, interstices whitish and diamondshaped; rhizines to $9 \mathrm{~mm}$, pale near margin and gradually darkening toward centre, simple to sparsely or squarrosely branched or even flocculent. Photobiont, cyanobacteria. Apothecia common, disk light to dark brown, to $9 \mathrm{~mm}$ across, saddle-shaped, on elongate lobes; spores acicular, (28-) 36-56 (-70) x $3.5-5 \mu \mathrm{m}$, invariably four-celled.

Variation: Until recently, $P$. praetextata has been ranked at the infraspecific level (e.g., Ozenda and Clauzade 1970, Thomson 1950) or even as representing only a regeneration form without taxonomic status (Thomson 1984). In situ experimental work by Thomson (1948) questioned the taxonomic validity of the 'regeneration lobuli' used to segregate this species

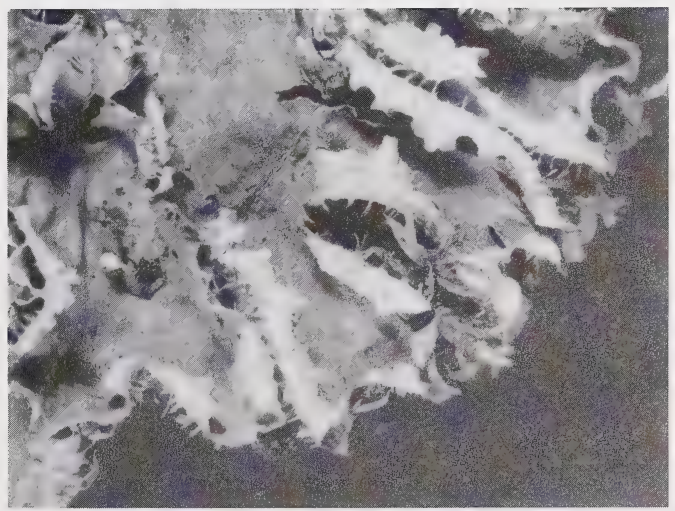

Figure 76. Peltigera praetextata habit. Close-up of lower right corner of Fig. 75. Note the typical upturned margins and thread-like rhizines. (Hastings C91.5.10, PMAE.) 
within the canina complex. Thomson suggested that virtually all species of Peltigera can produce these lobules under stress. However, field studies carried out by Lindahl (1953) suggested that, of the three species $P$. canina, $P$. rufescens, and $P$. praetextata, only the latter regularly produces "isidia" when cut or wounded. As a result, he concluded these propagules could be used as a taxonomic character, and were, in fact, the only valid species specific character separating the taxa.

Further research has revealed additional characters segregating $P$. praetextata from $P$. canina and $P$. rufescens (Goward et al. in prep., Vitikainen 1981). Peltigera praetextata differs from related species by its upturned lobe tips, mainly simple rhizines (Fig. 76), and typical phyllidia. Based on these concepts, we could readily distinguish $P$. praetextata specimens in Alberta (Appendix 1). Mature specimens are similar to $P$. canina, $P$. cinnamomea, and $P$. membranacea, but none of these commonly produces phyllidia or regeneration lobules and all three taxa have a plane to downturned margin compared to a rather upturned margin in $P$. praetextata (Appendix 1). Further, $P$. canina rarely has simple rhizines and never has tomentose veins. Peltigera cinnamomea lacks erect hairs on its typically rust-brown veins. Peltigera membranacea has a very thin thallus, the rhizines are typically squarrosely branched, and the veins are typically extremely narrow and raised. Small specimens of $P$. praetextata are commonly mistaken for $P$. rufescens, but the latter typically has confluent, densely branched, blackish rhizines and rather erect lobes. Peltigera rufescens is also a more xeric species not growing in mesic forests on mossy rotten logs as $P$. praetextata commonly does.

Ecology: This eurytopic lichen is found in habitats from Black Spruce bogs, mesic mixed White SpruceAspen Poplar stands, to dry pine woodlands. Forested sites range from deep-shaded to exposed. While commonly growing over mosses, on litter, and on burned or rotten logs, it occasionally has been collected on sandy soil. Extreme forms, which we referred to as $P$. praetextata, have been collected from the rocky alpine tundra of the Mountain Park area (Hastings C89.6.89 PMAE; Scopera 8568 ALTA).

Distribution in Alberta: This lichen is most commonly found in the Central Parkland and Boreal Mixedwood subregions (Fig. 77). It has been collected in the Foothills and Montane subregions, including an outlier on the Cypress Hills. It is apparently rare in tundra environments including the subarctic to the north and the alpine to the west. Peltigera praetextata is common over its range.

Distribution in North America: The distribution of this species in North America is not well documented as it has, until recently, often been considered as a regeneration form of $P$. canina var. rufescens (Ostafichuk 1966, Thomson 1950). Based on Thomson's data, however, it can be expected to be widespread, following a ubiquitous pattern similar to that observed in Europe (Vitikainen 1987). Additional specimens seen (ALTA): Canada: Newfoundland, Northwest Territories, and the Yukon Territory; U.S.A.: Colorado, Michigan, Minnesota, Missouri, New Mexico (herb. Goffinet), New York, Utah, and Washington.

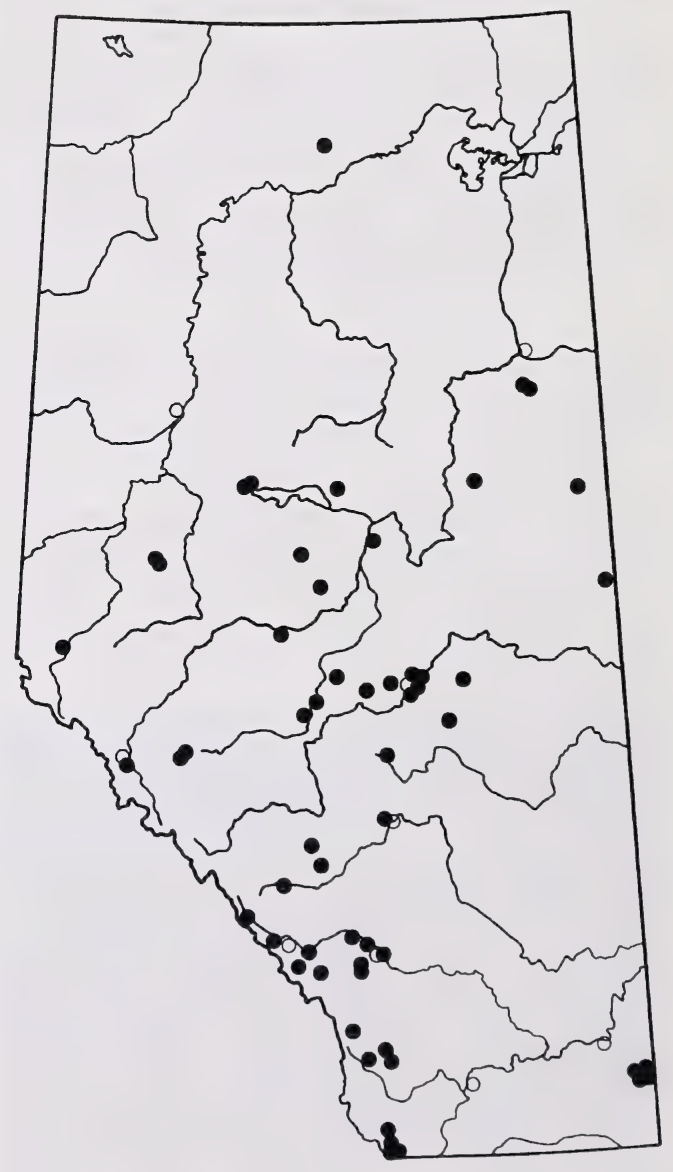

Figure 77. Distribution of Peltigera praetextata in Alberta. 


\section{Peltigera retifoveata Vitik.}

Illustrations: Figs. 78-80, map: Fig. 81.

Morphology: Thallus medium to large, to $20 \mathrm{~cm}$ across, rather loosely attached to the substrate; lobes 1 to $2 \mathrm{~cm}$ wide, branching, margins entire, upturned or plane, moderately thin, fragile when dry. Upper surface light grey, grey-brown to brown, with thick appressed tomentum thinning toward centre. Lower surface with a network of distinct to often anastomosing, tomentose, loose (soft) veins (rarely without erect hairs), ochraceous to dark brown toward centre, with pale, elongate to rounded, deep interstices; rhizines to $7 \mathrm{~mm}$, dark brown to black even near margin, simple to fasciculate, squarrosely to regularly branched. Photobiont, cyanobacteria. Apothecia occasional, disk brown to dark brown, almost black, small, saddle-shaped, on elongate lobes; spores acicular, (32-) 36-47 (61) x 3.5$4 \mu \mathrm{m}$, almost invariably four-celled (90 spores measured).

Variation: Peltigera retifoveata was recently described from North America and Europe by Vitikainen (1985). Most of the collections belonging to this species were initially identified as $P$. scabrosa (under $P$. pulverulenta auct. eur.) from which it differs by its tomentum and smooth upper surface. One collection (Nyland 168, CAFB) had developed numerous regeneration lobules along cracks, which made it look like $P$. praetextata. From the latter species and from all members of the canina group, $P$. retifoveata can, however, be easily distinguished morphologically by its cottony lower surface with deep interstices (Figs. 7980 ) and chemically by the presence of depsides and

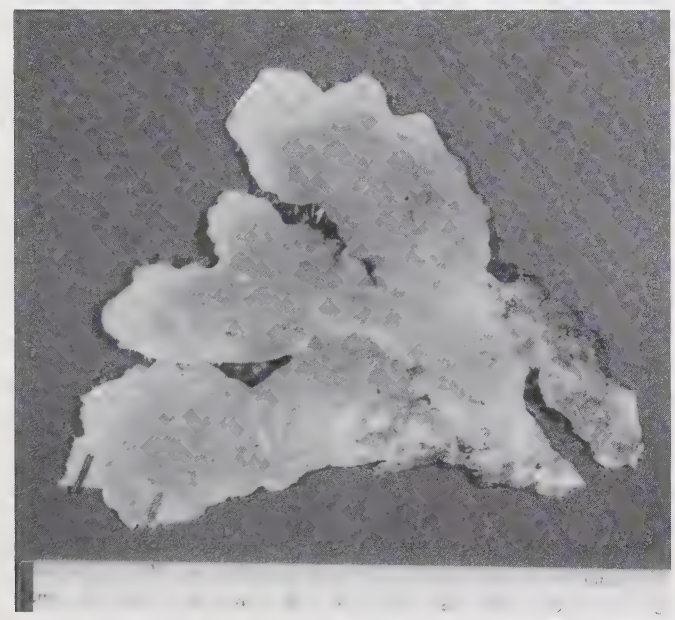

Figure 78. Peltigera retifoveata upper surface. (Horton 271, ALTA.)

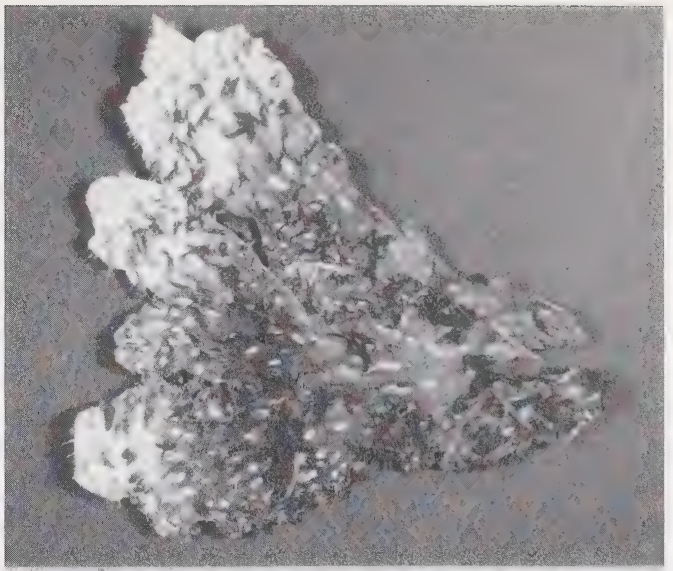

Figure 79. Peltigera retifoveata lower surface. It has elliptical interstices and thick, tomentose rhizines. (Horton 271, ALTA.)

triterpenoids (Vitikainen 1985). Holtan-Hartwig (1993) suggests placing $P$. retifoveata in "a group of its own" as the species differs further from the taxa of the $P$. canina group by the morphology of the hyphae making up the veins.

Ecology: Peltigera retifoveata occurs most commonly on litter and mosses in dry, coniferous habitats and in disturbed and/or exposed situations such as road banks. In natural conditions, it prefers pine-spruce forests and pine-lichen woodlands, especially on stabilized dunes. Occasionally it is found on mineral soil in disturbed coniferous forests.

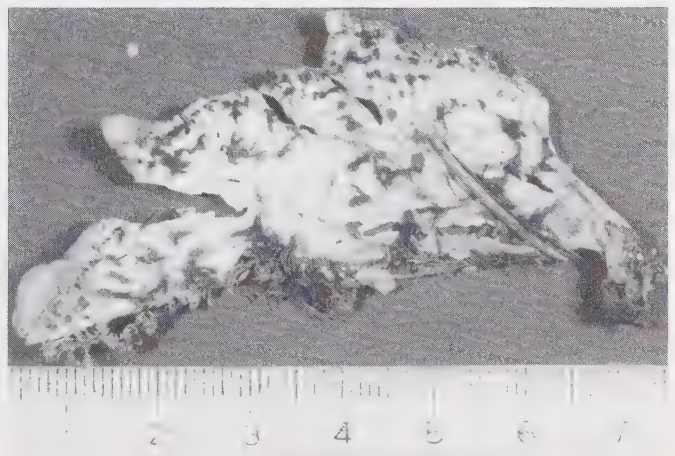

Figure 80. Peltigera retifoveata lower surface. Note the difference in color of the veins, these remain pale throughout, but are otherwise identical to Fig. 79. (Ostafichuk 1027, ALTA.) 
Distribution in Alberta: Peltigera retifoveata has been collected mostly from the Foothills subregion where it prefers upland sites (Fig. 81). It is also locally abundant in Lodgepole Pine woodlands in the Montane subregion. In the northern part of the province, it occurs in scattered localities in the Boreal Mixedwood, Peace River Parkland, Peace River Lowlands, and in the Subarctic on the Caribou Mountains. This species is uncommon over its range.

Distribution in North America: This essentially disjunct circumboreal species (Vitikainen 1985) has a north western distribution in North America and was recently reported from the continental United States (Goffinet 1992). Additional specimens seen (ALTA): Canada: British Columbia, Manitoba, Northwest Territories, Saskatchewan, and the Yukon Territory; U.S.A.: Alaska and Washington.

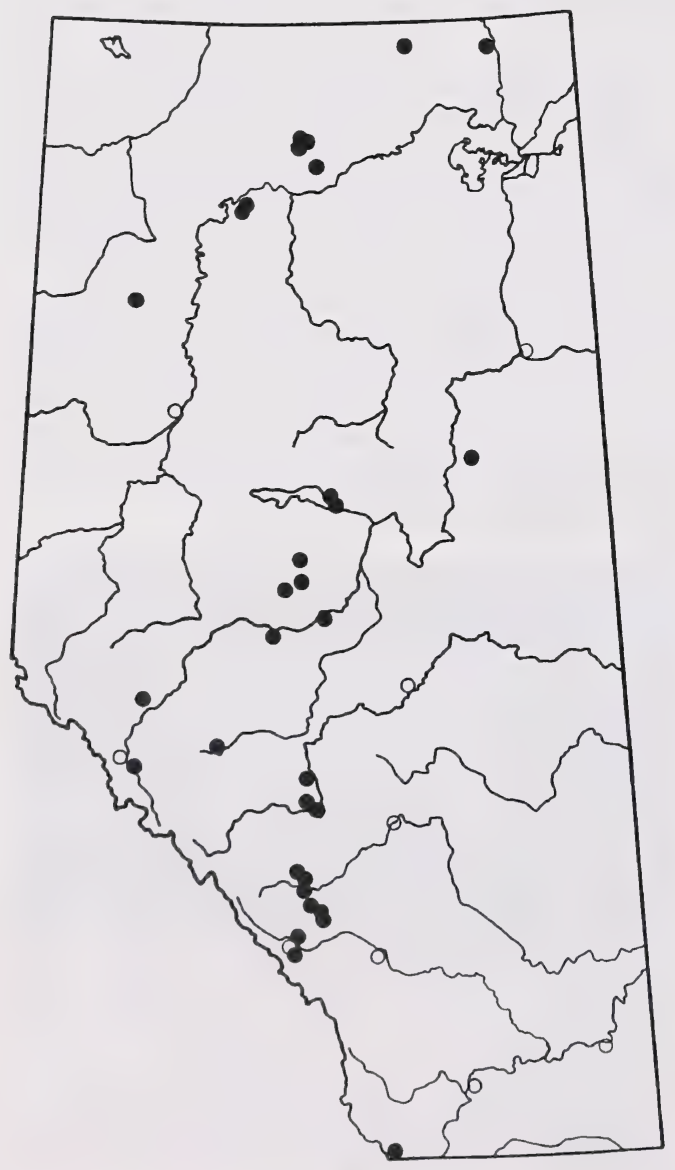

Figure 81. Distribution of Peltigera retifoveata in Alberta.
Peltigera rufescens (Weis.) Humb.

Illustrations: Figs. 82-83, map: Fig. 84. Appendix 1.

Morphology: Thallus small to medium, to $10 \mathrm{~cm}$ in diameter, closely appressed to the substrate; lobes commonly less then $1 \mathrm{~cm}$ wide, rarely reaching 1.5 $\mathrm{cm}$, branching, densely overlapping in dry habitats, margin entire, upturned to more rarely flat, rather thick and robust when dry. Upper surface grey to greyishbrown to brown, smooth, covered by a thick tomentum often extending toward centre and commonly with a white to light grey crust spreading to the margin. Lower surface with a network of distinct veins, these often anastomosing in the centre, veins dark brown to black, flat and glabrous; rhizines short, rarely to $8 \mathrm{~mm}$, black, rarely pale near margin, typically confluent and densely branching near margin, rarely simple almost throughout. Photobiont, cyanobacteria. Apothecia common, disk dark brown, saddleshaped, to $6 \mathrm{~mm}$ long and $1 \mathrm{~cm}$ wide, typically on erect, elongate lobes with strong, raised, whitish veins; spores acicular (44-) 47-57 (-72) x 2-4 $\mu \mathrm{m}$, mostly four-celled.

Variation: Peltigera rufescens has long been considered a variety of $P$. canina (e.g., Ozenda and Clauzade 1970, Thomson 1950). However, it differs from the latter by its upright margin and by its narrow lobes (to $1.5 \mathrm{~cm}$, Fig. 82). Some specimens of $P$. rufescens have simple to scarcely branched rhizines similar to those found in $P$. ponojensis or $P$. praetextata. Peltigera ponojensis can be distinguished by its typically pale lower surface, whitish rhizines, raised veins, and apothecia with flat margins. Peltigera praetextata segregates by its pale to brownish veins and rhizines, and by often developing its typical phyllidia or lobules. An

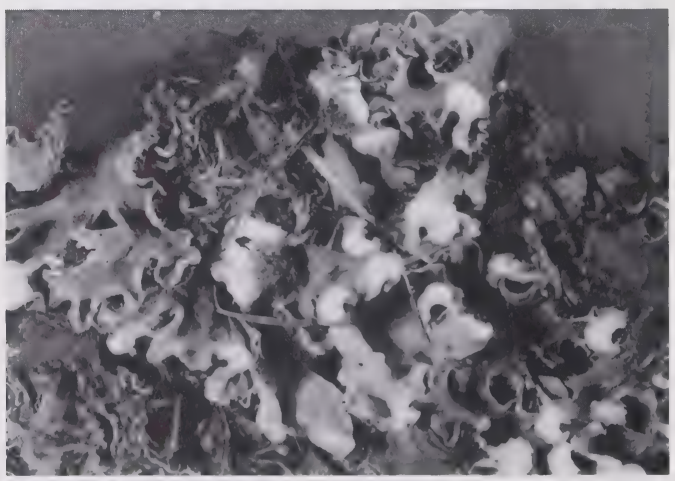

Figure 82. Peltigera rufescens habit. The erect, fertile lobes have strongly saddle-shaped apothecia. Magnification 1.1X. (Goffinet C90.4.167, PMAE.) 
Albertan specimen collected by MacNeil (3149, CANL) bears numerous regeneration lobuli, which is very unusual for $P$. rufescens. Peltigera kristinssonii, another species sometimes mistaken for $P$. rufescens, differs by its marginally scabrous and erect-tomentose cortex, fasciculate to squarrosely branched rhizines, and tomentose veins.

Fertile specimens of $P$. didactyla var. didactyla can also resemble $P$. rufescens as both thalli are often small and the apothecia-bearing lobes have strong, pale, raised veins. However, $P$. didactyla develops soralia and, in fertile specimens, one can often find their scars. In addition, $P$. didactyla has rather pale, simple rhizines, often confined to the centre, whereas $P$. rufescens bears abundantly branched, blackish, and anastomosing rhizines at the base of its fertile lobes (Fig. 83).

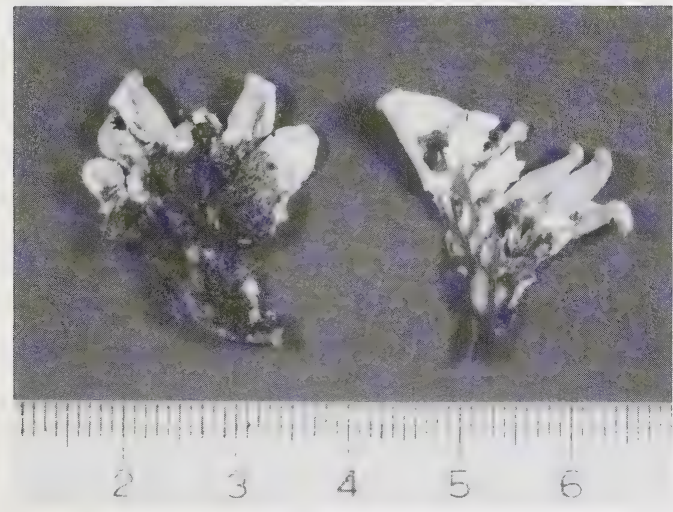

Figure 83. Peltigera rufescens lower surface. Note the abundantly branched and anastomosing rhizines (left) and the distinct dark veins (right, rhizines removed). (Goffinet C90.4.167, PMAE.)

Ecology: Peltigera rufescens occurs commonly on mineral soil or thin humus over mineral soil in dry coniferous dominated forests. It grows on stabilized sand dunes in pine-lichen woodlands, mineral soil in montane grasslands and pine forests, and in exposed, rocky alpine tundra. Peltigera rufescens is also common in natural and man-made disturbed sites such as alluvial gravel flats and roadside cutbanks. Rarely has it been collected on litter or humus in mesic White Spruce forests. In North America and Europe, this species is probably the most calciphilic member of the genus.

Distribution in Alberta: Peltigera rufescens is common in the forested central and southern parts of the province in Boreal Mixedwoods, Foothills, and Montane subregions (Fig. 84). It is also prevalent in the
Subalpine and Alpine. North of Lesser Slave Lake it becomes less common, being collected in scattered Boreal Mixedwood, Subarctic, and Canadian Shield localities where dry or disturbed microsites are available. In southeastern Alberta, $P$. rufescens has been collected in the Montane subregion of the Cypress Hills. This species is common in Alberta.

Distribution in North America: The species is widespread throughout North America. The map presented by Thomson (1984), under $P$. canina var. rufescens may represent the overall range of the species but some specimens may have been $P$. ponojensis which was not reported from North America until recently (see discussion under that species). Additional specimens seen (ALTA): Canada: British Columbia, Newfoundland, Northwest Territories, Ontario, Quebec, Saskatchewan, and the Yukon Territory; U.S.A.: Alaska, Arizona (herb. Goffinet), Colorado, Minnesota, South Dakota, Utah, Washington, and Wyoming.

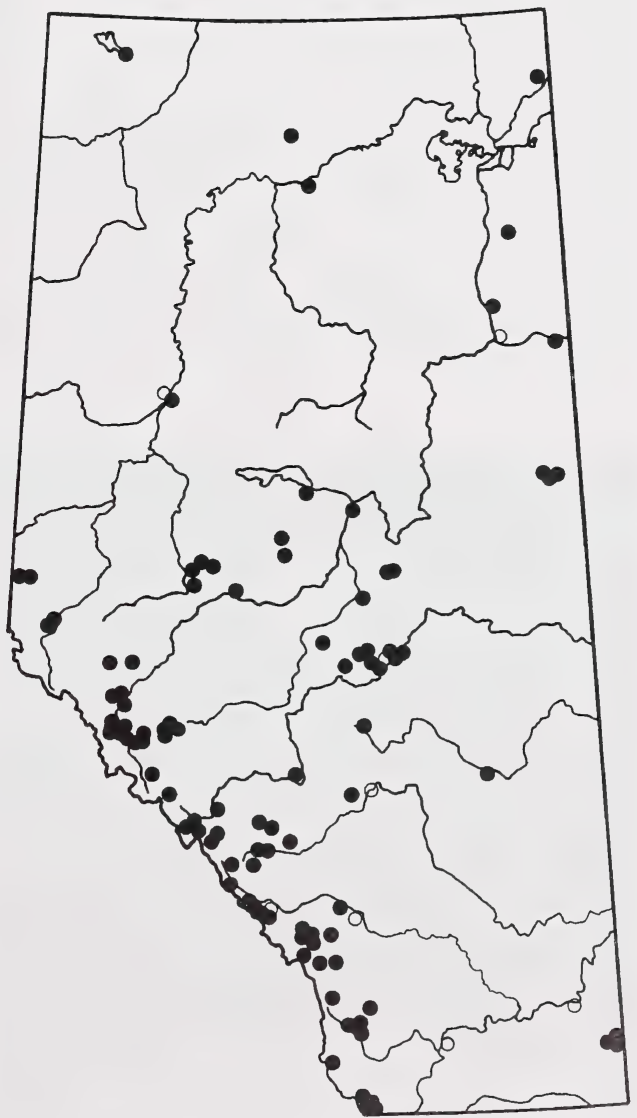

Figure 84. Distribution of Peltigera rufescens in Alberta. 
Peltigera scabrosa Th. Fr.

Illustrations: Figs. 85-86, map: Fig. 87.

Morphology: Thallus medium to large, loosely attached to the substrate; lobes to 3-4 cm across, branching, margin entire, plane to upturned, rather thin, fragile when dry. Upper surface light greenish-grey, greybrown, brown to dark blue, sometimes with yellowish tint, scabrous at least toward margin, glabrous. Lower surface ochraceous to whitish, veins ochraceous or light brown to dark brown toward the centre, overlapping or more or less distinct, interstices small, whitish, sometimes absent in the centre; rhizines to $4 \mathrm{~mm}$, dark brown even near margin, mostly penicillate near margin, to densely branched and fibrillose, or even simple toward centre, soon anastomosing. Photobiont, cyanobacteria. Apothecia occasional, disk chestnut brown, saddle-shaped, to $6 \mathrm{~mm}$ across, on elongate lobes; spores linear (53-) 62-78 (-84) x 3-4 $\mu \mathrm{m}$, mostly four-celled but sometimes to eight-celled.

Variation: Peltigera scabrosa is defined by its scabrous and glabrous upper surface and is easily recognized by its penicillate, dark brown rhizines which contrast with the ochraceous margin on the lower surface (Fig. 86). Peltigera kristinssonii is also slightly scabrous, but has erect tomentum toward the margin, tomentose veins, and does not produce any lichen substances. Specimens of $P$. neopolydactyla and $P$. retifoveata have often been mistaken for P. scabrosa (for points of separation see discussion under those spe-

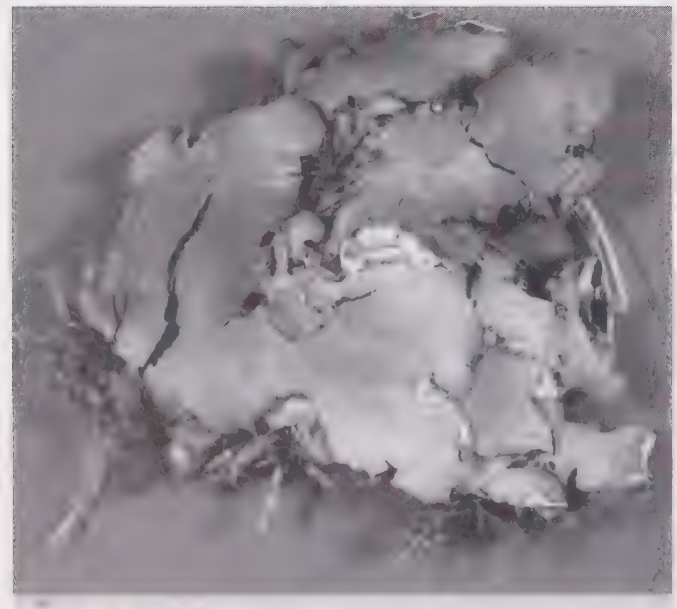

Figure 85. Peltigera scabrosa upper surface. (Vitikainen 9743, ALTA.) cies). Holtan-Hartwig (1988) described P. scabrosella from oceanic northern Europe and Greenland. Peltigera scabrosella segregates from $P$. scabrosa by its narrow lobes and pale brown to whitish marginal rhizines.

Ecology: This lichen most commonly grows on mosses and humus in moist to mesic coniferous dominated forests. It has been collected in boreal Black Spruce-Swamp Birch wetlands to subalpine Engelmann Spruce-Subalpine Fir forests. Rarely it is found in drier pine forests and, if so, it grows on mosses or humus in mesic microsites.

Distribution in Alberta: Peltigera scabrosa is found mostly in upland subregions. It is most common in the Foothills and occasionally extends into the lower reaches of the Subalpine subregion (Fig. 87). Towards the north, it has been collected in scattered localities in the Boreal Mixedwood, Boreal Highlands, Subarctic, and Canadian Shield. It apparently is rare in the southern part of the province, our only record south of Jasper National Park being a single collection from Waterton Lakes National Park (Fig. 87). The species is uncommon over its range.

Distribution in North America: This circumpolar species is found throughout arctic, boreal, and alpine North America (Thomson 1984). Additional specimens seen (ALTA): Canada: Labrador, Ontario, Saskatchewan, and the Yukon Territory; U.S.A.: Alaska and Minnesota

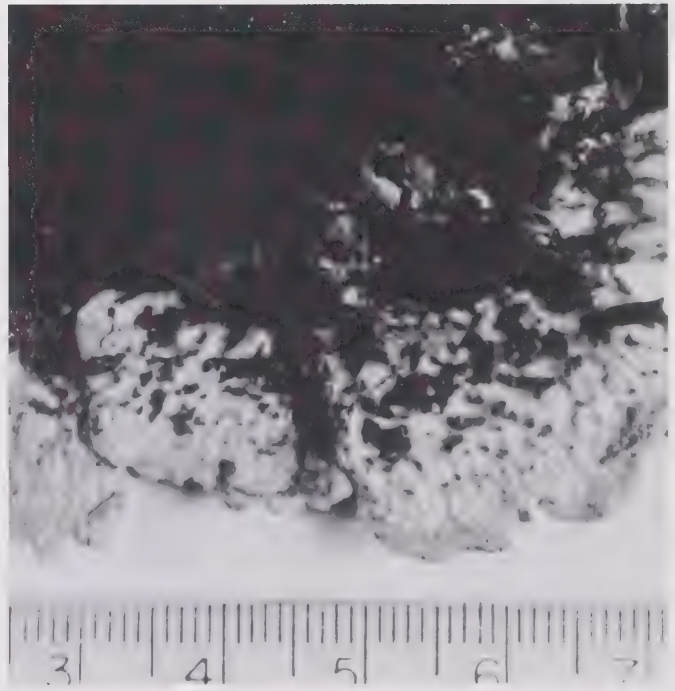

Figure 86. Peltigera scabrosa lower surface. The rhizines are dark, scattered, and penicillate. (Scotter 16573, CANL.) 


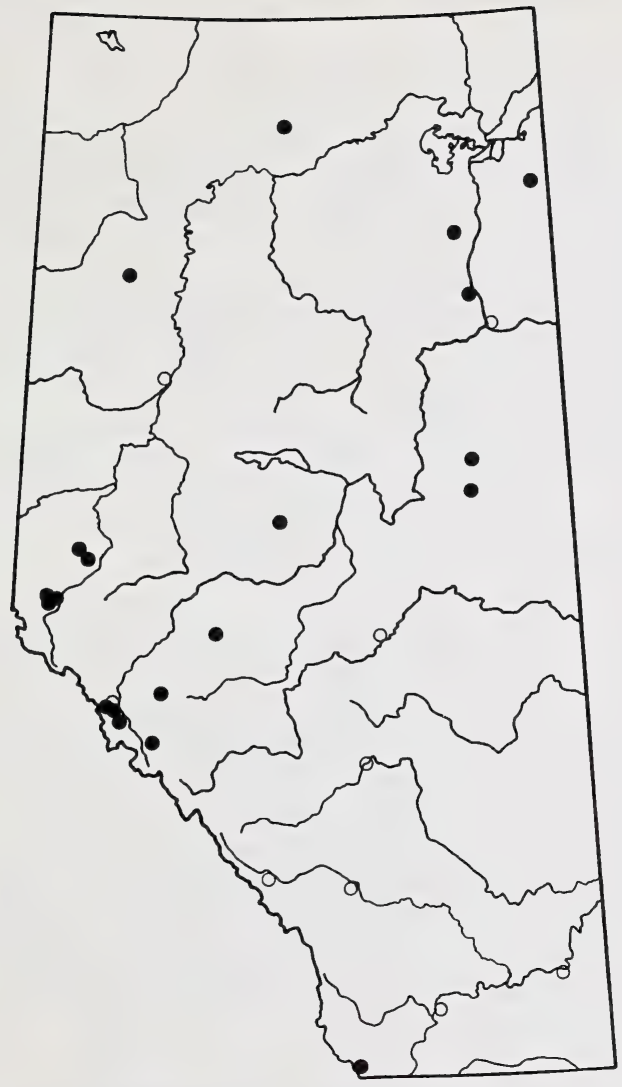

Figure 87. Distribution of Peltigera scabrosa in Alberta.

\section{Peltigera venosa (L.) Hoffm.}

Illustrations: Fig. 88, map: Fig. 89.

\section{A. The green phototype}

Morphology: Thallus small, fan shaped, often unilobate, firmly attached to the substrate; lobes 1 to 1.5 $\mathrm{cm}$ wide, scarcely branching, flat to concave, rather thin, fragile, margin entire and plane. Upper surface smooth, shiny, glabrous, light green to light brown when dry and bright, apple green when moist. Lower surface with a distinct network of brown, raised, and to $3 \mathrm{~mm}$ broad tomentose veins that become confluent toward the centre, interstices elongate, white and deep; rhizines to $7 \mathrm{~mm}$, dark brown, forming a thick bundle restricted to a single submarginal position; cephalodia dark blue, verrucose to flat and peltate on the veins. Photobiont, green algae. Apothecia frequent, usually numerous, dark brown to black, horizontal to slightly concave, circular, to $6 \mathrm{~mm}$ wide, on non-elongated lobes and thus appearing marginal, lower surface not corticate; spores narrowly elliptic, (23-) 28-38 (-41) x 5-8 $\mu \mathrm{m}$, mostly four-celled, but three- or five-celled spores occasionally found.

Variation: Peltigera venosa segregates readily from the other taxa having a green photobiont by its small size, its cephalodia that are located on the lower surface, and its marginal, horizontal apothecia (Fig. 88).

Ecology: Peltigera venosa commonly grows in mesic microsites on mineral soil or on thin humus over mineral soil. It is found in naturally disturbed but humid and mesic sites such as stream banks and near waterfalls in montane to subalpine pine-spruce-fir forests. Sometimes it is in montane Balsam Poplar-White Spruce forests along stream banks or on mineral soil exposed by uprooted trees. It also grows in man-made areas such as mesic roadcuts and trail edges. In the alpine tundra it occurs on mosses and humus over mineral soil.

Distribution in Alberta: This species is restricted to upland sites in western Alberta where it ranges from the Foothills to the Alpine subregions (Fig. 89). It is uncommon over its range.

Distribution in North America: This circumpolar species occurs throughout arctic, boreal, and alpine western and northeastern North America (Thomson 1950, 1984). In Europe, $P$. venosa is now restricted to higher elevations (Vitikainen 1981) and is threatened with extinction due to a lack of suitable habitats as a result of poor forest management (drainage and general lowering of the water table; Sérusiaux 1989). Additional specimens seen (ALTA): Canada: Northwest Territories and the Yukon Territory; U.S.A.: Colorado, Montana, and Oregon.

\section{B. The blue-green phototype}

This phototype of $P$. venosa is known in Alberta from only a single locality. The material is small and

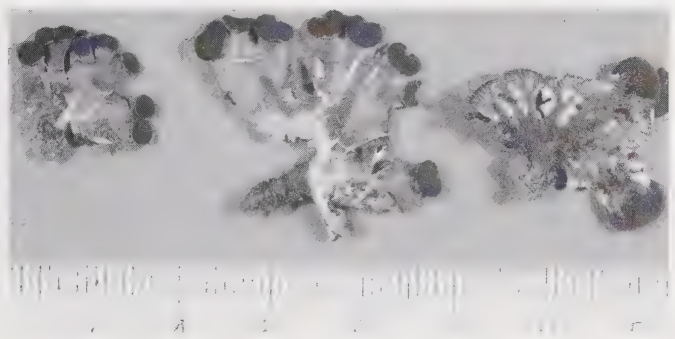

Figure 88. Peltigera venosa. Left and middle, upper surface showing numerous marginal, plane apothecia and single holdfast. Cracks formed on the middle specimens as the concave thallus was pressed for the photograph. Right, lower surface with distinct veins throughout. Note the cephalodia attached on veins. (Goffinet 1559, herb. Goffinet.) 
consists of a single thallus attached to the green phototype. Morphologically and anatomically the lobes with cyanobacteria look similar to those of a small species of Leptogium. The material was too small to allow for a thorough description without damaging the specimen. A detailed description of the development of the blue-green phototype is provided by Ott (1988) and, as already noted by Tønsberg and Holtan-Hartwig (1983), no chemical substances were detected by TLC in the blue-green lobes. In contrast with other bluegreen phototypes of the Peltigera aphthosa group, the blue-green phototype of $P$. venosa has, so far, been reported from Europe (Ott 1988, Purvis et al. 1992, and Tønsberg and Holtan-Hartwig 1983) and British Columbia (Goward et al., in prep.). The locality from Alberta is the most continental site yet reported from North America.

Distribution in Alberta: This phototype is known only from a single locality in the Montane subregion of Jasper National Park (Harris 1060, Harris pers. herb.; Fig. 89)

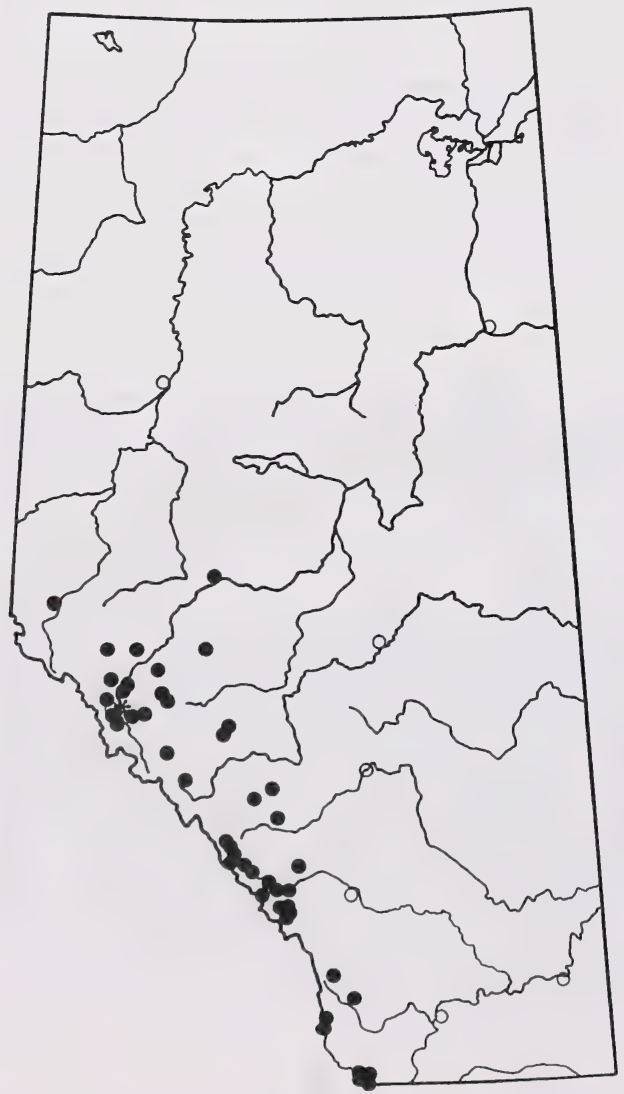

Figure 89. Distribution of Peltigera venosa in Alberta (solid dots: green phototype; star: blue-green phototype).

\section{Peltigera sp. 1}

Illustrations: Fig. 90, map: Fig. 91.

Morphology: Thallus medium, to $10 \mathrm{~cm}$ across, rather firmly appressed to the substrate; lobes to $2 \mathrm{~cm}$ wide, branching, moderately thin and fragile, margin plane. Upper surface grey to brownish-grey, glabrous, often somewhat pruinose near margin. Lower surface pale, darkening gradually toward centre or remaining pale throughout, veins raised, thick and ropy, smooth, interstices lenticular to elliptic, deep; rhizines to 5 $\mathrm{mm}$, pale to dark brown, penicillate, slender or stout, sparse. Photobiont, cyanobacteria. Apothecia uncommon, disk chestnut brown, to $5 \mathrm{~mm}$ wide, strongly saddle-shaped, on short narrow lobes; spores acicular, (53-) 55-67 (-74) x 3.5-5 $\mu \mathrm{m}$, four-celled.

Variation: Four specimens from Alberta could not be identified to any species presently known. Their morphology is somewhat similar to $P$. ponojensis, but differ by the glabrous cortex and apothecia with revolute margins. The absence of tomentum and the lack of secondary metabolites could lead to $P$. degenii Gyelnik, but the latter has membranous lobes, narrow veins, phyllidia, and is restricted to oceanic and temperate localities. Similar specimens are known from British Columbia where they were treated within $P$. ponojensis. The species is pending further studies (Goward et al. in prep.).

Ecology: This species grows over mosses on soil, in alpine vegetation dominated by Salix arctica and over epixylic mosses in montane forests.

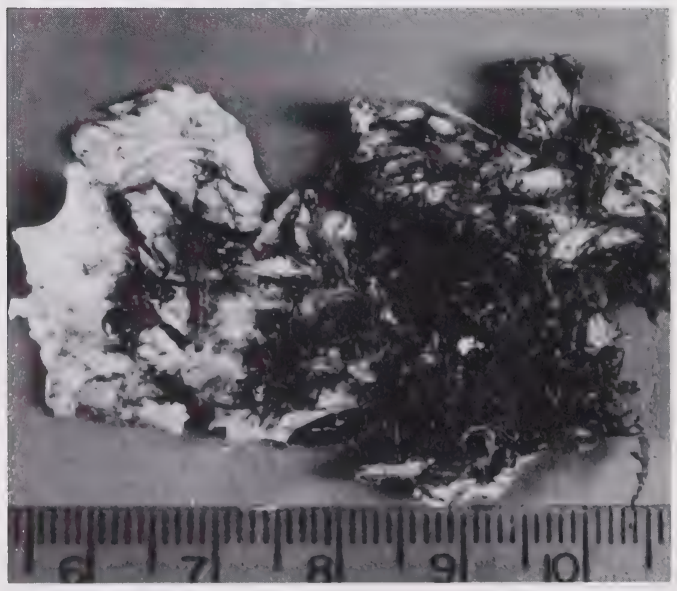

Figure 90. Peltigera sp. 1 lower surface. Note the ropy veins remaining pale throughout. (Goffinet C90.4.65, PMAE.) 
Distribution in Alberta: This lichen is restricted to the Rocky Mountains (Fig. 91).

Distribution in North America: Unknown but apparently restricted to western North America. Additional specimens seen (CANL): Canada: British Columbia; U.S.A.: Washington.

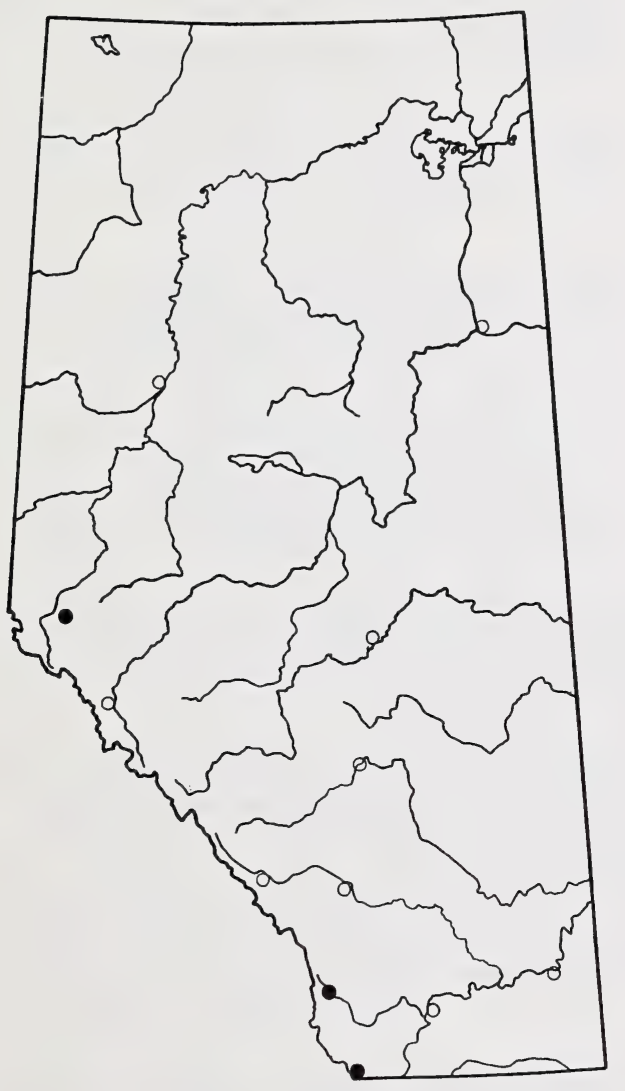

Figure 91. Distribution of Peltigera sp. 1. in Alberta.

\section{Excluded species}

\section{Peltigera occidentalis (Dahl) Krist.}

This species is characterized by a thick thallus with broad anastomosed veins and short rhizines (Goward et al. in prep). It would here key to $P$. neckeri from which it differs by its thick and leathery thallus and its chemistry (Goward et al. in prep., Vitikainen 1985). Ohlsson (1973) reports $P$. occidentalis from Alberta, based on two collections by Ostafichuk. We have only been able to examine one of the samples (Ostafichuk 1014, CANL) and agree with Vitikainen (1985) who referred both specimens, based on the chemistry reported by Ohlsson (1973), to $P$. retifoveata. No additional specimens have been found matching the description of $P$. occidentalis. Therefore, $P$. occidentalis should be deleted from the Albertan Peltigera flora even though it might be expected from higher elevations as it is known to occur in British Columbia (Goward et al. in prep.). 


\section{Literature Cited}

Achuff, P.L. 1992. Natural regions and subregions of Alberta: a revised classification for Protected Areas Management. Alberta Park Service. Alberta Tourism, Parks and Recreation. Edmonton, Alberta.

Ahti, T. and O. Vitikainen. 1977. Notes on the Lichens of Newfoundland. 5. Peltigeraceae. Annales Botanici Fennici 14: 89-94.

Anonymous. 1993. Alberta plants and fungi-master species list and species group checklist. Environmental Protection, Editorial Services.

Armaleo, D. and Ph. Clerc. 1991. Lichen chimeras: DNA suggests that one fungus forms two morphotypes. Experimental Mycology 15: 1-10.

Blum, O.B., A.V. Dombrovskaya, C.N. Inashvilli, A.V. Piterons, E.C. Roms, and V.P. Saviecz. 1975. Handbook of the lichens of the U.S.S.R. 3, Caliciaceae - Gyalectaceae. Academy of Science of the U.S.S.R., Moscow.

Brodo, I.M. and D.H.S. Richardson. 1978. Chimeroid associations in the genus Peltigera. The Lichenologist 10: 157-170.

Brodo, I.M., W.J. Noble, T. Ahti, and S. Clayden. 1987. Lichens new to North America from the flora of British Columbia, Canada. Mycotaxon 28: 99-110.

Clauzade, C. and C. Roux. 1985. Likenoj de Okcidenta Europo. Ilustrita Determinlibro. Bulletin de la Société Botanique du Centre-Ouest. Nouvelle Série-Numéro Spécial 7: 1-893.

Coppins, B.J. 1976. Distribution patterns shown by epiphytic lichens in the British Isles. In: Brown, D.H., D.L. Hawksworth, and R.H. Bailey (eds.) Lichenology: Progress and Problems. Academic Press. London. Pp. 249-278.

Dahl, E. 1950. Studies in the macrolichen flora of South West Greenland. Meddelelser om Grønland 150: $1-177+7$ plates +1 map.

Egan, R.S. 1987. A fifth checklist of the lichen-forming, lichenicolous and allied fungi of the continental United States and Canada. The Bryologist 90: 77174.

Goffinet, B. 1992. The North American distribution of Peltigera retifoveata. Evansia 9: 49-51.
Goffinet, B. and R.I. Hastings (in press). Two new sorediate taxa in the genus Peltigera (lichenized ascomycetes). The Lichenologist 26.

Gowan, S.P. and I.M. Brodo. 1988. The lichens of Fundy National Park, New Brunswick, Canada. The Bryologist 91: 255-325.

Gyelnik, V. 1931a. Notes on Peltigera. The Bryologist 34: 16-19.

Gyelnik, V. 1931b. Eine neue Peltigera-Art aus KolaLappland. Memoranda Societatis pro Fauna et Flora Fennica 7: 143-145.

Gyelnik, V. 1932. Additamenta ad cognitionem lichenum extraeuropaeorum. Annales de Cryptogamie exotique 4: $166-174$.

Hawksworth, D.L. 1980. Notes on some fungi occurring on Peltigeras, with a key to accepted species. Transaction of the British Mycological Society 74: 363-386.

Holtan-Hartwig, J. 1988. Two new species of Peltigera. The Lichenologist 20: 11-17.

Holtan-Hartwig, J. 1993. The lichen genus Peltigera, exclusive of the $P$. canina group, in Norway. Sommerfeltia 15: 1-77.

Honegger, R. 1978. The ascus apex in lichenized fungi I. The Lecanora-, Peltigera- and Teloschistes-types. The Lichenologist 10: 47-67.

Jahns, H.M. 1973. Anatomy, morphology, and development. In: Ahmadjian V. and M.E. Hale (eds.). The Lichens. Academic Press. New York. Pp. 358.

Jahns, H.M. and P. Frey. 1982. Thallus growth and development of the fruit bodies in Peltigera canina. Beiheft zu Nova Hedwigia 36: 485-498

Krog, H. 1968. The Macrolichens of Alaska. Norsk Polarinstitutt Skrifter 144: 1-180.

Lindahl, P.-O. 1953. The taxonomy and ecology of some Peltigera species, $P$. canina (L.) Willd., P. rufescens (Weis) Humb., P. praetextata (Flk.) Vain. Svensk Botanisk Tidskrift 47: 94-106 + 2 plates.

Lindahl, P.-O. 1960. The different types of isidia in the lichen genus Peltigera. Svensk Botanisk Tidskrift 54: $565-570+3$ plates. 
Linkola, K. 1913. Über die Thallusschuppen bei Peltigera lepidophora (Nyl.). Bericht der deutschen botanischen Gesellschaft 31: 52-54

Linkola, K. 1923. Über die Isidienbildung der Peltigera praetextata (Flk.) Zopf. Annales Societatis Zoologicae Botanicae Fennicae Vanamo 1: 65-90 +2 plates

Noble, W. J., T. Ahti, G.F. Otto, and I.M. Brodo. 1987. A second Checklist and Bibliography of the Lichens and Allied Fungi of British Columbia. Syllogeus 61: 1-95.

Ohlsson, K.E. 1973. New and interesting lichens of British Columbia. The Bryologist 76: 366-387.

Olech, M. and V. Alstrup. 1988. Notes on some species of Peltigera Willd. in Poland. Zeszyty Naukowe Universytetu Jagiellonskiego, Prace Botaniczne 17: 175-178.

Ostafichuk, M. 1966. The genus Peltigera in Alberta. Masters thesis. University of Alberta, 96 pp.

Ott, S. 1988. Photosymbiodemes and their development in Peltigera venosa. The Lichenologist 20: 361368.

Ozenda, P. and G. Clauzade. 1970. Les Lichens. Masson et Cie, Paris. 801 pp.

Poelt, J. 1974. Bestimmungsschlüssel Europäischer Flechten. Cramer. Vaduz.

Purvis, O.W., B.J. Coppins, D.L. Hawksworth, P.W. James, and D.M. Moore. 1992. The Lichen Flora of Great Britain and Ireland. Natural History Museum Publications. London.

Rose, F. 1976. Lichenological indicators of age and environmental continuity in woodlands. In: D.H. Brown, D.L. Hawksworth, and R.H. Bailey (eds.) Lichenology: Progress and Problems. Academic Press. London. Pp. 279-307.

Sérusiaux, E. 1989. Liste Rouge des Macrolichens dans la Communauté Européenne. Centre de Recherches sur les Lichens. Université de Liège. Belgium.

Stocker-Wörgötter, E. and R. Türk. 1990. Thallus formation of the cyanobacterial lichen Peltigera didactyla from soredia under laboratory conditions. Botanica Acta 103: 315-321.
Stone, D.F. 1989. Epiphytic succession on Quercus garryana branches in the Willamette Valley of Western Oregon. The Bryologist 92: 81-94.

Thomson, J.W. 1948. Experiments upon the regeneration of certain species of Peltigera, and their relationship to the taxonomy of the genus. Bulletin of the Torrey Botanical Club 75: 486-491.

Thomson, J.W. 1950. The species of Peltigera of North America north of Mexico. The American Midland Naturalist 44: 1-68.

Thomson, J.W. 1984. American Arctic Lichens. 1. The Macrolichens. Columbia University Press.

Tønsberg, T. and J. Holtan-Hartwig. 1983. Phycotype pairs in Nephroma, Peltigera and Lobaria in Norway. Nordic Journal of Botany 3: 681-688.

Vitikainen, O. 1981. Peltigera Willd., nom. cons. In: Poelt, J. and Vezda, A. (eds.) Bestimmungsschüssel Europäischer Flechten. Ergänzungsheft II. - Bibliotheca Lichenologica 16: 236-242.

Vitikainen, O. 1985. Three new species of Peltigera (lichenized Ascomycetes). Annales Botanici Fennici 22: 291-298.

Vitikainen, O. 1987. Distribution patterns of European Peltigera. In: Peveling, E. (ed.) Progress and Problems in Lichenology in the Eighties. Bibliotheca Lichenologica 25: 423-426.

Vitt, D.H., J.E. Marsh, and R.B. Bovey. 1988. A Photographic Field Guide to the Mosses, Lichens and Ferns of Northwestern North America. Lone Pine Publishing. Edmonton.

Weber, W.A. 1990. Additions to the lichen flora of Colorado and North America. Evansia 7: 17-25.

Wirth, V. 1987. Flechten Badden-Württenbergs. Ulmer. Stuttgart.

White, F.J. and P.W. James. 1985. A new guide to microchemical techniques for the identification of lichen substances. British Lichen Society Bulletin 57 (suppl.): 1-41 + 1 table.

Xi-Ling, C. 1986. Study on the Peltigera of Northeast China. Acta Mycologica Sinica 5: 18-29. 


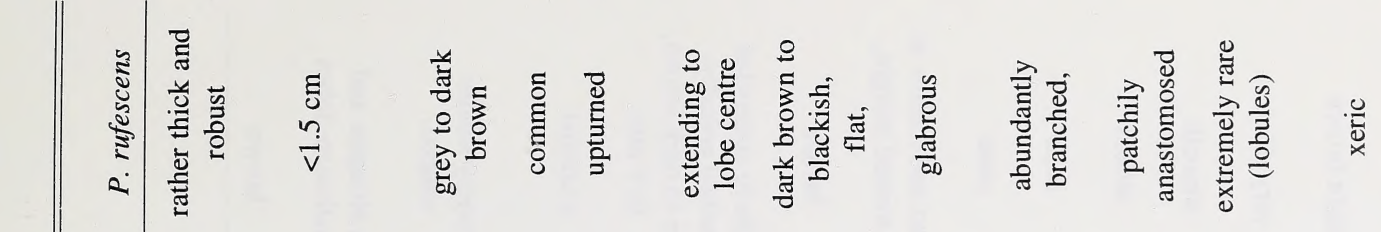

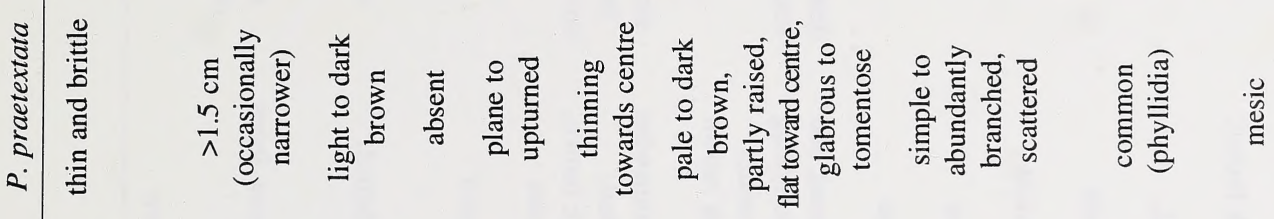

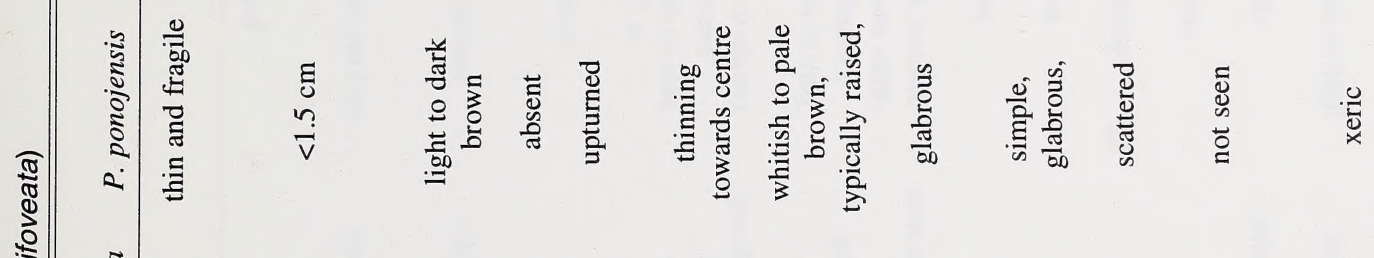

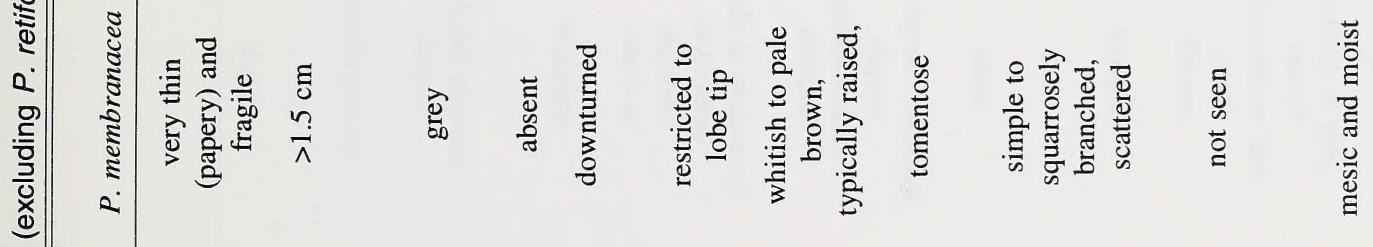

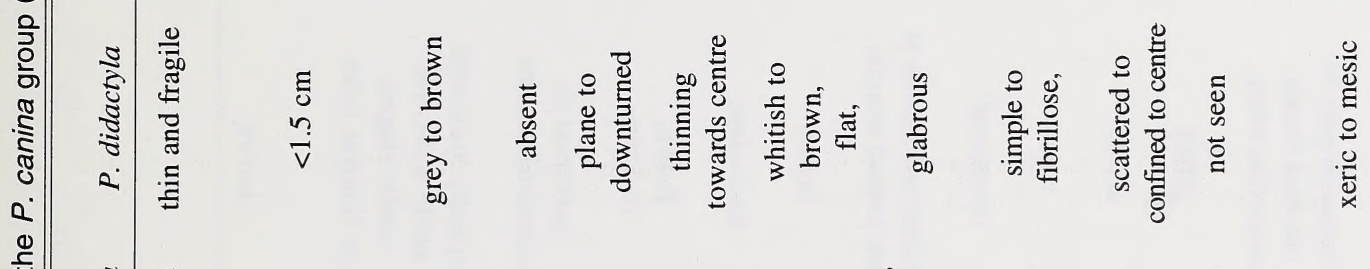

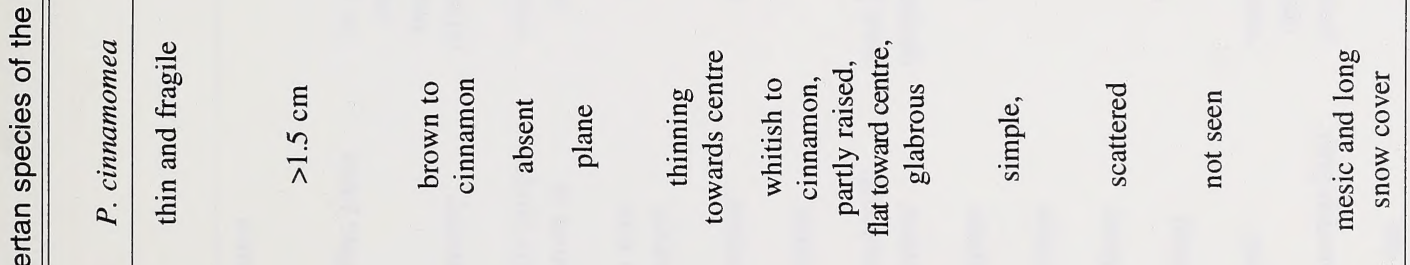

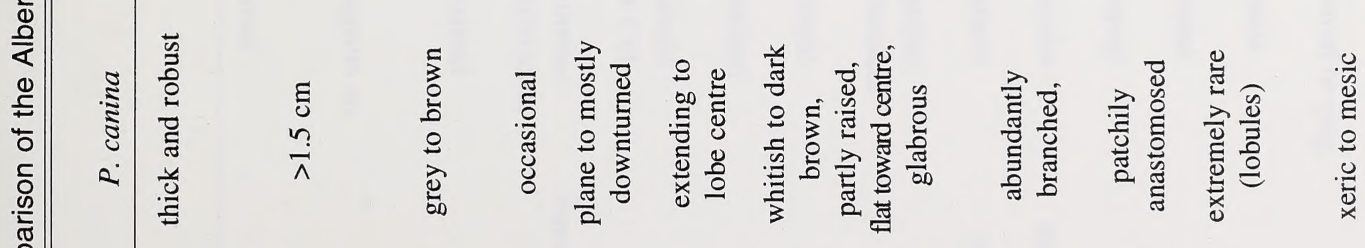

$$
\begin{aligned}
& \text { 亏 }
\end{aligned}
$$

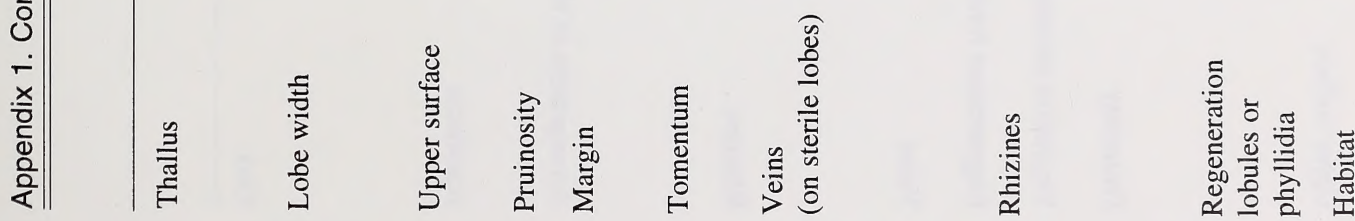




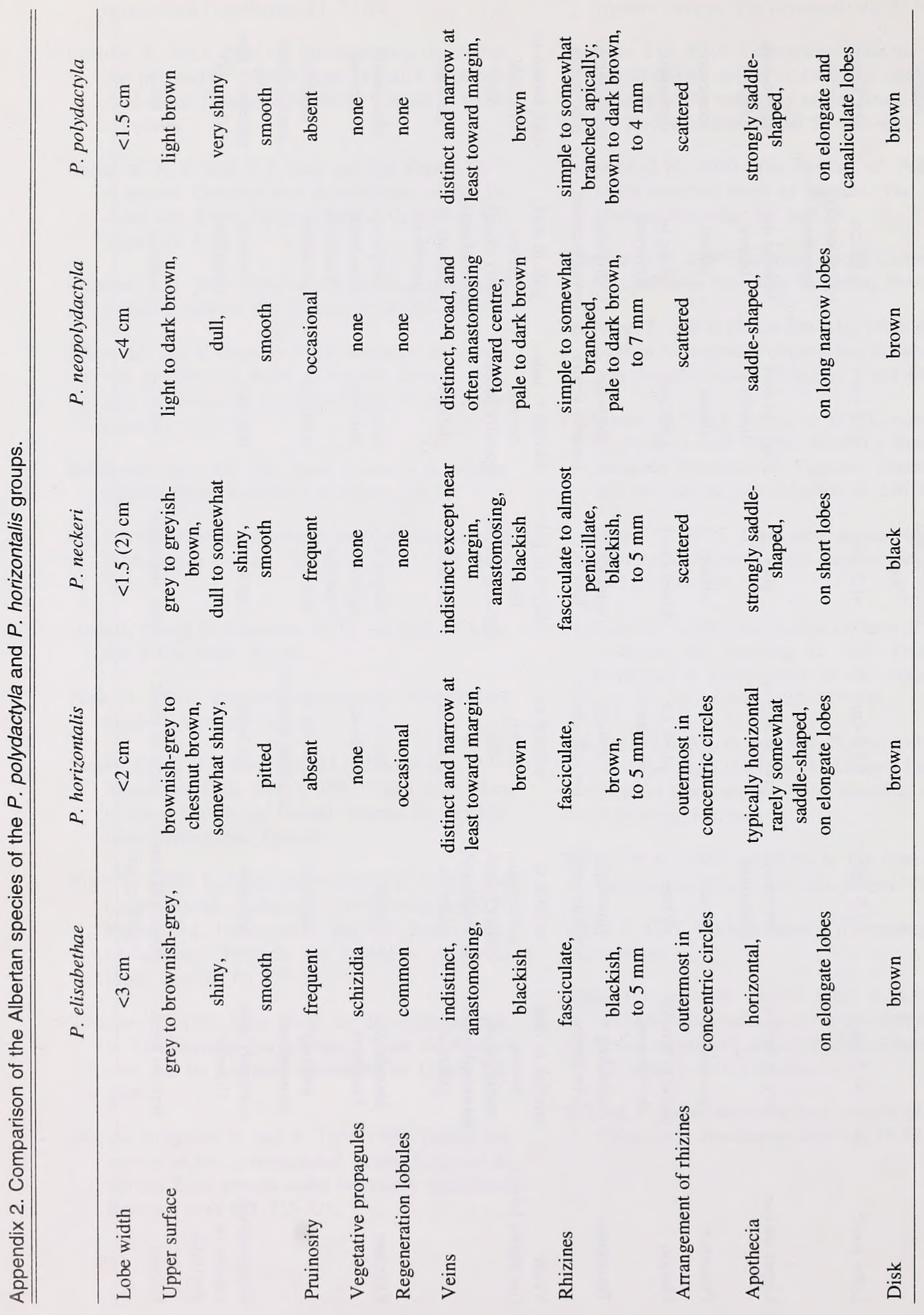





\section{NATURAL HISTORY OCCASIONAL PAPER TITLES}

No. 1 Alberta Birds 1961-1970. 1976. T.S. Sadler and M.T. Myres. 314 pp. (out of print)

No. 2 Mammals of the Edmonton Area. 1979. Hugh C. Smith. 34 pp. (out of print)

No. 3 A Bibliography of Alberta Ornithology. 1981. Martin K. McNicholl, Philip H.R. Stepney, Peter C. Boxall, and David E. Spalding. 380pp. (out of print)

No. 4 Plants and the Blackfoot. 1982. Alex Johnston. 106 pp.

No. 5 Rare Vascular Plants of Alberta. 1984. John G. Packer and Cheryl E. Bradley. 112 pp.

No. 6 A Checklist of the Mammals of Alberta. 1985. Hugh C. Smith. 11 pp. (out of print)

No. 7 Mammals of Southeastern Alberta. 1986. Hugh C. Smith. 59 pp. (out of print)

No. 8 A Bibliography of Alberta Mammalogy. 1987. David M. Ealey. 400 pp.

No. 9 Proceedings of the Workshop on Endangered Species in the Prairie Provinces. 1987. Geoffrey L. Holroyd, W. Bruce McGillivray, Philip H.R. Stepney, David M. Ealey, Garry C. Trottier, and Kevin E. Eberhart (eds.). 367 pp.

No. 10 Natural History of the Bistcho Lake Region, Northwest Alberta. 1988. W. Bruce McGillivray and Ross I. Hastings (eds.). 106 pp.

No. 11 A Checklist of the Mammals of Alberta (Revised 1989). 1989. Hugh C. Smith. 7 pp.

No. 12 Natural History of the Andrew Lake Region, Northeastern Alberta. 1990. W. Bruce McGillivray and Ross I. Hastings (eds.). 97 pp.

No. 13 Alberta Birds, 1971-1980. Volume 1. Non-Passerines. 1991. Harold W. Pinel, Wayne W. Smith, and Cleve R. Wershler. 243 pp.

No. 14 Bibliography of the Family Catostomidae (Cypriniformes). 1991. John Clay Bruner. 224 pp.

No. 15 Proceedings of the Second Endangered Species and Prairie Conservation Workshop. 1991. Geoffrey L. Holroyd, Gordon Burns, and Hugh C. Smith (eds.). 284 pp.

No. 16 A Bibliography of Alberta Ornithology (Second Edition). 1991. David M. Ealey and Martin K. McNicholl. 751 pp.

No. 17 Mammals of the Drumheller Area. 1992. Hugh C. Smith. 25 pp.

No. 18 Natural History of the Winefred Lake region, East-central Alberta. 1994. W. Bruce McGillivray and Ross I. Hastings (eds.). In press.

No. 19 Proceedings of the Third Prairie Conservation and Endangered Species Workshop. 1993. Geoffrey L. Holroyd, H. Loney Dickson, Mona Regnier, and Hugh C. Smith (eds.). 384 pp.

No. 20 Alberta Birds, 1971-1980. Volume 2. Passerines. 1993. Harold W. Pinel, Wayne W. Smith, and Cleve R. Wershler. 238 pp.

No. 21 The Lichen Genus Peltigera (Lichenized Ascomycetes) in Alberta. 1994. Bernard Goffinet and Ross I. Hastings. 54 pp. 